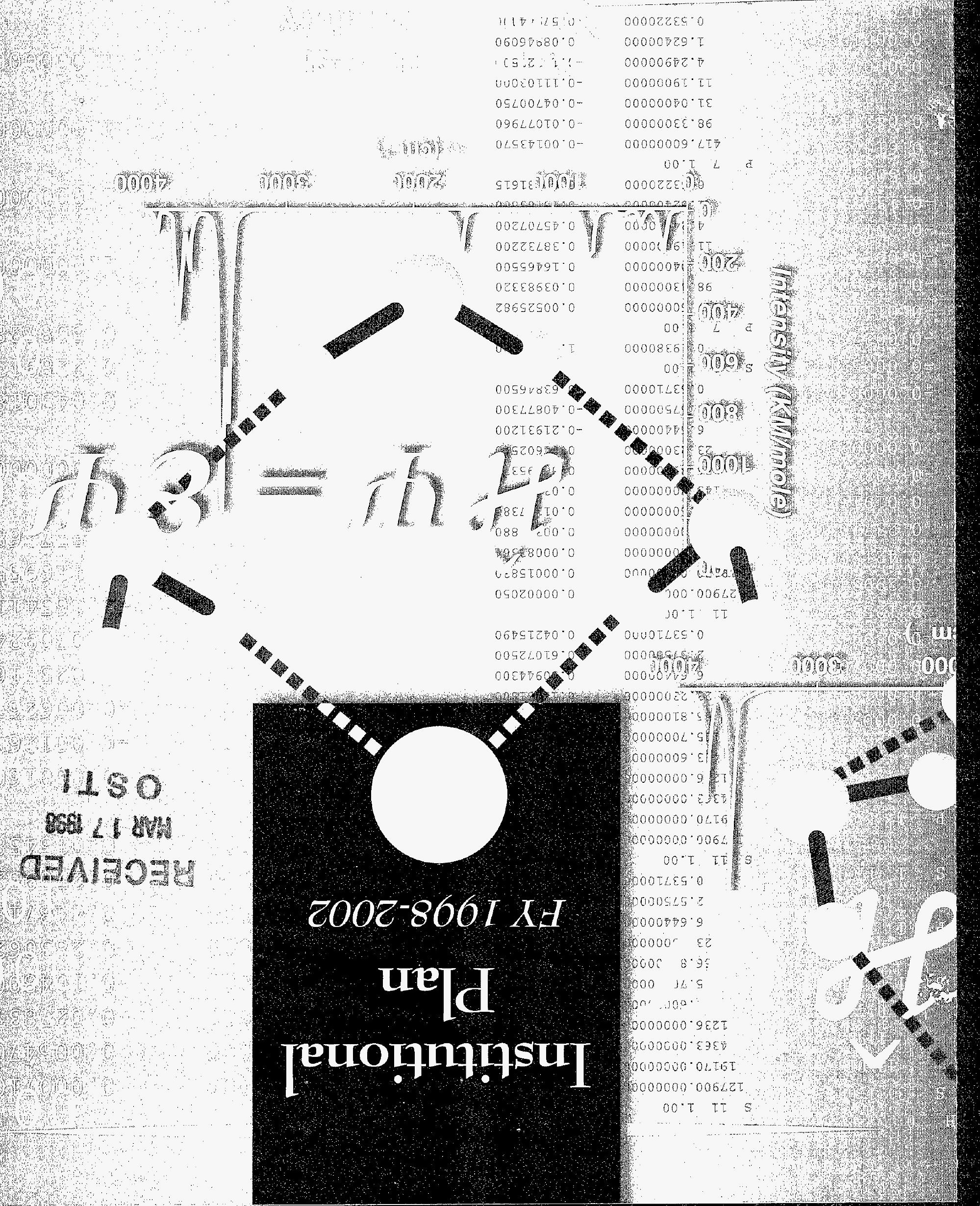




\section{The MOLECUlar SCIENCE COMPUTING}

FACILITY in the William R. Wiley

Environmental Molecular Sciences Laboratory contains the most powerful parallel supercomputer ever produced by IBM. Other programs in the MSCF include NWChem, a new generation of molecular modeling software for massively parallel computers; and ecce', the Extensible Computational Chemistry Environment which incorporates all steps of the analysis process into an integrated problemsolving environment.

NWChem consists of a suite of codes created by EMSL staff and collaborators to perform computational chemistry calculations on parallel computers and the high level data and control structures needed to make parallel programs easier to write, maintain, and extend. It also readily interfaces with other program suites, thus leveraging its existing functionality and making that functionality accessible to others. In 1997, NWChem was one of seven applications that was able to efficiently scale and use the computational power of a 1328-processor Cray T3E-900 supercomputer in the especially difficult area of molecular dynamics. This ability to successfully drive the most powerful supercomputers produced by both IBM and Cray is a strong demonstration of NWChem's portability and high parallel performance.

ecce' is a suite of distributed client/server applications that enable scientists to efficiently use computational programs for complex molecular modeling and analysis tasks by accessing networked, highperformance computers via their desktop workstations. The architecture is based on an objectoriented data model to support the management of derived molecular data and meta-data. An objectoriented database management system provides for tracking and complex data searches across the data sets. The framework is built for extensibility to other disciplines and is designed to simplify the interaction with complex computational codes. ecce' provides an intelligent graphical user interface and scientific visualization and analysis tools to aid in the automation of data generation, management, and analysis. The capabilities enable scientists to conveniently set up calculations and store, retrieve, and analyze the rapidly growing volumes of data produced by computational chemistry studies.

NWChem and ecce' combined with the Molecular Science Computing Facility's 512-processor IBM RISC System/6000 Scalable POWERparallel computer system and its associated EMASS data storage and archiving systems give Pacific Northwest National Laboratory and the EMSL a world-class computing environment dedicated to research in molecular science.

Dr. Thom H. Dunning Jr., a theoretical chemist and former director of the William R. Wiley Environmental Molecular Sciences Laboratory (EMSL), received the 1996 E. O. Lawrence Award in chemistry for his seminal contributions to the development of techniques used in the field of computational chemistry. Specifically, Dr. Dunning has been a leader in the development of basis sets, which are key to achieving accurate solutions of the Schrödinger equation. His research and leadership have contributed greatly to the widespread acceptance of theoretical and computational chemistry as necessary complements to experimental investigations in chemical research.

As the associate director of the EMSL Theory, Modeling and Simulation group, Dunning established programs that led to development of the EMSL Molecular Science Computing Facility.

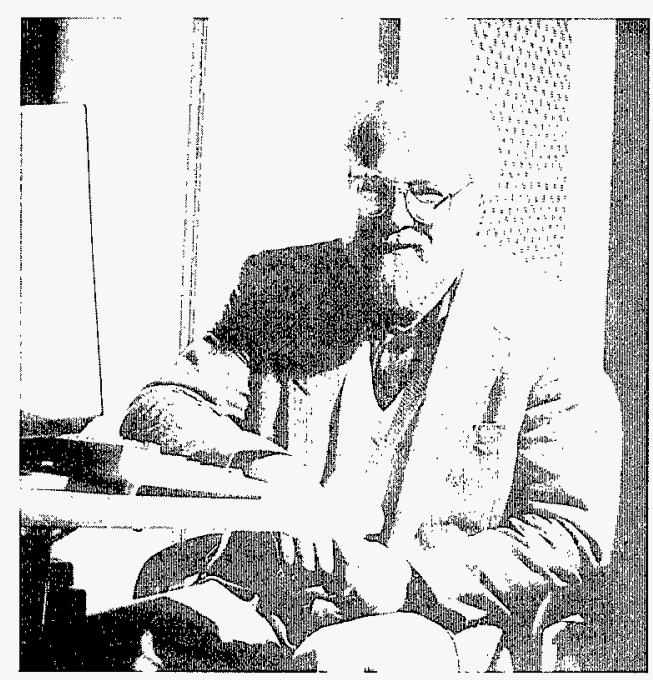




\title{
Pacific Northwest National Laboratory Institutional Plan FY 1998-2002
}

December 1997

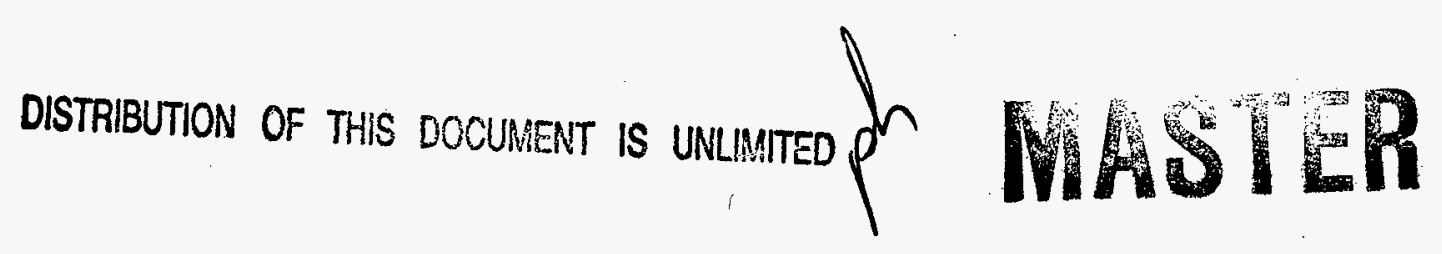

\author{
Prepared for the \\ U.S. Department of Energy \\ under Contract \\ DE-AC06-76RLO 1830
}

Pacific Northwest National Laboratory

Richland, Washington 99352 


\title{
DISCLAIMER
}

This report was prepared as an account of work sponsored by an agency of the United States Government. Neither the United States Government nor any agency thereof, nor Battelle Memorial Institute, nor any of their employees, makes any warranty, express or implied, or assumes any legal liability or responsibility for the accuracy, completeness, or usefulness of any information, apparatus, product, or process disclosed, or represents that its use would not infringe privately owned rights. Reference herein to any specific commercial product, process, or service by trade name, trademark, manufacturer, or otherwise does not necessarily constitute or imply its endorsement, recommendation, or favoring by the United States Government or any agency thereof, or Battelle Memorial Institute. The views and opinions of authors expressed herein do not necessarily state or reflect those of the United States Government or any agency thereof.

\author{
PACIFIC NORTHWEST NATIONAL LABORATORY \\ operated by \\ BATTELLE \\ for the \\ UNITED STATES DEPARTMENT OF ENERGY \\ under Contract DE-AC06-76RLO 1830
}

Printed in the United States of America

Available to DOE and DOE contractors from the

Office of Scientific and Technical Information, P.O. Box 62, Oak Ridge, TN 37831;

prices available from (615) 576-8401.

Available to the public from the National Technical Information Service, U.S. Department of Commerce, 5285 Port Royal Rd., Springfield, VA 22161

PNNL-11754

This document was printed on recycled paper.

(9/97) 


\section{ontents}

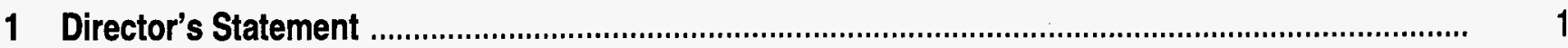

2 Laboratory Mission ............................................................................................................. 3

3 Laboratory Strategic Plan .....................................................................................................

Primary Planning Assumptions ..............................................................................................................

The Laboratory Agenda: Our Role in the Department of Energy Strategic Plan ................................... 5

Fundamental Strategies .............................................................................................................. 9

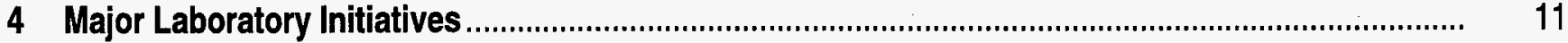

Molecular Sciences Research ........................................................................................................... 11

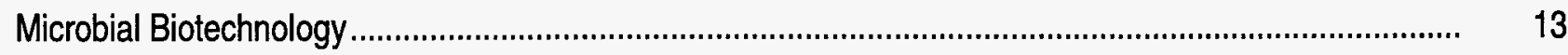

Computational Reactive Transport ...................................................................................................... 14

Science and Technology for Environmental Processing ..................................................................... 15

Microsystems Science and Engineering........................................................................................ 17

Detection and Characterization of Biopathogens .............................................................................. 18

Medical Technologies and Systems .............................................................................................. 19

5 Programmatic Strategy .......................................................................................................... 24

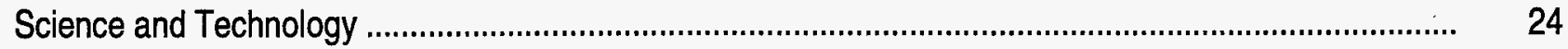

Biological and Environmental Research ................................................................................. 25

Basic Energy Sciences ........................................................................................................... 26

Office of Computational and Technology Research ..................................................................... 28

Laboratory Technology Research .............................................................................................. 28

Advanced Energy Projects ........................................................................................................ 28

Fusion Materials ............................................................................................................... 29

Other Office of Energy Research Programs .............................................................................. 29

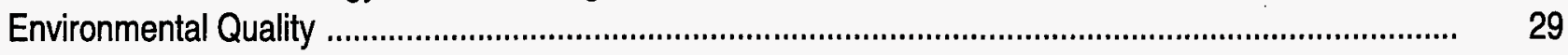

Office of Environmental Management .................................................................................... $\quad 30$

Office of Environmental, Safety, and Health ........................................................................... 32

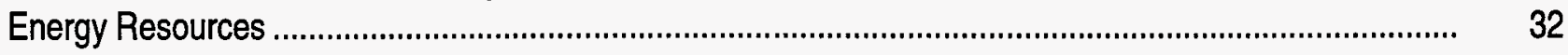

Office of Energy Efficiency and Renewable Energy ........................................................................ 33

Bonneville Power Administration ............................................................................................ 34

Office of Fossil Energy .......................................................................................................... 34

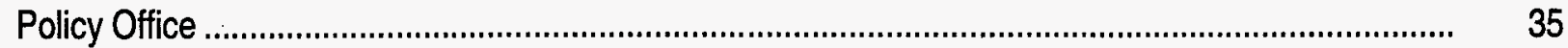

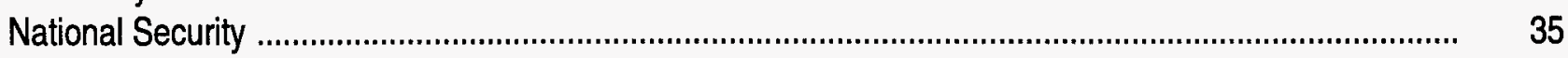

Office of Defense Programs ..........................................................................................

Office of Nonproliferation and National Security .......................................................................... $\quad 35$

Nuclear Energy ....................................................................................................................... 38

Office of Nuclear Energy, Science and Technology ………........................................................ 38

Work for Others .................................................................................................................. 
Department of Defense

Nuclear Regulatory Commission

Environmental Protection Agency

44

Other Federal Agencies and Nonfederal

6 Operations/Infrastructure Strategic Plan 46

Human Resources

46

Environment, Safety and Health Management.

46

Site and Facilities

49

Information Resources Management

53

Management Practices and Standards

55

Communications and Trust.

7 Resource Projections 58

Subcontracting and Procurement 71

Small and Disadvantaged Business Procurement 71

8 Acronyms and Abbreviations 


\section{Director's Statement}

The past year of accomplishments gives us ample reason to look for a bright future at Pacific Northwest National Laboratory. The scientific dedication of the William $\mathrm{R}$. Wiley Environmental Molecular Sciences Laboratory opened the door to a new era of scientific collaboration and put us well on the way to becoming the nation's premier environmental science and technology laboratory. The culmination of the three-year Operations Improvement Program provides us a firm foundation to meet our standard of operational excellence within the national laboratory system. A combination of expanded business and new initiatives keeps the Laboratory growing and diversifying so we can make new contributions to meeting national needs and provide increased stability and new opportunities for our staff, consistent with our environmental focus.

\section{On the Path to Premier}

Certainly one of the year's most memorable events was the October opening of EMSL. We invited U.S. Department of Energy officials, researchers, and members of the academic community to EMSL's first major scientific meeting to see firsthand how DOE's newest user facility will employ the best and brightest from Pacific Northwest and around the nation to tackle critical environmental problems.

We are, in fact, making significant progress in solving those problems through the Environmental Management Science Program (EMSP). The program, a collaboration between DOE's Office of Environmental Management and DOE's Office of Energy Research, funds basic science research in order to provide answers to some of the nation's most complex environmental problems. Through the research funded by EMSP, we can advance fundamental knowledge critical to developing new cleanup technologies that will more efficiently, cost-effectively, and safely clean up our nation's Cold War legacy.

In addition to being the newest user facility in the DOE system, EMSL represents to us how cutting-edge science will be conducted in the 21 st century. The environmental problems of today and tomorrow cannot be solved by single researchers, or even small groups of scientists, but rather by multidisciplinary, dynamic teams working in collaboration and utilizing a myriad of scientific instruments. EMSL will be the gathering place, either in actuality or through its virtual collaboratory, for researchers to team worldwide.

EMSL also will bring cutting-edge science to bear on all of DOE's missions. We'll use the basic science research done at EMSL to develop the next generation of technology for energy efficiency, advanced processing, and medical applications. With the basic science knowledge we gain, we can continue to deliver innovative technologies for DOE's environmental cleanup mission. Just last year, we demonstrated 14 technologies and deployed 21 into commercial use. For example, Pacific Northwest

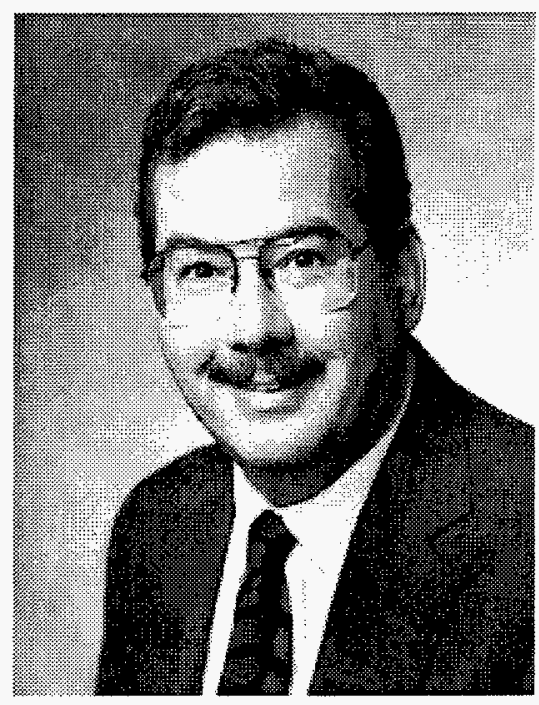

Dr. William J. Madia, Director, Pacific Northwest National Laboratory and TerraVac Corp. are teamed on a project to remediate a private electronics manufacturing site in Chicago. Closer to home, we helped to demonstrate how the Light-Duty Utility Arm could be used in the inspection of Hanford's waste tanks.

\section{Setting the Standard}

We also made excellent progress in our effort to become the benchmark for the best-managed national laboratory through the Operations Improvement Program (OIP). In OIP, initiated three years ago to improve and sustain operational excellence, we developed the tools and systems needed to work safely and efficiently now and into the next decade.

Two standout projects resulting from OIP are the StandardsBased Management System and the Integrated Environment, Safety, and Health Management System. The StandardsBased Management System has allowed us to replace thousands of hard-copy manuals with an electronic system that offers time, cost, and quality features. The Integrated Environment, Safety, and Health Management System enables staff and management to more efficiently complete projects. At the time OIP was initiated, the Laboratory's operations rating by DOE was "marginal." In our most recent appraisal given by DOE, we earned an "excellent." Now, with the tools and systems of OIP, we can set our sights on the highest rating of "outstanding." 


\section{Growing the Business}

In addition to our progress toward becoming the premier environmental science and technology laboratory and sustaining operational excellence, we made significant headway in our efforts to strengthen and diversify our research base. By increasing our research volume and broadening the range of clients we serve, we more effectively meet DOE's greatest needs and provide increased stability and new opportunities for our staff.

We continue to build Pacific Northwest's business base through our leadership role in global climate research. Through DOE's Atmospheric Radiation Measurement program, our researchers are focused on resolving critical scientific uncertainties in climate system models that help predict global environmental change. Over the past several years, we also helped to create six independent Energy Efficiency Centers in countries with economies in transition. These centers were developed to promote economic growth while mitigating harmful effects such as greenhouse emissions.

Our business abroad also remains strong through the International Nuclear Safety Program, sponsored by DOE's Office of Nuclear Energy, Science and Technology. In this cooperative effort with other national laboratories, U.S. commercial organizations, and host countries, Pacific Northwest provides lead technical and management support to improve the safety of Soviet-designed nuclear power plants. We are currently supporting nuclear safety at 64 nuclear reactor units throughout eastern Europe and the former Soviet Union.
While expanding our existing business base, we are diversifying our work to include a broader range of customers. Our partnership in the Northwest Alliance for Transportation Technologies (NATT) will most certainly provide us the opportunity to participate in some of the most exciting basic and applied research programs of the next decade. NATT, a partnership among Northwest industries, national laboratories, and universities, is aimed at developing advanced lightweight materials for the vehicle of the future. Researchers

from Pacific Northwest will join NATT project teams to define, develop, and test technologies for a vehicle with triple today's fuel efficiency and greatly reduced emissions.

\section{Looking to a Bright Future}

We have made good progress this year. We opened the doors of EMSL, embraced the standards set through the Operations Improvement Program, and have grown and diversified the business base of Pacific Northwest.

There is still much to be done, but because we all are dedicated to the Laboratory's success, our future appears bright and our confidence that Pacific Northwest will "make a difference" remains high.

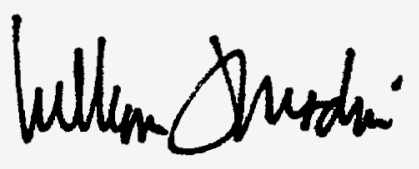




\section{Laboratory Mission}

Pacific Northwest National Laboratory's core mission is to deliver environmental science and technology in the service of the nation and humanity. Through basic research we create fundamental knowledge of natural, engineered, and social systems that is the basis for both effective environmental technology and sound public policy. We solve legacy environmental problems by delivering technologies that remedy existing environmental hazards, we address today's environmental needs with technologies that prevent pollution and minimize waste, and we are laying the technical foundation for tomorrow's inherently clean energy and industrial processes. We also apply our capabilities to meet selected national security, energy, and human health needs; strengthen the U.S. economy; and support the education of future scientists and engineers.
This mission is in line with the U.S. Department of Energy's Strategic Plan and Strategic Laboratory Mission Plan, where Pacific Northwest is designated as a principal laboratory in the environmental quality mission, a major contributing laboratory in both science and technology and energy, and a participating laboratory in national security.

The mission is also consistent with the technical work carried out at our Laboratory. Fully two-thirds of the Laboratory's work is in environmental science, environmental technology, or both. Further, our projects in support of DOE's national security and energy missions often draw heavily on capabilities we have developed in support of our environmental mission. 
It is not news to anyone who has more than casual contact with the Department of Energy laboratories that we are living in a time of rapid change. We can easily list the forces that are shaping our world, from the accelerating pace of scientific and technological advances to upheavals in the U.S. political environment and budgetary policy to the playing out of the many sequels to the end of the cold war. Reliably forecasting the future toward which those changes will carry us is much harder.

The task of forecasting is made difficult because of the complex crosscurrents that underlie so many of the forces that shape our environment. The opportunity for science and technology to provide dramatic new benefits to our nation has never been greater, yet as a nation we are rethinking our federal investment. Demands for a secure scientific foundation for public policy and for new technologies to meet human needs are exacerbated by growing populations and consequent pressure on our environment, yet popular interest in science appears to be declining. The scientific community, in the main, argues for continuation of the funding model that has supported us so generously and yielded great benefits, while Congress and the public demand greater relevance of our work to national needs. Internationally, the muchtouted victories of democracy and free market economics are juxtaposed with increasing unrest and ethnic conflict in many regions of the world. Buffeted by these crosscurrents, and the short-term chaos in policy, budgets, programs, and the regulatory practices that they engender, we can feel like sailors on a small boat in a Brownian sea.

If we believe that there is little chance that we can forecast likely futures with sufficient insight to develop useful longrange plans, we may conclude that the most sensible course is to retain as much flexibility as possible, being prepared to react quickly as events unfold. And, indeed, flexibility clearly is an important element of any sensible strategy in these turbulent times.

Yet in spite of the short-term perturbations, we believe that there are indeed some stable trends that shape our future. We also believe that there are a set of guiding principles and general strategies that will help us prepare for a range of likely futures. In brief, our overarching goal is to make the Pacific Northwest National Laboratory the most relevant and productive supplier of science and technology in those areas where we concentrate our efforts. We intend to strengthen our scientific foundations and strongly couple these foundations to our core environmental mission and to our work in energy, national security, and health. We will operate our facilities and programs with distinction. If we provide timely delivery of high-quality products meeting national needs at a reasonable cost while exercising stewardship for our staff, intellectual capital, research equipment and facilities, community, and the environment, then this Laboratory will have a bright future.

In this strategic plan we lay out our views on the most critical long-term trends that are the basis for these beliefs and provide the details of our strategy. In subsequent sections we describe the actions we are undertaking in line with this plan: the major initiatives that we are undertaking to strengthen our capabilities in key technical areas and to address critical scientific issues, our programmatic strategy in each of the Department of Energy's primary missions, and our approach to facility operations and laboratory management.

\section{Primary Planning Assumptions}

The task of reexamining underlying planning assumptions is a continuous one. There are changes since the last publication of this plan in each of the major areas that we review: science and technology policy and budgets, national needs, the Department of Energy, and the national laboratory system.

With regard to national needs that will drive science and technology policy in the intermediate and longer term:

- The tension between economic development, or meeting human needs, and protection of our environment will be a primary long-term driver for science and technology investments. Technology that allows economic growth while maintaining our environment is critical. It is likely that the United States will undertake international commitments in such areas as limiting carbon dioxide emissions that will require a substantial technology response.

- There is a strong, and broadly recognized, dependence of our prosperity on technological innovation. The welldocumented trend in industrial investment toward shortterm, product-related research will likely continue. Many industries will, therefore, look to government-supported research in the universities and federal laboratories to provide the new knowledge from which breakthrough commercial technologies can arise.

- We expect that social and political instability and consequent regional-scale conflicts, with occasional spillover in the form of terrorism against U.S. targets, will continue for the foreseeable future. The U.S. role in peacemaking or multilateral peacekeeping efforts, and in nonproliferation and arms control, will be a significant driver for national security needs. 
- The United States will be increasingly driven by both enlightened self-interest and international political pressure to engage in cooperative efforts in environmental protection, economic development, and resource management. Major portions of our science and technology agenda will derive from our international engagements and treaty commitments.

\section{Science and technology:}

- Advances in scientific instrumentation, computing and information technology, scientific knowledge, and engineering practices will continue to be very rapid by past standards. Continual reinvestment in the knowledge and expertise of staff and in research equipment and supporting infrastructure is required for any research institution to remain competitive.

- The dramatic advance in our understanding of biological systems at the molecular level may well be the dominant scientific theme for the foreseeable future. Molecular biology and related areas of investigation will see substantial investment and have dramatic effects not only on medicine and human health but on industrial process technology, and on our understanding and management of the environment.

- Our mastery of the small - the ability to manipulate matter on the molecular and even atomic scale-will be a second major scientific theme of the coming years. Transforming effects on everything from human health to industrial production technology are likely.

With regard to science and technology policy and budgets:

- The total national investment, public and private, in science and technology will grow slowly over the next few years. Federal investment will be sharply constrained for the foreseeable future by the ongoing attempt to balance the federal budget. We believe that the declines in science and technology funding may not be as severe as proposed in the current budget balancing plan. However, reductions in inflation-adjusted funding outside of the biomedical area are possible over the next 5 years. As a result, there will be unprecedented technical and political competition for scarce federal resources.

- The view that federal research and development investments should be explicitly tied to the most pressing technology and policy needs has increasing support in Congress and with the public, and is beginning to be heard more and more from leaders in the scientific community. An increased share of the available resources will be allocated to needs-driven research programs in areas such as health care, transportation, environmental remediation and protection, national security, and energy.

- Accountability for delivery of tangible results from public investment will continue to grow.

- A reduction in the overall size of the federal laboratory system remains likely.
With regard to the Department of Energy and the laboratory system:

- The core missions of the Department will continue to be broadly recognized as important to the nation and appropriate for federal support.

- The Department of Energy and its national laboratories will remain under fierce pressure to improve management practices and increase productivity. In response, DOE and the laboratories will continue the trend toward use of best commercial practice, outcome-oriented performance measures, external regulation, and elimination of lowvalue-added activities.

- The pressure for excellence in operations will be intense. Research facilities that are perceived as posing hazards to nearby populations will be impossible to operate.

- The Department will continue to expect the national laboratories to increase the share of funding from nondepartmental sources, to operate more closely as a system when carrying out major programs, and to demonstrate strong mission focus.

\section{The Laboratory Agenda: Our Role in the Department of Energy Strategic Plan}

The primary elements of our strategy are captured in a framework that we call the Laboratory Agenda. Our agenda has four components: Strategic Objectives, our broad, long-term (5 to 10 year) goals for the future of the Laboratory; Critical Outcomes, our highest level intermediate-term ( 3 to 5 year) tangible results that we deliver for DOE; Laboratory-Level Initiatives, the specific programs that we put in place to achieve our outcomes; and tactical or shorter-term implementing actions that we undertake.

The Laboratory Agenda is determined by the match between national needs as articulated in the Department's strategic plans and our technical capabilities. The Department's Strategic Plan and the plans prepared by Energy Research and other mission organizations, establish goals in each of the Department's core missions. The Strategic Laboratory Mission Plan describes the role of the national laboratories, as a group and individually, in carrying out the Department's Strategic Plan and in each of the Department's major programs.

We have organized our Laboratory agenda around three longterm strategic objectives. Our first, becoming a premier environmental laboratory through our science and technology contributions, provides the long-term framework for our primary objectives in support of the Department's missions. Becoming the benchmark standard for laboratory management provides the framework for our response to the critical success factors articulated in the DOE Strategic Plan, and to the improvement efforts that have derived from the Department's response to the Galvin Commission report and other studies. Our final strategic objective, achieving focused, strategic growth, represents our commitment to ensure that 


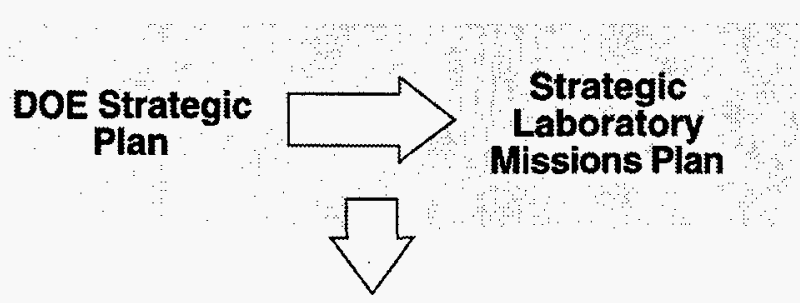

Pacific Northwest National Laboratory Agenda

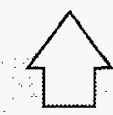

Pacific Northwest National Laboratory Capabilities

Laboratory Agenda

the Laboratory remains a vital resource to the Department over time, and incorporates our efforts in support of the Department's commitments to local economic development and diversification of its host communities.

\section{Creating a Premier Environmental Laboratory: Our Role in DOE's Core Missions}

We intend to be a premier national laboratory as measured by the science and technology we produce, focused around our core environmental science and technology mission, and with significant contributions in our energy, national security, and health work. We here describe our role and objectives in each of these areas.

\section{Science and Technology}

We intend to strengthen the scientific core of our laboratory, improving both the quality and scientific impact of our basic research programs and strengthening their tie to outcomes important to the Department, Congress, and the public. By so doing, it is our intent over time to become recognized as a principal laboratory in the Department's Science and Technology mission.

A little more than a decade ago, Pacific Northwest National Laboratory embarked on a concerted effort to build a preeminent basic research capability in several areas of the chemical, material, and life sciences critical to our core environmental mission. With the October 1996 dedication of the William R. Wiley Environmental Molecular Sciences Laboratory, our first major scientific user facility, we reached a significant milestone on that effort.

Our highest priority in support of DOE's Science and Technology mission is to deliver the Environmental Molecular Sciences Laboratory as a preeminent collaborative research facility, and in so doing, bring the nation's best scientific talent to the Department's critical environmental challenges. We must now bring that effort to fruition by successfully operating the EMSL as a user facility and maintaining an outstanding and scientifically productive core staff and set of core research programs.

In keeping with our environmental mission, our science portfolio has two primary components. We are heavily engaged in the environmental sciences, including the investigation of the processes by which contaminants are transported and transformed in the environment and the impacts of those contaminants on ecological systems. Renewed investment in several of these areas is required. We also maintain leading-edge programs in those aspects of the chemical, material, and life sciences that underlie creation of environmental technology, or that are required to understand the interaction between natural and biological or engineered systems.

In line with the Energy Research strategic plan, we are also continuing our emphasis on fundamental science related to human health and to the development of applied medical technologies that derive from our technical capabilities in imaging, information technology, materials science, and other areas. Our goal is to help improve the condition of human health through the development of fundamental scientific understanding and deployment of technologies that facilitate the assessment and management of health risks, the analysis of the safety and effectiveness of pharmaceuticals, and that reduce the time and resources required to develop drugs and chemicals and microbes for bioremediation.

We also intend to continue our emphasis on bringing new scientific knowledge to bear on DOE's environmental, energy, and national security missions. For example, knowledge developed through the programs housed in the EMSL must have significant impact on DOE's environmental remediation programs at Hanford and across the complex, and more broadly, on the environmental management challenges facing the nation. Similarly, our energy programs are directed toward supporting the Department in defining and executing a science-based energy strategy that provides real alternatives for our nation over the coming decades. These programs increasingly reflect the application of basic scientific and engineering work to the creation of new, environmentally benign, pollution preventing energy and process technologies. Our nonproliferation and arms control programs must remain well-connected to our environmental science and technology base in areas such as radiation detection and chemical sensors.

Finally, we are continuing our emphasis on partnerships for scientific research and education. We are increasing the fraction of our research that is carried out in partnership with the university community and continuing to provide research participation opportunities to visiting students, teachers, and university faculty. We will continue our contributions to systemic reform of scientific and mathematics education in support of DOE's efforts to provide a technically trained, diverse workforce of the future and to ensure a technically 




The William R. Wiley Environmental Molecular Sciences Laboratory, a new scientific user facility, was dedicated in October 1996.

literate citizenry. We will continue to concentrate on curricular reform, on regional outreach, and on strengthening our ties with minority institutions.

\section{Environmental Quality}

Pacific Northwest is designated as a principal laboratory for the Environmental Quality mission in the Strategic Laboratory Mission Plan. In keeping with that designation, we have strong roles in the reduction of the health and environmental risks associated with both legacy production sites and current operations and in development of environmental technology.

We and our research partners will deliver knowledge required to make scientifically sound risk-based decisions and deliver technology that reduces the cost and improves the timeliness and effectiveness of environmental remediation at Hanford and across the entire DOE complex. We will support DOE in achieving a scientifically defensible, risk-based remediation strategy and schedule, and deliver technology that helps DOE meet that schedule at affordable cost. To fulfill this intent, we have added a fundamental molecular sciences capability to our long-term strength in the environmental sciences. On the engineering side, we are strengthening our system engineering skills to complement our long-standing capability in the design of complex processing systems.

To fulfill the Department's strategic intent and to meet the expectations of the nation's taxpayers, the environmental remediation program requires intense effort over the next few years. In the long term, however, a strategy of pollution prevention and environmental protection must replace the strategy of waste management and environmental restoration. Our intent is that Pacific Northwest, in partnership with our sister laboratories and with U.S. industry, will be a national resource of environmentally acceptable technology and, again in partnership with our laboratory and university colleagues, will provide the underlying science required for future advances. Our principal focus areas, in line with the DOE Strategic Plan and as reflected in our current initiatives, are industrial process technology, energy generation technology, and commercial and residential energy enduse technologies.

\section{Energy Resources}

We believe that DOE's Energy Resources mission will be of increasing importance to the nation for the foreseeable future. As discussed earlier, we believe that the Department will lead the development of a more strongly science-based energy strategy, toward which we hope to contribute. Our objectives in the energy area are to contribute in two principal ways:

- for the near term, improving the utilization of the current national and international energy infrastructure through development of technologies that save energy and control costs

- for the longer term, developing the next generation of science and technology to increase our nation's energy security in an environmentally acceptable manner consistent with an increasingly competitive energy marketplace. 
Accordingly, we will continue our focus on enhancing the resource efficiency and performance of existing energy assets (and most particularly transmission and distribution systems), and our work with government and the utility industry to develop a new generation of distributed energy systems. We will also continue our investment in the capabilities required to develop and deploy resource-efficient pollution prevention and waste minimization technologies that enhance the economic, energy-efficiency, and environmental performance of government and U.S. industry.

Finally, we are supporting the Department's efforts to respond to international agreements on climate and carbon dioxide emissions and to help developing and rebuilding countries create a balanced, coordinated, and sustainable portfolio of energy sources; efficient or sustainable energy consumption practices; and a reliable energy infrastructure. Over the last few years, we have become increasingly engaged in Eastern Europe, the Far East, and Central and South America through the creation of independent Energy Efficiency Centers and in the rehabilitation of the energy infrastructure of the former eastern block states, and we expect to continue to play an active role. We believe that this outreach effort will be of increasing importance to DOE.

\section{National Security}

Our national security work is focused on support of DOE's nonproliferation and arms control goal. The rationale for our involvement is straightforward. The Laboratory's core technical capabilities and key technologies, developed through our environmental science and technology programs have direct application to critical nonproliferation and arms control challenges facing the Department as well as meeting national security needs in defense-related activities. In addition, and of particular current interest, our expertise in nuclear power and related technologies is highly relevant to current U.S. policy goals to reduce the danger associated with powerproducing reactors in the former Soviet Union.

Our primary objective is to leverage our environmental science and technology base to develop arms control, nonproliferation, and intelligence technologies that enhance national security and reduce the danger from weapons of mass destruction. We also pride ourselves on the ability to respond rapidly to urgent technology needs in our areas of expertise and plan to maintain that capability. Finally, we have assumed significant programmatic and technical responsibilities in DOE's effort to reduce the danger associated with power reactors in the former Soviet Union.

\section{Benchmark Standard for Laboratory Management}

Our Strategic Objective is to be the benchmark standard of excellence for laboratory management, providing the Department of Energy and the nation with the greatest possible research product for each dollar invested in our laboratory while fully meeting our responsibilities for the health and safety of our workers and the public and for protecting the environment. This Strategic Objective provides the long-term framework for our response to the set of improvement initiatives that DOE has launched over the last few years. The associated goals and initiatives represent our commitment to DOE to be "best in class" in meeting the performance expectations of the public.

We have established three objectives in the areas covered by DOE's Critical Success Factors that we believe are essential to the continued success and vitality of the Laboratory. First, we believe that the heart of the Laboratory is our research and administrative staff. Accordingly, we are committed to building a tradition of interactive personal and institutional leadership, encompassing the entire staff of the Laboratory. We seek to recruit, develop, and retain a diverse staff recognized for scientific, intellectual, and personal leadership for the integrity of our research and business practices, and for our contributions to the community and the nation.

Second, the Department's Strategic Plan communicates a strong and unambiguous commitment to operations to ensure the health and safety of our workforce and the public and with respect for the environment. We will manage our facilities and conduct our work in a manner that protects the environment and the health and safety of our staff and the public. We and the Department jointly established this commitment in our planning for 1995 by the recognition that, although our environment, safety, and health statistics were good as compared to industry standards, our operating practices did not yet fully conform to the standard of excellence expected by DOE and the public. We have evolved as rapidly as possible through implementation of a Laboratorywide Operations Improvement Program to an improved level of performance. In carrying out this effort, we have worked with DOE to establish the appropriate standards for each aspect of our operations, and to design management systems to ensure that we cost-effectively meet those standards. While making these significant changes, we remain committed to maintaining or exceeding our past performance on traditional measures of environment, safety, and health outcomes.

Third, we must meet DOE's and the public's expectation for cost-effective operation. We have significantly improved our productivity and cost-effectiveness, and strive to be one of the highest value providers of science and technology in the world. We are committed to becoming the benchmark case for management of national laboratories in terms of the value of the work we do; the quality of the working environment; our organizational effectiveness; the stewardship of our human, physical, and intellectual assets; and our costeffectiveness. We are achieving a significant increase in the fraction of total staff time devoted to research and development, accelerating the delivery of new technical products, decreasing the cycle time associated with administrative and management functions, and ensuring effective stewardship of the Laboratory's people, facilities, and programs. We have also initiated efforts to strengthen our peer review practices in line with DOE guidance. We are well under way in an effort to redesign all of our management systems to ensure that each system effectively supports our scientific and engineering projects. 
Because of the fierce cost pressures to which we are all responding, we must take care not to lose sight of stewardship and scientific excellence as we seek to improve our efficiency. Apparent increases in productivity obtained by reducing cost through failure to reinvest or failure to develop new capabilities are counterproductive. Efficiency improvements in needed activities and elimination of unnecessary or low-value activities will provide the needed productivity increase. However, in making these improvements we must take great care not to compromise our ability to respond to current and future national needs. We are, therefore, committed to maintaining our investment in Laboratory Directed Research and Development.

Finally, we must support what is a key theme in the Department's response to public concern regarding the safety and impact at its facilities. We recognize that our high-level objectives require a foundation of effective communication and trust, both within our institution and between us and our customers, partners, and the public. Continuous, rapid change in the world to which we respond and in our own business and management practices is inevitable. If our staff are to successfully respond to these changes, they must have confidence that the Laboratory is home to open, honest communication. If our customers and partners are to continue to entrust us with significant resources and shared responsibility for their future, they, too, must have confidence in both our character and our competence. Each staff member, whether working in research, in administrative functions, or in management, is accountable for, and entitled to, this foundation.

\section{Focused, Strategic Growth}

As our third strategic objective, we intend to achieve focused, strategic growth, through which we will provide stability and opportunity for our staff, continually renew and strengthen our technical capabilities, and increase our contribution to the nation.

This objective reflects a new emphasis on growth as an essential element of our overall long-term strategy. It also reflects the Department's direction that the laboratories are to diversify their funding sources. Although we recognize that it may seem paradoxical to assert the need for growth at a time when resources are so obviously constrained, we have concluded that this objective is a crucial element of our long-term stewardship for this laboratory. There are four factors that have led us to this conclusion:

1. A modest level of overall growth will significantly increase our ability to provide stability and opportunity to our staff.

2. To maintain the vitality of any research institution, it is necessary to have a continuing infusion of new ideas and new talent. Growth will ensure that we are able to offer opportunities to highly capable scientists and engineers.

3. To fully realize the benefits of the reductions we have made in overhead and fixed costs, we need to spread the remaining costs over a larger research base. Given the improvements we have made, even modest growth in our research business will give us very substantial leverage in reducing charge-out rates and increasing the fraction of our staff working directly on projects.

4. Today's capabilities will not meet tomorrow's DOE needs. We must continually strengthen the technical capabilities and performance of this Laboratory if we are to remain relevant to evolving national needs.

The level of growth we envision is modest, perhaps increases of a few percent per year in both funding over inflation and in the size of the technical staff. In selecting opportunities through which we will achieve this growth, we will continue to emphasize the fit of those opportunities with both our mission strategy and our technical capabilities, the importance of that work to our clients and the nation, and the quality of opportunities provided to our staff. Finally, we recognize that growth in capability and impact may as readily come through collaboration as through additions to staff count, and strengthened outreach to university, government laboratory, and industrial collaborators is a key part of our growth strategy.

\section{Fundamental Strategies}

We close by articulating a crosscutting set of fundamental strategies that we will use to achieve the outcomes described above. We believe that there are five broad, closely linked, and enduring strategies critical to our future.

- We will maintain a clear mission focus. Over the last few years we have more tightly focused the Laboratory's programs around our core environmental mission, and those elements of DOE's other missions that best match our core competencies. With the publication of the Strategic Laboratory Mission Plan, this strategy has been reinforced as a fundamental expectation that the Department has for each of the laboratories.

- We will build and maintain an outstanding fundamental science capability, directly and effectively linked to the nation's highest priority environmental needs and policy issues. When we made the transition to being an Energy Research laboratory, we made the commitment to establish a fundamental science capability fully on par with our traditional engineering and applied science strengths. Through Laboratory Directed Research and Development and our programmatic investments, we have developed leadingedge fundamental science programs and capabilities in selected areas of molecular, environmental, and life sciences that we believe are particularly relevant to the Department's environmental mission. The William R. Wiley Environmental Molecular Sciences Laboratory is the cornerstone of this strategy.

- We will bring the full technical resource of the nation to critical problems through broad partnerships with our sister national laboratories and with universities and industry. The breadth and complexity of DOE's missions make 
it unlikely that any single institution will maintain the complete set of core competencies required to respond fully to mission needs. We believe we can best meet the Department's needs for comprehensive solutions to complex problems by building partnerships that draw on the most appropriate resources of the laboratory system, our universities, and U.S. industry.

- We will dramatically enhance our technical productivity while protecting the health and safety of our staff, the public, and the environment. Both DOE requirements and our duty to the public and taxpayers require that we achieve cost-effective excellence in our operations, fully meet the
Department's expectations for conduct of operation, and deliver the highest possible return on the nation's investment in our programs. In cooperation with DOE, we have achieved dramatic operational improvements within the last two years, and will continue to focus in this area.

On the basis of this strategy, we have a bright future. Our science and technology is and will remain highly relevant to important national needs. We have become one of the most productive and cost-effective laboratories in our country. As a result, we are confident that Pacific Northwest National Laboratory will be making significant science and technology contributions well into the next century and beyond.

\section{Pacific Northwest National Laboratory FY 1998 Critical Outcomes}

Environmental Technology - Battelle will be instrimental in the development, demonstration, and deployment of new and innovative technologies and approaches that 1 allow environmental cleanup to be done faster, at lower cost, or more effectively, 2) minimize waste generation; 3 ) enhance the effectiveness of waste treatment processes; or 4) result in inherently clean and energy efficient industrial processes. Because of the need to increase the impact of the Laboratory's scientific and technical contributions, the development, demonstration, and deployment of technologies and approaches nay not be limited to environmental restoration or waste management technology, but may also include broader envirommental technologies of interest to the Department of Energy, ( $\mathrm{eg}$. groundwater monitoring and modeling), (lassified programs are not included in this Critical Outcome.

Scientific Excellence - Battelle will deliver more and better R\&D for each dollar, becoming the science and technology provider of choice in the markets the I aboratory serves.
Scientific and Technical Contributions - Battelle Will increase the PNNI Scientific and Techical Contribution related to the core capabilities and within mission, goals, and objectives of the Department of Energy,

Operational Excellence- Battelle will conduct all work and operate Laboratory facilities with distinction, fully supportive of and integrated with the I aboratory's science and technology mission and filly protective of workers, the public, and the environment.

Leadership and Management - Battelle will provide leaders and systems that effectively support the mission areas of the Department of Energy.

Community Relations - Battelle will involve and benefit the communities to assure that PNNI and Battelle remain valued assets to the Tri-Cities and the Northwest Region. 


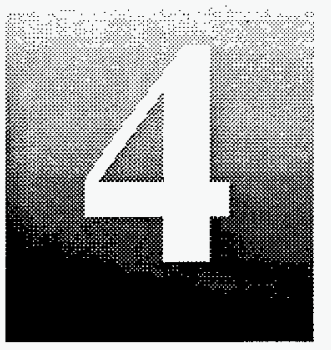

\section{Major Laboratory Initiatives}

Our scientific initiatives are designed to build substantial capabilities to meet significant national needs, consistent with our core environmental science and technology missions, U.S. Department of Energy missions, and strategic plan. For example, over the last decade the molecular sciences initiative has helped establish the scientific capabilities and staff that underpin the Environmental Molecular Sciences Laboratory. Similarly, a multiyear initiative, formally concluded last year, provided the technical foundation and new capabilities for the significant role that Pacific Northwest National Laboratory is now playing in global climate change research, from fundamental science to integrated assessment.

Our current initiatives ${ }^{(a)}$ are similarly aimed at significantly enhancing PNNL and our ability to contribute to the major challenges facing the Department of Energy. The Microsystems Science and Engineering initiative is establishing the science base and other technical capabilities necessary to develop miniature systems that rely on novel microscale structures for highly efficient, scaleable energy and chemical systems. We believe that this area of research will prove to have substantial, long-term importance for DOE's environmental and energy missions. Our Microbial Biotechnology initiative is building capabilities in fundamental microbiology with applications to bioremediation and the potential biological treatment of waste streams. The Computational Reactive Transport initiative is building on the substantial investments in computational chemistry that DOE has made through our Chemical Sciences programs and in the Molecular Sciences Computing Facility in the EMSL to address critical challenges in reactive chemical transport in subsurface environments and viscous flows. Through the Science and Technology for Environmental Processing initiative, we are continuing to build the science base for both the Department's weapons site cleanup programs and for the likely increased requirements for environmentally conscious process technology. Similarly, the other initiatives presented here are each directed to establishment of substantial new research capabilities with clear relevance to what we believe will be among the most pressing challenges facing DOE in the years to come.

\section{Molecular Sciences Research}

The Molecular Sciences Research initiative has been a key component in the Laboratory's effort to provide the

(a) Initiatives are provided for consideration by the Department of Energy. Inclusion in the plan does not imply Departmental funding or intent to implement any initiative. fundamental science base necessary to support DOE's environmental missions. It also served as the basis for the research programs that were established for and are currently conducted in the EMSL, the DOE's new scientific user facility, which began operations in October 1998.

This initiative focused on developing EMSL research program areas that will lead to the molecular-level understanding of important environmental issues such as

- the chemical, physical, and biological processes in natural and contaminated environments

- ways to use natural processes to clean up contaminated soils and groundwater

- processes and techniques that can be used to extract and destroy chemical wastes and to separate and store radioactive wastes

- the impact of radioactive and chemical contaminants on human health and the ecosystem.

This research provides the fundamental knowledge needed to develop permanent, cost-effective solutions to the nation's environmental problems and environmentally acceptable energy options for the future. Capabilities and expertise developed in several projects under this initiative are making significant contributions to new DOE programs, such as the Environmental Management Science Program, the Natural and Accelerated Bioremediation Program, and the Environmental Technology Partnerships Program.

Collaborative research involving scientists from other DOE and government laboratories, universities, and industry has been a key ingredient in this initiative. Programmatic support is provided by various DOE offices as shown in the initiatives table at the end of this section. Multiyear resource requirements also are shown in the initiatives table at the end of this section and are not included in the Resource Projections.

The Molecular Science Research initiative enters its final year in FY 1998, and the scope of the initiative has been reduced accordingly. Many of the capabilities in environmental molecular science developed under this initiative are being incorporated in the fundamental science aspects of other Laboratory initiatives, such as those focused on microbial biotechnology, reactive transport, or science and technology for environmental processing, and on new efforts in contaminant remediation and molecular biology.

We have completed activities in Chemical and Waste Processing; much of the research associated with this area 


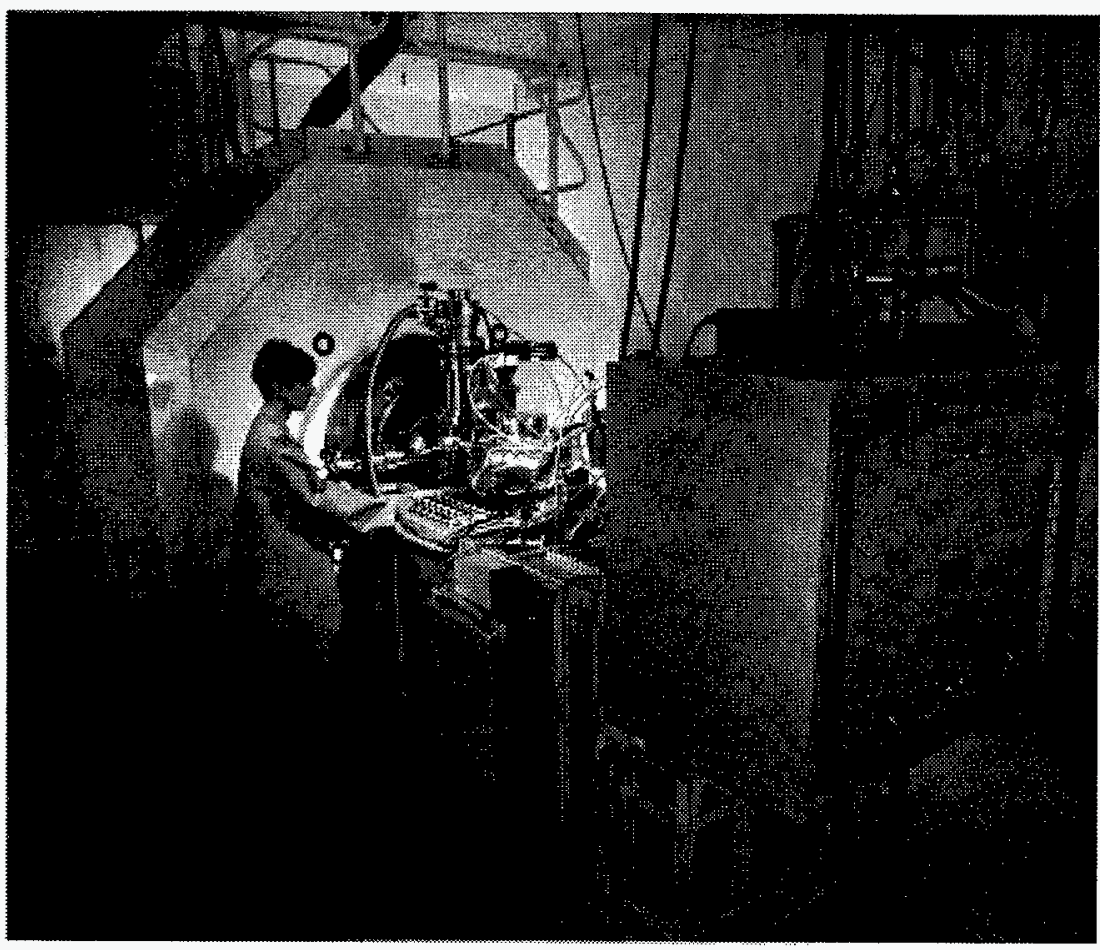

The EMSL High Field Mass Spectrometry Facility, which contains the world's first 11.5-tesla Fourier transform ion cyclotron resonance spectrometer focuses on biochemical applications of mass spectrometry, including combinatorial chemistry and sequencing applications.

investigations of homogeneous and simple heterogeneous systems, where key reactions and reaction sequences can be isolated and studied, can yield accurate physicochemical models of natural reaction processes. These models and molecular techniques can, in turn, be used to characterize and simulate contaminant reactivity in complex natural systems, forming the basis for development of improved biogeochemical reaction models.

\section{Supporting activities include}

- Study and control of enzymatic reactions occurring at biological membranes in aqueous environments at nanometer spatial resolution.

- Investigation of the structure/function of biodegradative enzymes with potential bioremediation applications.

- Investigation of the adsorption, desorption, and diffusion of oxyanions on mineral surfaces. This work provides a basis for understanding transport of contaminants through soils.

\section{Health Effects from Environmental Contaminants}

now is being supported by the Environmental Management Science Program and the Environmental Technology Partnerships Program.

The major research programs in the Molecular Sciences Research thrusts of this initiative for FY 1998 are described below.

\section{Environmental Fate and Transport}

The chemical contamination of soils and groundwater is a national problem that requires modern scientific and engineering approaches to solve. The DOE manages over 10,000 contaminated locations at 137 sites as a result of its production and testing of nuclear materials. Metals, radionuclides, and fuel and chlorinated hydrocarbons have been discharged to soil and subsurface systems as single constituents and as complex mixtures with other reactive, but nontoxic chemicals. Basic scientific advances in environmental chemistry and microbiology can contribute to development of innovative in situ remediation techniques by characterizing the subsurface chemical and biologic processes that control contaminant distribution between solids and water, chemical speciation and form, and flux.

Molecular science plays a key role in the study of environmental mineral and biologic surfaces, and in identifying the mechanisms of biogeochemical reactions that control contaminant transport, fate, and remediation. Molecular-scale
Health risks, particularly from cancer, play a major role in establishing cleanup standards and priorities. Accurate cancer risk assessment requires a thorough mechanistic understanding of the neoplastic processes occurring after exposure. Genomic damage is generally accepted to be the underlying mechanism of cancer induction; however, cancer risk analysis is limited by our knowledge of how normal cellular processes are involved in the expression of DNA damage. Such damage may result from direct interaction of a carcinogen with DNA or by indirect mechanisms that change the level or persistence of endogenous DNA damage. Understanding carcinogenic processes can only be achieved through fundamental data on biological systems at all levels of organization (i.e., macromolecules to whole animals).

The mechanism by which the body's repair enzymes recognize the presence of DNA damage is unclear, as are the mechanisms by which damage recognition and repair triggers alterations in gene expression. Protein-DNA and proteinprotein interactions control the pathways that define the response of a cell to DNA damage. Such interactions are not limited to that of the repair proteins with damaged DNA, but also include transcription factors that function to regulate the expression of gene products and thereby protect the higherorder integrity of the organism. In addition, the structure of the chromatin itself needs to be determined, since it is becoming clear that histone-DNA interactions are not static and contribute to the control of gene expression. Protein-protein 
interactions involved in the signaling of DNA damage must also be examined, since it is these pathways that bridge the recognition of DNA damage with changes in gene expression.

Activities that support this program are

- Structural and mechanistic studies of proteins, DNA-adducts, and alteredDNA/protein complexes to provide a molecular-level understanding of DNAprotein and protein-protein interactions in DNA damage recognition and repair.

- Development of an automated in vitro microanalysis technique for detecting DNA damage, combining the sensitivity of adsorption voltammetry with precision flow injection analysis control.

- Development of a special nuclear magnetic resonance (NMR) spectrometer in which the signals obtained from specific materials can be significantly enhanced by the use of dynamic nuclear polarization (DNP). This NMR will be used to evaluate the potential of DNPNMR in a variety of projects of environmental significance.

\section{Environmental Molecular Sciences Collaboratory}

Recent and continuing advances in computing and communications technologies are rapidly expanding the possibilities for collaborative research. It is now possible to create a "virtual laboratory" where researchers at multiple sites work together electronically to solve large, complex research and development problems. Collaboratory approaches offer nothing short of a revolution in how resources can be applied to scientific research in the DOE system.

The role of the EMSL as a collaborative user facility, its multidisciplinary environmental mission, and its unique facilities and modern computing and communications infrastructure make it an ideal focus for collaboratory development and operation. An Environmental Molecular Sciences Collaboratory (EMSC) will enable geographically separated researchers to work cooperatively with EMSL staff using the unique resources of the EMSL as well as those at their home institutions to build the knowledge base needed to develop more effective and efficient remediation technologies, to decrease the time between scientific discovery and application, and to improve the coordination of the nation's environmental research efforts.

To provide the required technical capabilities for an EMSC, the Molecular Sciences Research initiative includes an activity focused on development of a new generation of research instruments that permit remote instrument monitoring and control, and scientific data sharing and analysis across the Internet.

\section{Microbial Biotechnology}

The goal of the Microbial Biotechnology initiative is to build a comprehensive capability in microbial systems that significantly contributes to DOE's core mission. This initiative is building on Laboratory strengths in environmental microbiology and molecular sciences to establish capability in fundamental microbiology (molecular biology, microbial genome mapping and sequencing, bacterial enzymology, physiology and metabolism); microbial and molecular applications in key areas (bioremediation, biotreatment of industrial waste streams); and technology planning and analysis (risk management; ethical, economic, and social issues). A key objective is to link fundamental capability in molecular sciences being developed in the EMSL to practical use of microbial systems for restoration of DOE sites.

Fundamental research is serving as a basis for new technologies that are examined through joint scientific research. Examples of opportunities under investigation include the following:

- Novel biological methods for improving the range and efficiency of energy production and chemical processing (e.g., high-temperature biocatalysis), for selective concentration and conversion of wastes and environmental contaminants, and for supporting an improved understanding of global climate change (e.g., biogeochemical cycles). 


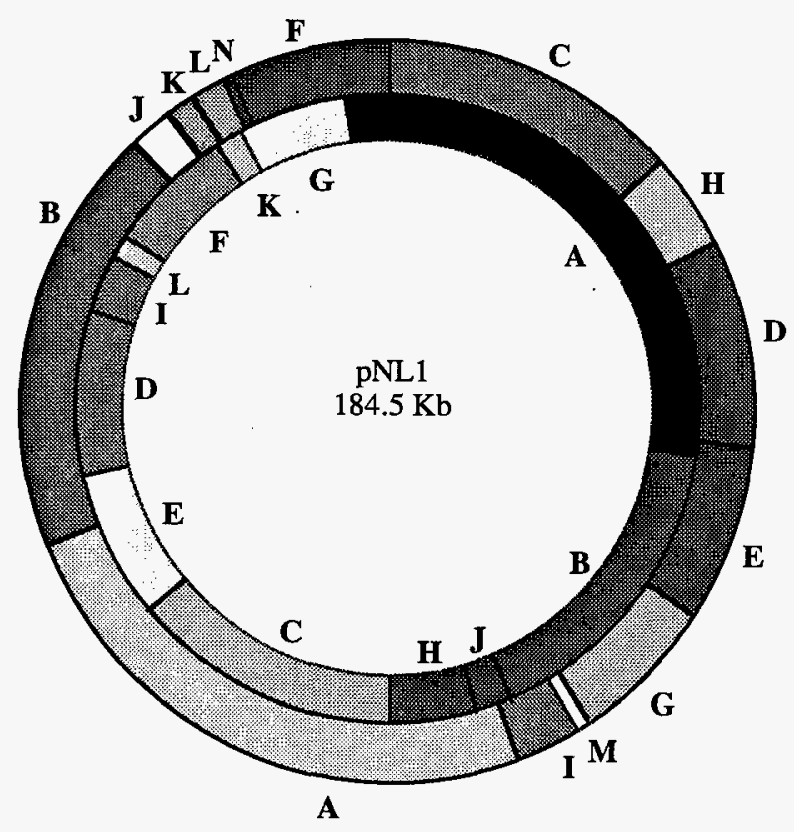

This self-conjugative plasmid encodes genes that are required for degradation of aromatic compounds including p-cresol, m-xylene, and naphthalene.

- Microbial systems for cost-effective treatment of metals and radionuclides and chlorinated hydrocarbons in contaminated aquifers and industrial waste streams through advanced bioprocesses based on enzymatic alteration of valence states and reductive dehalogenation.

- New concepts for the use of natural processes in environmental restoration (e.g., bioremediation) through metal reduction, dechlorination, and degradation of aromatic compounds.

- Basic research in molecular ecology is supporting the development of methods for in situ detection of metabolic activity and the construction of gene probes for specific organisms and activities to improve the performance of field-scale bioremediation research, development, and deployment.

- Isolating and characterizing microorganisms from unexplored and extreme environments to determine their roles in natural biogeochemical processes, to understand their origins, and to examine their potential for new industrial processes.

- Mapping and sequencing the genomes of industrially and environmentally important bacteria to provide the basis for understanding and enhancing important and novel functions.

- Elucidating the structure and function of important enzymes that act as novel biological catalysts and of biomolecules that control critical biogeochemical processes in the environment. For example, PNNL has successfully isolated and purified the first reductive dehalogenase linked to energy metabolism.

- Understanding the mechanisms whereby organisms reduce redox-sensitive elements, such as uranium, chromium, and technetium, critical to development of both in situ and ex situ biotreatment technologies for these elements.

- Developing near-field optical microscopy to examine electron transport phenomena of PNNL-isolated dehalogenase and monooxygenase enzymes at the single-molecule level, providing unprecedented information on enzyme kinetics, reaction intermediates, and reaction mechanisms.

- Identifying phylogenetic and functional molecular probes in bacterial dehalogenase and metal reductase systems.

- Identifying and assessing key social and economic issues, including comparative impacts of competing technologies, environmental stewardship, and ethical and risk perception issues that will accompany the commercialization of new microbial biotechnologies.

The growing success of the Laboratory's interdisciplinary approach to technology development and transfer is underscored by a number of research awards and important intellectual property in biotechnology, including four Federal Laboratory Consortium and R\&D 100 awards and over 40 patents awarded and pending.

Funding projections for this initiative are given in the initiatives table at the end of this section and are not included in the Resource Projections section. Programmatic support for this initiative is sought through DOE offices with basic and applied research businesses, including microbial genomic and bioremediation (Natural and Accelerated Bioremediation Research) and health effects (nucleotide excision and repair) programs in the Office of Biological and Environmental Research (OBER); Energy Biosciences in the Office of Basic Energy Sciences; the DOE-Environmental Management (Environmental Management Science Program and focus areas, including landfill stabilization and contaminant plume containment and mixed waste characterization, treatment, and disposal); bioremediation programs with DOE-OBER (Environmental Technology Partnerships); DOE-INTEL; and the Advanced Industrial Concepts Program in the DOE, Office of Industrial Technology. New interfaces with other federal agencies and industry are also rapidly developing.

\section{Computational Reactive Transport}

It has long been recognized that computational modeling of the transport, fate, and processing of contaminants is a challenge of the first magnitude, a so-called "Computational Science Grand Challenge," because of the complexity, large variations in temporal and spatial scales, and urgency of the problems at hand. However, what has been less appreciated is the scope of the many multiple interconnected challenges 
that must be addressed to make substantial progress in the computational modeling of these complex physical, chemical, and biological systems. In order to meet these needs, PNNL has initiated a significant effort in computational science. The initial effort in this area was in computational molecular science funded by the EMSL Project--OCTR (DOE-MICS) program in high-performance computing and DOE-ER (BES, Chemical Sciences). This led to the establishment of the Molecular Sciences Computing Facility with a high-performance, massively parallel IBM supercomputer, a novel database system, and the computational chemistry software NWChem and the associated problem-solving environment ecce' (Extensible Computational Chemistry Environment). NWChem is a high-performance suite of software that is scalable and portable on a wide range of parallel architectures.

In order to expand our capabilities in computational science, we have launched a new initiative in Computational Reactive Transport. The focus of this initiative is to develop methodology and software for high-performance parallel computing systems in the area of reactive transport. This effort will integrate PNNL's proven strengths in computational molecular science and our efforts in reactive transport for environmental dynamics models and waste process models to accomplish the following goals:

- provide advanced applications software for "Grand Challenge" class problems in a way that significantly and demonstrably advances solutions to one or more DOE missions

- impact substantially the high-performance computing community by creating and introducing into general practice software tools and procedures necessary for the development and use of high-performance computational models

- bring into technical practice novel computing hardware and software architectures that provide significant performance gains beyond the current state of the art

- become a leading center for data storage, analysis, and dissemination in the areas of computational molecular science, including thermochemical and kinetic data and subsurface environmental data and models

- substantially enhance our capabilities so that we are able to generate support for a future high-performance computing center.

To meet the above goals, this initiative is focused on the development of a new generation of environmental modeling software that takes full advantage of the current (and continuing) advances in computer hardware. The development of high-performance codes and problem-solving environments is focused in these new areas:

- Reactive Chemical Transport in Subsurface Environments. Predict the fate and transport of contaminants in these regimes and serve as an active partner in the design and execution of any required remedial actions.
- Reactive Chemical Transport in Viscous Flows. Minimize the construction and operational costs and maximize worker safety in facilities built to treat DOE's legacy of stored wastes, as well as improve "green" manufacturing technologies for the chemical-based industries.

- Computational Environmental Molecular Science. Provide the fundamental chemical information required to model reactive chemical transport in the subsurface and for waste processing.

Through the initiative, PNNL is developing a highperformance reactive transport modeling capability that will result in the first generation of models that fully address the coupling of the dominant processes controlling the behavior of chemical and biological components in highly resolved, three-dimensional depictions of the subsurface. This modeling capability will provide a fundamental test bed with unprecedented detail in process and resolution to assess proposed remediation technologies and designs. The ultimate goal is a stronger scientific basis for waste management decision making by mechanistically integrating physical, chemical, and biological processes in complex, site-specific subsurface environments under engineered remediation stresses.

\section{Science and Technology for Environmental Processing}

Process technology is central to support the Department's energy and environmental missions. New process technology is required to design systems for producing energy, food, or products that minimize the use of valuable resource inputs and reduce waste outputs. The Science and Technology for Environmental Processing (STEP) initiative is intended to develop and apply the science necessary to develop clean processes.

To effectively impact the resource inputs and waste output of any chemical process, new chemical conversion, separations, and synthesis technologies will be needed. This initiative is focused on these areas. Three distinct problem areas are being investigated: 1) aqueous conversion, 2) anion separations, and 3) gas-phase corona synthesis. Novel chemical conversion approaches are the key to reducing pollution at the source and have the potential to make significant improvements in the overall energy and material input requirements. Innovative separations technologies are key to effective recovery and recycle approaches and are often inextricably linked to conversion processes to achieve major efficiency gains. Finally, innovative synthetic pathways for the partial oxidation of organics that are more energy efficient and significantly reduce, or eliminate, the generation of secondary waste streams are essential to the design of closed loop processes. 


\section{Aqueous Conversion}

Through our efforts in the area of aqueous conversion, PNNL will create viable new processes and technologies that will allow for aqueous processing of industrially important chemicals: organic acids, monomers for plastics production, and solvents. Aqueous-based processing will eliminate the need for a wide range of organic solvents and may allow the use of biomass for chemical feedstocks.

Aqueous processing of biomass requires processing routes to convert cellular solids into water-soluble species such as simple sugars and the chemical transformation (e.g., reduction) of these sugars to desired products.

The viable economic conversion of biopolymers to monomers, such as sugars, has a number of significant technical challenges. Two techniques are viewed as key to creating an intermediate sugar stream: direct chemical (i.e., acid) and enzyme hydrolysis. We are investigating the complex reaction pathways to each of these techniques.

We are also studying issues that relate to enzyme stability in industrial processing including activity in diverse processing conditions and microbial fouling. Other issues include contact between substrate and enzymes during processing. The mechanical stability of these enzymes is also a challenging technical concern for their commercial use.

To get to the core of the stability issues, we are carrying out an integrated enzyme modeling/experimental program. Cross-linking of enzyme crystals seems to be the most promising approach for improving the stability of enzymes. The technique of cross-linking enzymes is in its infancy: the mechanisms involved in enzyme stabilization are not understood, the choice of cross-linking agents is limited, and the techniques are not well characterized. Simulation studies to understand the changes in enzyme activity and stability will be performed. Protein flexibility is anticipated to play an important role in enzyme stability and will be investigated through molecular dynamics simulations.

The final component of this effort is the development of catalysts and their supports for aqueous phase processing. In addition to being critical to developing renewable biomass feedstocks, there is increasing industrial interest for solventfree, environmentally benign processes, including wastewater treatment. Technical challenges include limited existing technology for catalysts used in water, incompatibility of conventional supports in a hydrothermal processing environment (due to solubility, crystalline instability, and chemical reactivity), and the instability of the catalytic metal phase (aggregation of dispersed materials).

\section{Anion Separations}

Selective separation of anionic species from aqueous solutions is a critical need for a wide range of applications including industrial water recycle; wastewater, drinking water, and agricultural waste treatment; environmental cleanup; and radioactive waste disposal. Systems that can achieve highly selective cation separations are increasingly being developed, but commercially available technologies, such as ion exchange, have limited selectivity for anion separations. This is a result of the large ionic radii of anions, high free energy of solvation, and a wide range of topologies. The complexation behavior of anionic species exhibits much less variability than seen for common cations, resulting in relative selectivity factors of 10 or less for most anion separations compared with cation selectivities that can exceed $10^{5}$.

The separating agents most commonly used for commercial separations of anions via solvent extraction and ion exchange cannot achieve the high performance characteristics needs for many environmental and industrial applications where contaminants need to be removed from very dilute streams or from mixtures of competing anions. New separating agents need to be developed with enhanced selectivity and overall performance. There are also new deployment methods that can improve overall performance and minimize secondary waste generation. Our work is to explore combinations of new separating materials and deployment methods to enhance the performance of anion removal systems. From this improved performance, a wide range of previously economically prohibitive separations can be performed.

We have identified and integrated three key components necessary to deploy new anion separations technologies: 1) molecular design of anion separations agents; 2) superstructural assembly of anion exchange materials; and 3) process development through integration of ligands, materials, and physical processes to provide synergistic enhancement of anion separations.

The function of each component and the integration of the components into an anion separation process can be seen using the following example. At the molecular level, ligand development is required to design cationic sites that are capable of selectively binding different anions on the basis of anion size and topology, charge density, hydrogen-bond donor/acceptor properties, and Lewis-basic character. Molecular dynamics simulations will be used to provide information on the interactions between the anions and the agents, and this information will be used to guide the synthesis of specific separating agents. The agents are to be assembled into well-controlled systems using advanced synthesis techniques such as biomimetic and self-assembly processes, electrochemical deposition, and surfactant-based sol-gel chemistry (mesoporous synthesis). Enhanced selectivity is obtained by controlled assembly of the separating agent on the nanometer- and micrometer-length scale and fine tuning size-limited diffusion, electrostatic binding, and solvation interactions. The engineered form of the anion separation materials will then be used in specially developed processes where integration of the material properties and chemical/physical driving forces such as the electrochemical potential and oscillatory or pulsed fields provide enhanced anion selectivity. The design and process development activities will be based on overall system requirements such that the new technologies can be deployed/integrated into existing industrial processing and treatment plants. 


\section{Gas-Phase Corona Synthesis}

The controlled oxidation of organics is one of "Grand Challenges" of industrial chemical research. Even in the presence of catalysts, organics tend to "burn" in conventional thermally activated oxidations which require temperatures above $4001^{\circ} \mathrm{C}$ to dissociate either the oxygen or the organic, which tends to be completely oxidized to $\mathrm{CO}$ and $\mathrm{CO}_{2}$.

Partial oxidation reactions are exceedingly difficult to perform both because the intermediates are either highly reactive with regard to further oxidation, or because the products are thermally unstable. The ability to specifically control the site and amount of oxidation would enable the use of cheap feedstocks (simple alkanes and alkenes) to make a wide range of commercially important intermediates.

A new technology, developed at PNNL for waste destruction, is the gas-phase corona reactor (GPCR). This plasma-driven chemical reactor can also be used for synthesis, however, utilizing the non-equilibrium plasma to produce high-energy active species which follow different reaction pathways than those available through traditional thermal activation.

While significant research into the development of a plasmadriven chemical synthesis reactor system has been conducted over the years, only ozone formation has to date proven economically viable. The technical challenges are that the reactions pathways have, so far, not been controllable and have consumed too much power. This is, in part, due to the high effective temperature of the plasma.

The development of powerful, inexpensive computing engines, capable of solving the Boltzmann equation for realistic boundary and initial conditions offers significant opportunity to understand the relationships between the basic discharge processes and the final outcome of the chemical processes they drive.

In this work the fundamental mechanisms for the controlled oxidation of organics will be studied. The new capabilities of the EMSL will be used to probe the creation and reactivity of anions produced within the gas-phase corona, and to identify the extent to which dielectric packing materials within the reactor can be activated within the plasma to catalyze partial oxidation reactions.

\section{Microsystems Science and Engineering}

The objective of the Microsystems Science and Engineering initiative is to establish the capabilities necessary to develop miniature systems that rely on microscale structures to radically reduce the size of energy and chemical systems. By taking advantage of the high rates of heat and mass transfer available in microstructures, a wide range of thermal and chemical systems and components can be miniaturized, resulting in high production rates in compact hardware volumes. Examples include components such as heat exchangers, chemical reactors, separations devices, gas absorbers, gas generators, and combustors. Examples of potential miniaturized systems include compact combustion systems,

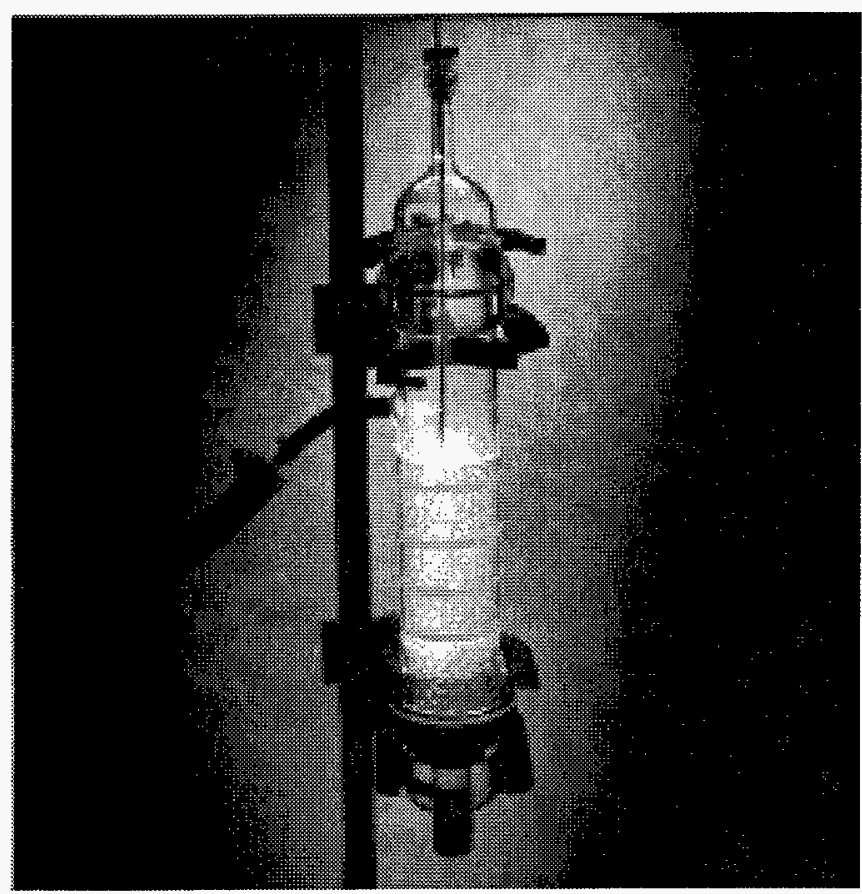

The gas-phase corona reactor system destroys gaseous contaminants, such as trichloroethylene, with 99 percent efficiency-a lower-cost alternative to conventional waste treatment.

miniature absorption heat pumps, miniature heat engines, compact fuel processors for hydrogen production, compact chemical separation systems, and microscale techniques for improving heat transfer to gases.

In this initiative, we are developing both the scientific basis and the engineering capability required to realize the remarkable potential of microscale technology.

\section{Microtechnology Science}

Microstructures offer opportunities to exploit molecular interactions and surface effects that otherwise would have been considered as secondary effects within conventional (macroscale) systems. We currently lack, however, both an understanding of many microscale phenomena and suitable modeling tools for the relevant length and time scales. Our investigations are focused on developing appropriate modeling tools and demonstrating high functionality surfaces. Research thrusts include the following:

- Lattice-Boltzman Simulation of Micro Fluids Systems. Lattice-Boltzman simulation is a method of simulating thermal and hydrodynamics processes that is particularly attractive for modeling microscale phenomena. LatticeBoltzman simulation explicitly incorporates surface and phase interface effects, which are critically important in microscale thermal systems. Molecular dynamics modeling, although limited to very short time and length scales, is used to establish boundary conditions for these simulation tools. 

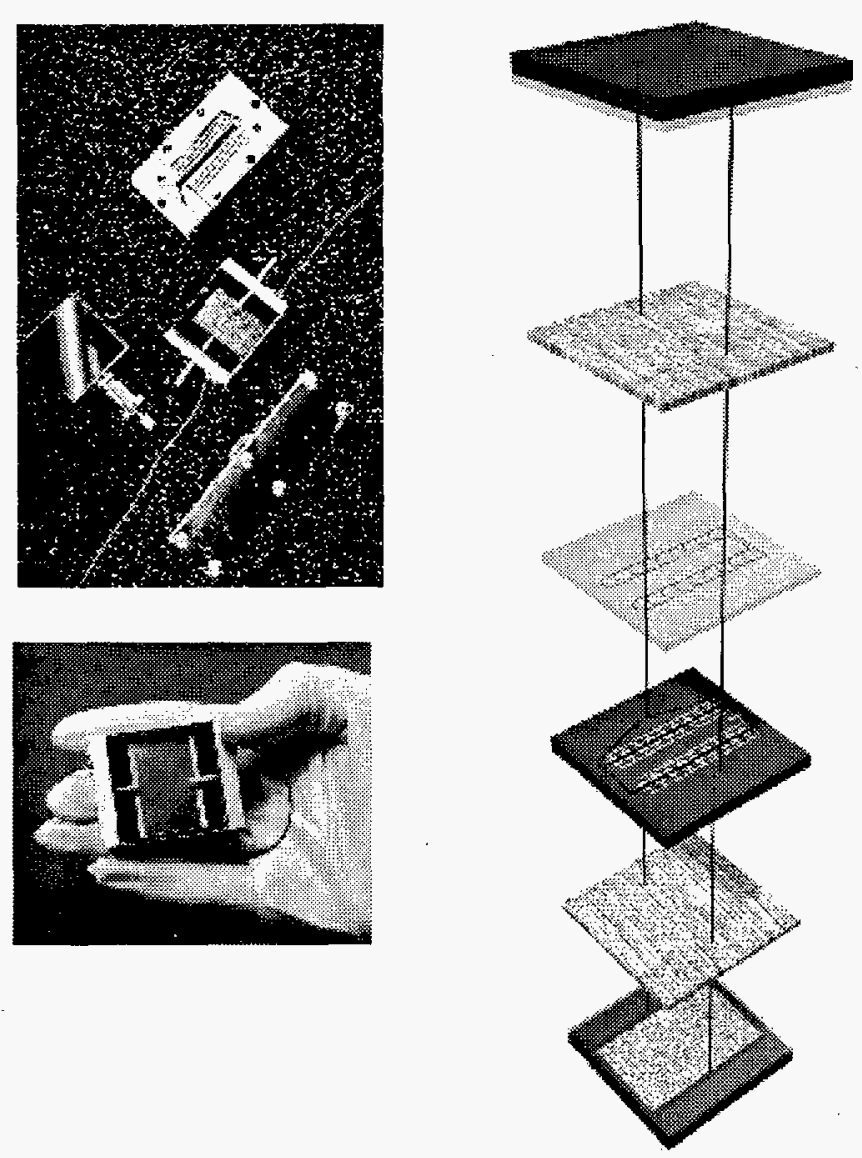

Compact, microtechnology-based components.

- High Functionality Surfaces in Microchannels. Recent advances in molecular sciences have resulted in exciting new opportunities for the nanoscale engineering of surfaces to allow the development of high functionality surfaces and microscale active control of surface properties. This effort focuses on using the capabilities available in the Environmental Molecular Sciences Laboratory to develop high functionality surfaces that can be embedded in microscale components and systems.

\section{Microfabrication}

Efforts in microfabrication are focused on extending our existing capabilities to include high precision, rapid prototyping, and low-cost fabrication techniques in microsystems technologies. New capabilities include high-precision laser micromachining, microscale electrochemical micromachining, and low-cost laminate fabrication.

The microfabrication thrust of this initiative focuses on development of inexpensive, high aspect ratio fabrication techniques for metals, ceramics, and plastics, as well as the capability to design, develop, and demonstrate low-cost, advanced, microsystems manufacturing techniques for use in mass production.

\section{Chemical and Energy Systems Miniaturization}

We are undertaking to develop and demonstrate specific microtechnology-based components and systems. Specific activities include the following:

- Hydrocarbon Processing with Microchannel Reactors. The use of microchannel catalytic reactors for hydrocarbon processing provides short residence times and a high degree of control over other reaction parameters, allowing a radical reduction in size for components such as partial oxidation reactors and fuel vaporizers. Our goal is to demonstrate compact systems for hydrogen production and methanol synthesis for automotive, portable, and distributed energy and chemical processing applications.

- Mesoscopic Heat-Actuated Heat Pump Demonstration. The high heat and mass transfer rates available in microscale devices can be used to radically reduce the size of heat-actuated heat pumps. This effort focuses on demonstrating a compact absorption cycle heat pump for manportable, automotive, and space conditioning applications.

- Development and Testing of Microchemical Separations Systems. Properly designed microstructures enable rapid mass transfer between fluids. These phenomena can be exploited to produce compact separations systems with very high processing rates.

- Microscale Active Enhancement of Heat Transfer to Gases. Microscale devices offer new methods for enhancing heat transfer from solid surfaces to gases, a key issue in the performance of power plants, automobiles, and heat pumps.

\section{Detection and Characterization of Biopathogens}

The goal of the Detection and Characterization of Biopathogens initiative is to conduct fundamental and applied science that leads to more rapid, sensitive, and deployable technologies for detecting and characterizing pathogens in the environmental, public health and safety, and national security and defense arenas. The same technologies are equally applicable to monitoring microorganisms of importance that are nonpathogenic; for example, microorganisms critical for bioprocessing energy-related wastes or biodegradation of environmental contaminants at government and industry sites. Improved detection and characterization technologies are needed because current methods are often costly and response times are inadequate, precluding routine or effective use in wastewater processing, bioremediation, control of disease-causing microorganisms in hospitals and foods, and protection of civil and military personnel from terrorist and battlefield threats.

This initiative is a natural outgrowth from research conducted at the Laboratory in response to the Department of Energy environmental research and health protection missions. We are leveraging our internal capabilities with those of others outside the Laboratory. Already, we have developed 
collaborations with the University of Washington, Johns Hopkins Applied Physics Laboratory, Auburn University, and several private-sector firms. The initiative builds upon Laboratory strengths in the biological, chemical, and material science areas including environmental and molecular microbiology, analytical detection and characterization of biomacromolecules, microtechnology, and sensor systems.

Major thrust areas are

- sample acquisition, preparation, and delivery

- background and reference data and analytical methods

- integrated systems.

\section{Sample Acquisition, Preparation, and Delivery}

Although a wide range of detection concepts and sensors are available, their real-world application is often limited by the inability to acquire, purify, and/or concentrate the sample into a format that the detector or sensor can effectively deal with. This critical gap is widely recognized by research and development (companies and contractors), supplier (premiere analytical instrument developers and biotechnology companies), and user (government agencies) communities, but little effort is being focused on the problem. The initiative is focusing on automated technologies that will enable the rapid and efficient processing of environmental samples and serve as the required "front-end" to sensor systems. Examples of areas under investigation include

- novel, improved methods of aerosol collection and processing

- research leading to the potential development of a rapid and efficient automated nucleic acid extraction, purification, and concentration system.

\section{Background and Reference Data and Analytical Methods}

Improved analytical methods are needed to improve the speed, sensitivity, miniaturization, and/or fieldability of detection technologies. Exquisite sensitivity is required for many pathogens because exposure to very low numbers of cells can cause disease or death. Rapid analysis is required for economic reasons and in some cases to minimize exposure of populations to the pathogen. Widespread use of detection systems beyond the laboratory will also require miniaturization and ruggedness. Background and reference knowledge is needed to design highly selective and specific recognition chemistries, understand whether a detector response represents a true signal or noise, and analyze complex information. Research in the initiative seeks to develop new analytical concepts and approaches in the following areas:

- novel information analysis tools for background and reference purposes

- advanced pattern recognition algorithms for optical recognition of microorganisms
- matrix-assisted laser desorption/ionization mass spectrometry for rapid fingerprinting of microorganisms in a miniaturized format

- ion cyclotron resonance mass spectrometry analysis of polymerase chain reaction products and coupled algorithms for identification of specific microorganisms

- highly efficient, flow injection-based affinity capture and concentration methods for cells, proteins, and nucleic acids

- application of small genosensor microarrays (DNA chips) for simultaneous screening of environmental samples for specific microorganisms.

\section{Integrated Systems}

Research in this thrust area is focused on examining the feasibility of bringing together-on a single platform-the sample acquisition, processing, and detection/characterization functions. In most fields of use, no such systems currently exist, and where they do exist, they are the size of large vehicles. Because no single detector or sensor is optimal for all microorganisms, all fields of use, or all possible scenarios within a field of use, integrated systems must contain multiple detection and characterization technologies. Integrated systems with hierarchical technologies also must be "smart" to minimize reagent (and for remote applications, power) consumption, and implement only those detectors or sensors that are needed. Research activities in integrated systems include

- implementation of a systems approach to define the required chemistries, interfaces, and information processing needs

- construction of a prototype laminate platform that seamlessly integrates power, microelectronic, and hydraulic (mesofluidic and microfluidic pumps and channels) requirements

- component development and engineering.

\section{Medical Technologies and Systems}

The science and technology capabilities of the DOE system have made significant contributions in advancing medical diagnosis and treatment, particularly in the area of nuclear medicine. Through ongoing programmatic efforts for DOE, the Department of Defense, and the commercial sector, researchers at Pacific Northwest and other national laboratories are developing basic scientific knowledge, breakthrough medical products, and innovative ways to improve health care delivery systems that will reduce the cost and improve the efficacy and accessibility of health care. However, significant opportunity exists to expand the role that the DOE laboratory system plays in advancing scientific knowledge and developing technology to address significant military and civilian medical issues. 


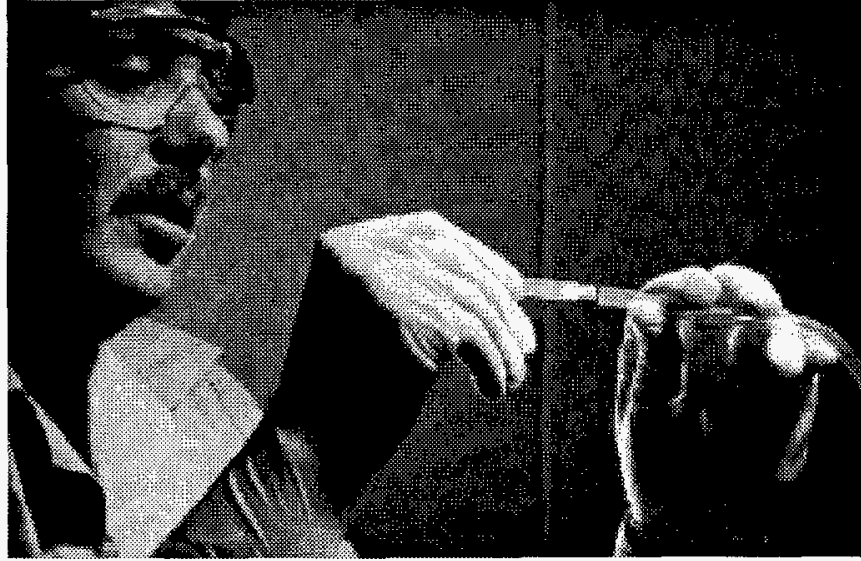

Vascular stents being developed at the Pacific Northwest National Laboratory provide structure around which veins or arteries can heal. The stent is then absorbed into the body.

The objective of the Medical Technologies and Systems initiative is to enhance fundamental capabilities that will lead to higher quality health care at lower cost. Current focus areas include biomaterials science and engineering and selective sensors.

\section{Biomaterials Science and Engineering}

The objective of biomaterials science and engineering is to advance the state of the art in biomaterials and apply that fundamental knowledge to develop materials and materials processes for in vivo and in vitro applications. This fundamental knowledge will allow scientists and engineers to design, synthesize, and develop a new generation of materials that aid in healing, eliminate undesired physiological responses, and replicate the function of normal tissues. Much of the same fundamental knowledge gained through this research can be applied to other areas beyond the medical arena, such as biofouling in power plants and industrial processes.

The biomaterials science and engineering program has five goals: 1) gain a thorough understanding of the healing process and the pathogenesis of infection and materials/tissue interactions, 2) develop biologically based novel synthesis and processing routes for current and new materials, 3 ) use molecular modeling and simulation of natural and synthetic biomaterials to assist in the selection of potential materials,

4) broadly communicate basic science knowledge, and

5) transfer medically relevant biomaterials and processes to the marketplace.

\section{Interfacial Interactions of Biomolecules at Surfaces}

The behavior of biomolecules at surfaces is relevant to both naturally occurring and technically derived processes. In many systems, interaction between biomolecules and surfaces have significant consequences, both desirable and undesirable.
Biofouling events are highly undesirable in areas such as food processing, sea water desalination, and artificial kidney devices. Applications where the adsorption of biomolecules is desirable include immobilization of enzymes on solid matrices and the control of protein adsorption affinities for biochemical purification processes.

The objective of the research conducted in these areas is to develop a fundamental understanding of how interfaces control biomolecular interactions. Current research is focused on protein and cell growth systems that will provide information on how to form antithrombogenic surfaces to support applied research such as development of bioresorbable vascular or bowel connectors using polyphosphazenes. Researchers are examining endothelial cell growth and competitive protein adsorption as a function of surface properties and competitive cell growth between endothelial cells and platelets. Since protein adsorption and conformation are key to cell adhesion and growth, the chromatographic studies will begin to address the kinetics of protein adsorption, and coupled mass-spectral studies will be used to gain a better understanding of time-dependent changes in conformation.

\section{Biobased Functional Materials and Devices}

In another study, researchers are addressing the significant issues associated with developing implantable bioreactors that can restore lost organ function or produce recombinant DNA- and cell-based therapies in vivo using feedback from biological systems to regulate production and delivery. The critical science issues that need to be addressed to make implantable bioreactors feasible are 1) how to maintain immunoisolation of transplanted cells using artificial barriers while permitting crossover of low molecular weight substances (nutrients, electrolytes, oxygen, bioreactive secretory products) and 2) how to adequately vascularize the device. Current research is focused on selecting an appropriate encasing material and structure for maintaining viable Islets of Langerhans. The material must have a pore size small enough to exclude the cellular and humoral arms of the recipient's immune system and large enough to allow the exchange of nutrients and secreted insulin. In addition, various biocompatible scaffolds for promoting vascularization in vivo will be developed and tested in animal models.

\section{Novel Biomaterials and Materials Development Processes}

The Laboratory is applying a fundamental understanding of surface interactions and its extensive capabilities in materials development and processing to a number of applied research efforts that will enable advances in medical devices and therapeutics. We are investigating

- use of molecular self-assembly methods in conjunction with biological peptides to impart antimicrobial activity to a surface 
- use of polyphosphazene materials for the reconnection of veins and arteries

- exploring PNNL's aqueous-based near net shape forming process (NNSF) for its potential application in producing medical devices or implants, such as femoral heads

- exploring a new drug delivery system utilizing stimulisensitive polymers

- development of a new oxygen electrolyzer membrane material that will allow for reduced operating temperature and improved start-up time and efficiency.

\section{Next Generation Nuclear Medicine}

Alpha-emitting radionuclides have the potential to provide a more effective way of treating cancer than the more common gamma-emitting radionuclides. Alpha-emitters have higher linear energy transfer and deposit more localized energy in the region of the cell nucleus than other forms of radiation. This makes them more effective in killing cells even under hypoxic conditions, and, unlike beta- and gammaemitters, they are not dose-rate limited.

The objectives of the research in this area are to prepare and test an immunoconjugate containing radium-223 as a potential therapeutic radiopharmaceutical. The main challenge has been to assemble and test the individual components needed for the immunoconjugate.

A second challenge has been to form a stable chemical link between the ligand and the antibody. The next challenge was to find a suitable linker between the various candidate ligands and the antibody protein. This project focuses on the design and synthesis of new macrocyclic ligands that complex radium $(\mathrm{Ra} 2+)$, can be linked covalently to antibodies, and exhibit chemical stability in physiological media. Research in FY 1997 has been successful in dealing with these challenges, and biodistribution studies are under way to determine uptake in normal organs and tumor tissue and to determine the stability of the radiolabeled immunoconjugate. Initial in vivo studies will be conducted to demonstrate efficacy of the immunoconjugate in the treatment of tumors. These data will provide the proof of concept to support a research proposal to the DOE's Office of Biological and Environmental Research.

\section{Selective Sensors}

The Laboratory is enhancing its sensor capabilities to develop state-of-the-art diagnostics systems. Near-term areas of focus include proof-of-principle experiments to

- demonstrate the applicability of laser-based methods for disease detection through analysis of constituents in breath

- establish the technical basis for developing ultrasensitive sensors to detect endotoxins in solution (e.g., in blood, saline, or water).

Programmatic support for elements of the Medical Technology and Systems initiative is sought through DOE offices that emphasize basic and applied research. Included among these are the Medical Applications and Biophysics Research program, the Basic Energy Sciences Material Science program, and the Laboratory Technology Research program. In addition, several other opportunities are emerging with the U.S. Department of Defense, particularly in the areas of combat casualty care and with industry through Cooperative Research and Development Agreements. Funding projections are shown in the table at the end of the section and are not included in the Resource Projections. 


\section{Pacific Northwest National Laboratory Initiatives}

\section{(Budget Authorization S in Millions)}

Fiscallyear

40.40 Initiative

Molecular Sciences Research

Operating

Basic Energy Sciences.

Biological and Environmental Research

Other Energy Research.

Environmental Management and Other

Capital

Basic Energy Sciences

Biological and Environmental Research

Other Energy Research

Environmental Management and Other

Total Molecular Sciences Research

Microbial Biotechnology

Energy Researchif

Environmental Management

Energy Efficiency and Renewable Energy

Fossil Energy

Nonproliferation and National Secunty

Other Federal Agencies

Industry

Capital Equipment

Total Microbial Biotechnology

\section{Computational Reactive Transport}

Environmental Management

Energy Research

Energy Efficiency and Renewable Energy

Other DOE

\section{$\mathrm{DoD}$}

Prvate

Capital:

Total Computational Reactive Transport

Science and Technology for Environmental Processing

DOE Operating

Capital

Private

Total Science and Technology for

Environmental Processing
1997

1998

1999

2000

2001

2002

?.?.

\section{0}

20

2.0

30

10

0.5

0.5

0.5

16.3

8.0
3.0
3.0
3.5

100

- 0.5

0.5

0.4

199

2.2

2.5

0.0

0.0

07

0.7

2.5

0.0

8.6

00

1.1.

00

00

01

00

0.0

1.2

1.4

0.0

00

1,4
3.0

2.8

0.5

0.5

10

4. 10

2.5

0.6

11.9 .

0,2

4. 14

0.0

. 0.0

02

0.3

0.0

2.1

2.1

110

0.0

20 .

30

$$
9.0
$$

95

100

50

3.4

S 0

3.1

32

4,5

4.5

0.6 .

0.5

0.4

22.6

20

42.1

0.7

0.6

0.9

0.6

0.6

0.5

250

27.6

3.3

3.0

0.8 .

0.8

1.5

20

$3 \times 0$

19

16.3

4. 3

40

20

1,5

3.0

2.5

50

3.0

24.5

0.4

17.

0.0

0.0 .

$$
0.3
$$

05

0.4

3.3

10

0.0

30

0.2

0.0

4.0

0.6

2.6

00

0.3

0.5

1.8

58

40

42

4.5

0.4

0.0

4.

0.5

0.0

42

4,7 


\section{Pacific Northwest National Laboratory Initiatives (contd)}

\section{(Budget Authorization S in Millions)}






\section{Programmatic Strategy}

\section{Science and Technology}

Preeminent basic research capabilities and programs are central to the mission success and long-term viability of Pacific Northwest National Laboratory. Over the last decade we believe we have significantly increased the quality and impact of our basic research portfolio. We have built the William R. Wiley Environmental Molecular Sciences Laboratory (EMSL), added first-rate scientific staff, and developed major new programs in the environmental, life, chemical, and material sciences. We intend to continue strengthening our capabilities and programs, with the objective of having Pacific Northwest recognized as a principal laboratory in the Department of Energy's science mission.

Our programmatic strategy has five central elements:

- through a strong culture of peer review and commitment to excellence, we will deliver top quality science with significant impact on DOE's mission needs

- we will become a more integral part of our nation's basic research enterprise through operation of the EMSL as a highly productive collaborative research facility, through strong partnerships with our colleagues at research universities and our sister laboratories, and by participating in the training of the next generation of scientists

- to ensure the maximum impact on DOE's missions, we will take a "Grand Challenge" approach, building broad, interdisciplinary programs targeting central and scientifically demanding problems, primarily in our core environmental mission

- we will help demonstrate and communicate the value of DOE's research programs and our own and our collaborators' contributions to the public

- we will ensure our continued ability to operate complex scientific laboratory facilities by conducting our research in a safe and environmentally responsible manner.

\section{User Facility Operation}

PNNL operates two user facilities for the Office of Energy Research-the William R. Wiley Environmental Molecular Sciences Laboratory and a research aircraft. Additionally, PNNL is a key participant in managing and operating the climate research facilities of DOE's Atmospheric Radiation Measurement (ARM) program. The ARM field sites provide the research community with broad capabilities for studying radiative transport issues of importance to climate. We have also undertaken, through the Pacific Northwest ConsortiumCollaborative Access Team (PNC-CAT), development of the beam lines at the Advanced Photon Source.

\section{William R. Wiley Environmental Molecular Sciences Laboratory}

A key to addressing the environmental challenges facing the nation is the William R. Wiley Environmental Molecular Sciences Laboratory. This new national scientific user facility, sponsored by DOE's Office of Biological and Environmental Research, greatly enhances the nation's existing environmental research capabilities by providing the new generation of experimental and computational capabilities needed to address complex scientific issues that are pertinent to solving the nation's environmental cleanup problems.

The complement of research equipment and general laboratory infrastructure in the EMSL supports molecular research across a broad spectrum of environmental problems. Much of the instrumentation within the EMSL has been developed to specifically focus on environmental molecular science. Seven research facilities are available for use by the scientific community. The largest groupings of specialized instrumentation are housed in three facilities: the High Field Magnetic Resonance Facility, the High Field Mass Spectrometry Facility, and the Molecular Science Computing Facility. In addition to these major facilities, the EMSL offers four research facilities that are made up of collections of both specialized and state-of-the-art equipment. These suites of equipment are in the Nanostructural Materials Research Facility, the Interfacial Structures and Compositions Research Facility, the Reactions at Interfaces Facility, and the Gas-Phase Monitoring and Detection Research Facility.

All of these facilities support a full range of collaborative, independent, and proprietary research in the EMSL. By taking advantage of combinations of these facilities, visiting researchers are afforded an opportunity to create their own unique multidisciplinary approach to addressing specific research problems.

\section{Atmospheric Radiation Measurement Complex}

PNNL has lead responsibility for many aspects of the DOEled, multilaboratory ARM program; these responsibilities include management of the ARM Program Office, leadership of the development of the ARM data system, and operation of the ARM Experiment Center, the primary real-time data distribution facility of the ARM data system. The major facilities of ARM include the three field measurement sites 
(in Oklahoma, the Tropical Western Pacific, and Alaska) and the ARM data archive, each operated by other DOE laboratories, as well as the Experiment Center at PNNL. The ARM Program Office, coordinating the efforts of the DOE national laboratories, ensures that the ARM facilities are available to and used by a broad spectrum of users in the climate change, atmospheric research, and satellite remote sensing communities.

\section{Gulfstream 1 Airplane}

The Gulfstream 1 airplane is an advanced sampling platform to gather data for atmospheric processes important to the global environment. The aircraft can be deployed throughout the world and can be configured with instruments for a wide variety of measurements.

\section{Pacific Northwest Consortium - Collaborative Access Team}

PNNL, in collaboration with a group of U.S. and Canadian universities, is developing two beam lines at the Advanced Photon Source located at Argonne National Laboratory. The beam lines are optimized for environmental research, including the ability to handle radioactive samples by PNC-CAT members and the general scientific community.

In the following sections, we briefly discuss the major research programs we are carrying out in support of this programmatic strategy.

\section{Biological and Environmental Research (KP)}

Pacific Northwest National Laboratory is a major participant in DOE's Office of Biological and Environmental Research (OBER) programs. Our research portfolio is increasingly focused on complex environmental and health problems that require multidisciplinary teams to address problems at multiple temporal and spatial scales. We use unique research capabilities and facilities at PNNL and partnerships with scientists from many national and international institutions to address key OBER missions.

The Laboratory's environmental research is broadly based and includes the effects of natural events and human activities on the environment, as well as development of technologies to minimize impacts and remediate damage. Our environmental research programs use state-of-the-art facilities to study subsurface science and bioremediation, as well as atmospheric and climate research (including global change) critical to understanding the transport and transformation of toxic substances in the biosphere. Health effects research examines mechanisms by which hazardous physical and chemical agents affect living systems. Emphasis is on determining the molecular bases of receptor-mediated processes at the cellular level.

\section{Environmental Sciences Division}

Pacific Northwest National Laboratory supports OBER's scientific programs in environmental processes and environmental remediation, including fundamental and applied research in atmospheric science, global climate change, ecological research, subsurface science, microbial genomics, and bioremediation. Multidisciplinary efforts in many of the programs focus on describing molecular level phenomena, such as interfacial chemistry and the impact of spatial heterogeneity to understand natural processes and human-induced changes that govern contaminant behavior and influence climate at the landscape, regional, and global scales. Component programs in environmental processes to which the Laboratory makes important contributions include the ARM program; Computer Hardware, Advanced Mathematics and Model Physics (CHAMMP) program; and the Atmospheric Science, Oceanic Research, and Integrated Assessment programs. PNNL also contributes to the Environmental Management Science, Environmental Technology Partnerships, and Natural and Accelerated Bioremediation Research (NABIR) programs in OBER's environmental remediation portfolio. Under OBER's management and direction, PNNL provides national leadership to support the development and implementation of the ARM and NABIR programs. 


\section{R\&D 100 Award Winner}

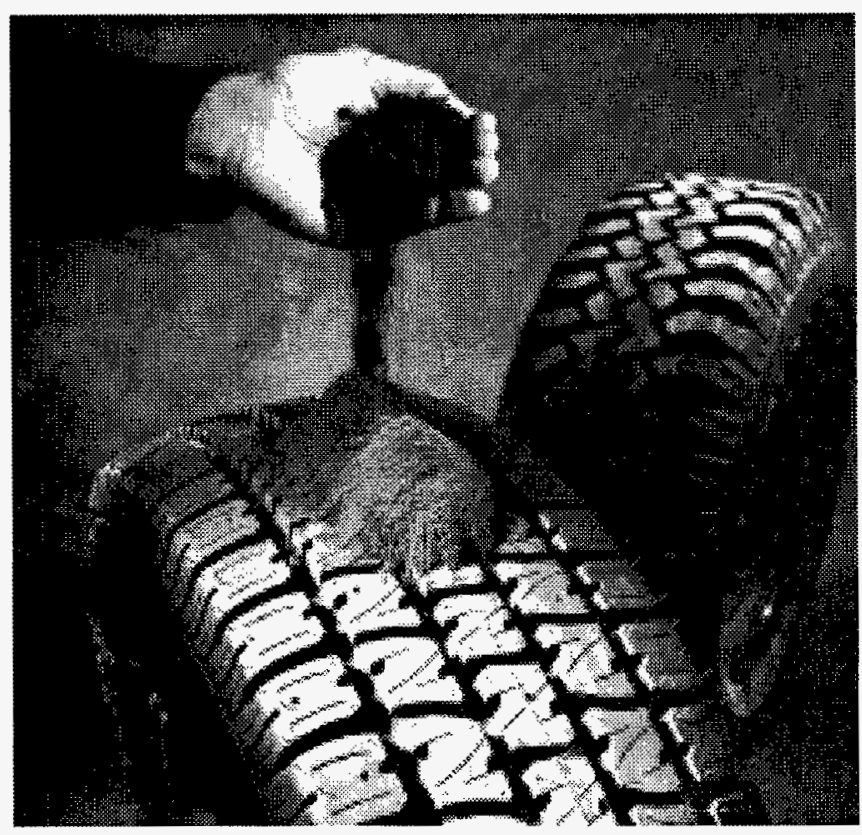

The RubberCycle ${ }^{\mathrm{TM}}$ technology is a technically sound, costeffective method for solving the waste tire disposal problem and cleaning up a major environmental hazard while reducing costs to businesses and consumers. The RubberCycle technology is based on a bioprocess that uses thiophillic, or sulfur-loving, microorganisms that create chemically reactive sites on the surface of finely ground tire rubber particles derived from waste tires. This mixed recycled and virgin vulcanized rubber exhibits better performance than allvirgin rubber. The RubberCycle system can be integrated with existing recycling operations. It does not require hazardous chemicals and has no significant waste effluent.

Pacific Northwest National Laboratory invests discretionary resources to maintain its environmental sciences programs and develop new leading-edge capabilities for our environmental research programs. New multidisciplinary capabilities are being developed in molecular sciences, contaminant fate and transport research and modeling, microbial biotechnology, and atmospheric research.

\section{Health Effects and Life Sciences}

Biological research at PNNL uses a multi-level approach incorporating studies from the molecular level to the wholeanimal level. Emphasis is placed on understanding effects at low doses, characteristic of occupational and environmental exposures. We are seeking a quantitative understanding of mechanisms that underlie the health effects of chemical and physical agents by taking an integrated approach, using dosimetric, molecular, cellular, and experimental animal techniques. Alterations in the structure and function of genetic material are investigated in vivo and in vitro as biological indications of the development of subsequent disease processes in living animals. Key studies analyze interactions of repair enzymes and other regulatory proteins with damaged DNA. Non-genotoxic mechanisms are another focus of the research, identifying critical pathways affected and the subsequent effect in vitro and in vivo. The objective is to identify the precise causes of disease resulting from exposure to hazardous agents and to predict human susceptibility to these diseases. This information will provide a scientific basis for performing risk analysis and establishing health standards important to environmental cleanup.

We are emphasizing the development of new research programs to define the structural and regulatory basis of DNA damage and cell signaling in DNA repair processes. The influence of chromatin in damage recognition and repair is another focus of the overall program. These issues are being addressed using the unique resources in the EMSL coupled with molecular biology and molecular modeling.

Future directions for PNNL research programs in this area will emphasize integrated (molecular to whole animal) research to understand low dose effects, building on newly acquired capabilities in DNA replication and repair and on the newly established modes-of-action framework.

\section{Medical Applications and Biophysical Research}

Medical applications and biophysical research at PNNL builds on the Laboratory's prior contributions in radiation physics, dosimetry, and biophysics. Current research is providing methodologies for medical applications including novel uses of magnetic resonance imaging. For example, we are building a nuclear magnetic resonance (NMR) microscope capable of monitoring biological processes in real time. Current efforts are aimed at developing the hardware and software for in vivo NMR analysis of the growth and regression of lesions induced in mice exposed to toxic chemicals, and of in vitro studies of viable cells maintained under physiologic conditions.

PNNL is also developing efficient radiochemical separation methods and improved generator designs to make radium-223, actinium-225, and bismuth-213 available to clinical researchers. Future directions in this program will build on the new measurement science capability in the EMSL to explore medical uses of alpha-particle emitting radionuclides. Theoretical and modeling capabilities will be used to design highly selective chelating agents for new therapeutic agent concepts including the use of radium-223 immunoconjugates for cell targeting of micrometastic cancer.

\section{Basic Energy Sciences}

Research at PNNL supported by the Office of Basic Energy Sciences is key to the Laboratory's commitment to establish a world-class science base in chemical, material, and geochemical sciences. Programs supported by BES provide strong contributions to DOE's mission in basic science. Our $\mathrm{BES}$ programs are increasingly focused on achieving a 
fundamental understanding of complex, multidimensional environmental problems associated with the production and consumption of energy and the cleanup of our past contaminant releases, as well as the development of new knowledge required to promote economic prosperity and minimize future environmental insults.

\section{Chemical Sciences}

The Division of Chemical Sciences sponsors major research programs in chemical physics and molecular processes at PNNL. The primary focus of our chemical physics research is development of a molecular level understanding of chemistry at liquid-solid interfaces and condensed phases important to problems at DOE's contaminated waste sites. Our molecular theory and modeling programs develop new theoretical and modeling methods and apply these methods to the study on groundwater chemistry, chemistry at aqueous/ mineral interfaces, separations chemistry, and nuclear waste forms. For example, we have developed a new generation of molecular modeling software and procedures that take advantage of the computational power offered by massively parallel computers in the EMSL. Our chemical structure and dynamics programs explore reactions at a wide variety of solid/liquid interfaces and the dynamics of biological systems, as well as develop new analytical methods. Recent studies of radiolysis in mixed-phase systems have identified key mechanisms for the generation of potentially explosive gases generated from the aging of organic chemicals in DOE tank waste.

Research programs in the area of molecular processes focus on energy-intensive chemical conversions. We conduct fundamental studies of reactions in supercritical fluids, free radical chemistry at high temperatures, laser spectroscopy, and theoretical studies of heterogeneous catalysts. Research at PNNL has recently identified new reaction pathways (5-member ring complexes) in hydrogen atom transfer reactions that are important in reduction of hydrocarbons by photochemical and thermal processes.

\section{Materials Sciences}

Materials research at PNNL is primarily focused on 1) the development of unique synthesis techniques for producing new or improved materials in an environmentally conscious manner, and 2) the reaction of materials with their environment. These activities underpin many applied programs and technological issues relevant to DOE. New capabilities will build on expertise in three areas: thin-film optical materials and protective coatings; synthesis and characterization of advanced nanoscale composites, ceramics, and intermetallics; and mixed conductors for low-temperature gas separation. Research on environmental effects on ceramic stability and on stress corrosion and corrosion fatigue of metals and ceramics is an internationally recognized area of expertise

\section{R\&D 100 Award Winner}

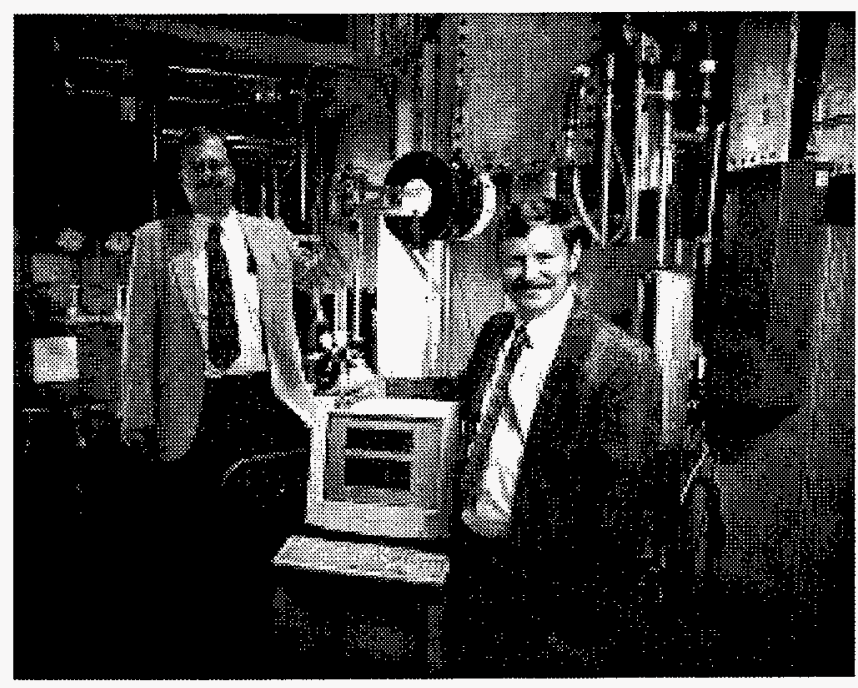

The Refractory Corrosion Monitor uses frequency-tunable microwave radiation transmitted into the furnace insulation from outside the furnace to provide accurate real-time monitoring of refractory insulation thickness while a furnace is in operation. High-temperature furnaces are used to manufacture materials such as glass and steel, in waste remediation, and for power production. A key feature of these furnaces is the refractory insulation that contains the high-temperature region inside a furnace. This refractory is subject to harsh conditions that cause its deterioration and impact the furnace's lifetime. The ability to monitor the refractory condition during furnace operation will improve the productivity and lifetime of furnace components and minimize downtime for refractory inspections.

of the Laboratory. The effects of aqueous, gaseous, irradiation, and thermal environments are being evaluated.

Our research has developed new biomimetic coatings produced from aqueous solution using a surface-induced mineralization process. This low-temperature, aqueous solution process can coat both highly porous and smooth surfaces with demonstrated applications of bioactive calcium phosphate for orthopedic implants.

In our research programs in superplastic behavior, we are studying fundamental interfacial structure and composition to understand the underlying mechanisms of grain boundary sliding and precipitation effects on crystallization relative to superplastic behavior. The studies have resulted in the development of new superplastic materials that are ideal for the automotive industry. In addition, other PNNL research programs are focused on alloy development and theoretical and process modeling issues relevant to downstream industrial use. 


\section{Engineering and Geosciences}

Engineering and geosciences research at PNNL is focused on developing a molecular level understanding of the surface chemistry and reactivity of environmentally important mineral phases. In the computational area of the program, emphasis is placed on the transfer of information from the molecular scale to the macroscopic or thermodynamic level. The transfer of information across such time and length scales is one of the most challenging problems facing researchers applying molecular level information to in-the-field environmental problems. The experimental program in engineering and geosciences is focused on the surface chemistry of carbonate minerals and is well integrated with theoretical modeling efforts. In addition to the EMSL, program researchers use DOE's national user facilities including the National Synchrotron Light Source at Brookhaven and the Stanford Synchrotron Research Laboratory, and will be using the Advanced Photon Source at Argonne National Laboratory.

\section{Office of Computational and Technology Research}

Research at PNNL for the Office of Computational and Technology Research supports the Department's need for computational resources to support a wide variety of research programs and link basic research with industrial needs to foster revolutionary technology spin-offs. Our research is primarily centered in the area of mathematical information and computational sciences.

Our Computational Chemistry for Nuclear Waste Characterization and Processing: Relativistic Quantum Chemistry of Actinides is one of two projects selected for phase two Grand Challenge funding in the chemistry/biochemistry area. We will develop and apply the methods of relativistic quantum chemistry to assist in understanding and predicting the chemistry of the actinides and lanthanides, a class of molecules commonly encountered in DOE's environmental management mission. Our implementation of relativistic quantum chemical methods for massively parallel computers will, for the first time, provide capabilities for modeling heavy-element compounds similar to those currently available for light-element compounds.

Our research as part of the new DOE 2000 Initiative is to accelerate the ability of DOE to accomplish its mission through advanced computing and collaboration technologies. In this program, PNNL scientists in collaboration with scientists from ANL, Lawrence Berkeley National Laboratory, and Sandia National Laboratories are designing a Collaborative Integration Framework, the "software bus" required for communication among collaboratory tools, data transport, resource location, etc. We are also developing a modular, extensible electronic notebook based on modern objectoriented design that is able to incorporate scientific and nontechnical information in a wide range of forms, from text to equations, from instrument charts to three-dimensional visualizations (with LBNL and Oak Ridge National Laboratory).
Tools that manage real-time collaboration sessions are being developed that will enable scientists to interact as if they were physically collocated (jointly with ANL). Together, these projects will provide major pieces of the architecture of the DOE 2000 collaboratory environment, which will be used by DOE 2000 Collaboratory Pilot Projects, the EMSL Collaboratory, and other developing collaborations at PNNL and in the DOE system.

Our research program in Computational Thermochemistry: A High Performance Computing Application for the Chemical Industry is developing computational chemistry technology for the design of energy-efficient processes in the chemical industry that are safe with minimal environmental impact. This program is in collaboration with the National Institute of Standards and Technology, DuPont, and Dow.

\section{Laboratory Technology Research (KU)}

The Laboratory Technology Research program funds partnership projects with private-sector companies that utilize the scientific capabilities of the Energy Research multiprogram laboratories and those provided by the private partners to achieve DOE missions. The program is also a key source of assistance to small and regional businesses. A recent external peer review validated the high quality of the science associated with the program.

Research supported by this program between PNNL and ThermoQuest Inc. has resulted in a spectrometer device to spearhead development of a new class of U.S.-manufactured analytical instruments for measuring trace elements and radionuclides. Uses of the spectrometer include environmental monitoring, weapon treaty verification, and semiconductor manufacturing. The technology was selected for an R\&D 100 Award and a Federal Laboratory Consortium (FLC) Award. A patent has been applied for, and a license to the technology is in negotiation.

Another effort in collaboration with Moltech and DuPont has resulted in a new process for depositing and bonding thin, multilayered polymer films. The process is known as the liquid multilayer/polymer multilayer process. Applications include the production of advanced lithium polymer batteries and reflective coatings on windows to improve energy efficiency. The technology was selected for an R\&D 100 Award and an FLC Award and has been licensed to two companies.

\section{Advanced Energy Projects}

The Advanced Energy Projects (AEP) program funds highrisk, innovative research directed at exploring totally new approaches to addressing energy-related problems. In FY 1997, PNNL was awarded its first new start under the AEP program in several years. This three-year project, Metal-Ion Promoted and Semiconductor-Catalyzed Selective Oxidation of Alkanes, is directed at assessing the technical advantages 
and limitations of a potentially energy-efficient reaction sequence for selectively oxidizing hydrocarbons.

\section{Fusion Materials (AT)}

The Fusion Materials program at the Laboratory is focused on developing and characterizing advanced materials for first-wall/blanket structures of fusion power systems. The long-term objective of the program is to enhance the economic and environmental attractiveness of the fusion energy option. Work at the Laboratory includes determining the response of reference candidate materials to neutron irradiation, developing new materials with improved properties, developing reduced activation materials, and developing theory and modeling to predict the effect of neutron irradiation on materials. This predictive capability is needed to account for differences in the neutron spectrum of fission reactors, where these experiments are performed, and that of fusion reactors. Example accomplishments include

- atomic-scale computer annealing simulations for studying the evolution of defect structures in irradiated metals

- development of oxide dispersion strengthened ferritic alloys with improved high-temperature creep strength

- characterization of the effect of loading mode on the fracture toughness of ferritic and vanadium alloys

- life-prediction of fiber reinforced silicon carbide composites as a function of stress, temperature, and the oxygen concentration in helium.

\section{Other Office of Energy Research Programs}

PNNL also participates in special single investigator projects funded by other program offices in OER. We conduct work with Energy Research Analysis on planning and economic analysis to support science policy and with High Energy Physics to study double-beta decay of germanium-76. Our research for University and Science Education establishes partnerships and alliances with academic institutions and contributes to implementation of national initiatives to improve science, mathematics, and technology education. For example, the Center for Environmental Science Education is a major science education reform initiative to form academic partnerships with national, regional, state, and local agencies, institutions, and organizations committed to developing a scientifically literate society through environmental science education and research. The Center combines the science, engineering, and technology capabilities of the Laboratory with other partners to create a broad range of environmental science education projects/products reaching students and teachers from elementary school to graduate school, as well as the community at large.

\section{FLC Award Winner}

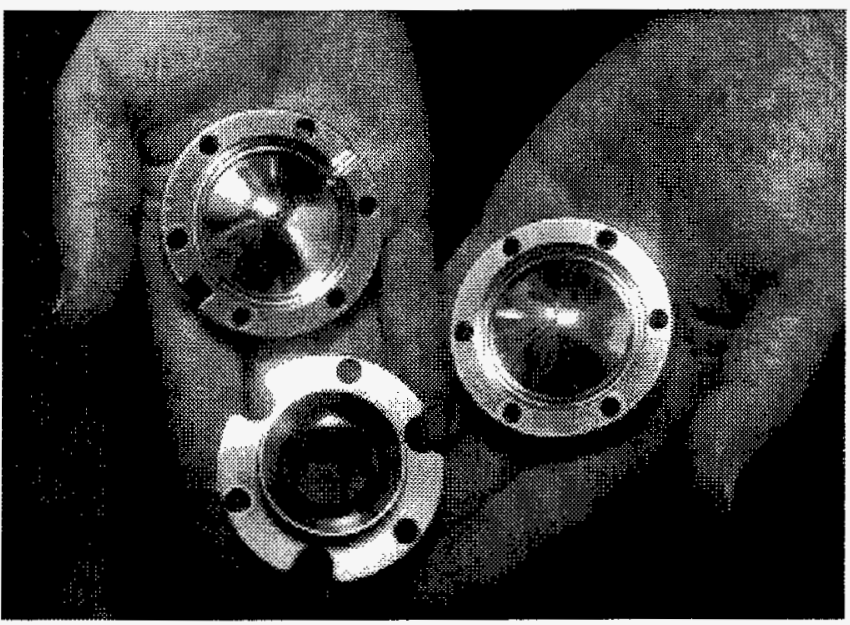

These three hand-held metallic ion trap electrodes are the key components of the Plasma Source Quistor (PSQ) mass spectrometer. The PSQ provides improved detection and analysis of atomic sample constituents (natural and/or radioactive elements and isotopes). During system operation, ions enter the trap through the small openings of the upper-left electrode, are trapped in the center (ring) electrode, and are ejected through the center of the electrode on the right. While the ions are trapped, researchers can perform chemical manipulations to enhance sensitivity and reduce interferences.

PNNL researchers recognized the potential for combining the best features of two widely used analytical tools, inductively coupled plasma ion sources and ion trap mass spectrometers, to create a new instrument. They convinced a manufacturer of mass spectrometers of the PSQ's potential, and subsequent technology transfer activities have developed into a strong partnership.

\section{Environmental Quality}

PNNL fulfills a number of critical roles in DOE's environmental quality programs. The Laboratory efforts extend from studies on the fundamental scientific underpinnings of DOE's highest priority problems, to a substantial development program for new technologies, to actual deployment of these new technologies on problems at Hanford and other DOE sites through a variety of commercial partners. In addition to science-based solutions, the Laboratory uses its comprehensive systems, risk, safety, security, and policy expertise to provide help in understanding, defining, and prioritizing DOE's highly complex problems, and to provide nontechnological solutions to those problems when appropriate. This section addresses the Laboratory's approach to supporting the environmental quality mission and summarizes the content of the major constituent programs. 


\section{Approach}

Our primary objective is to provide breakthrough solutions to the most demanding technological challenges facing DOE's environmental mission. In this regard, we recognize the particular importance and value of linking our Energy Research science activities to our environmental quality programs. We expect that the fundamental research the Laboratory is conducting will increase our understanding of complex environmental systems; thereby, leading to new technologies that will fill technological gaps in the current cleanup program or provide new solutions which can reduce costs or risks and increase effectiveness. With the opening of the EMSL, we expect to be able to bring forward breakthrough solutions for several of DOE's critical environmental problems.

The Laboratory is pursuing several initiatives through programs, such as Laboratory Directed Research and Development (LDRD), which will be directly used by our environmental programs. The Laboratory has been a longtime supporter of the Applied Process Engineering Laboratory (APEL), which is scheduled for operation in 1998. This facility will include the full complement of services needed to develop and demonstrate a variety of waste treatment and chemical processes under a single set of operating permits. It will be available to all Laboratory programs, private industry, and universities. The Science and Technology for Environmental Processes (STEP) initiative will significantly increase our understanding of chemical conversion and separations processes that can be applied to treatment processes for DOE wastes, as well as new sustainable processes useful in a variety of commercial enterprises. Other science-focused initiatives also will create new scientific understanding and capabilities that will be used by the Laboratory to address the environmental problems of DOE and others.

\section{Office of Environmental Management}

The major component of the Laboratory's environmental quality mission is support to DOE's Office of Environmental Management (DOE-EM). This support includes a broad range of work, such as basic studies on waste and contaminant interactions, systems engineering-based analyses and planning, development and application of risk management approaches, regulatory and policy analyses, environmental monitoring, technology development and deployment, and management of actual cleanup operations. Our work is focused primarily on solving problems at Hanford, but includes support to other DOE sites and several components of the DOE-EM national program. The other major area of support is for the Office of Environment, Safety, and Health. In this mission area, our critical outcomes include providing solutions to Hanford problems, demonstrating new technologies, and deploying new solutions through commercial partners. In achieving these outcomes we are

- using risk-based and systems approaches to back up our management efforts and technology decisions
- promoting technology utilization by leveraging outside resources made available through proper management of intellectual property and transfer to local businesses

- using a disciplined safety-conscious approach to deliver high-quality results

- ensuring that our solutions are complete, fully responsive to the needs, and consistent with the EM 10-year vision.

The Laboratory's support to DOE-EM is structured into four main areas: the Hanford Site, environmental science and technology, technical management and deployment at Headquarters and other DOE sites, and management or technical services via contracts directly or through commercial partners.

\section{Hanford Programs}

The Laboratory expects to remain a major player in the management and cleanup of the Hanford Site through the 10-year planning horizon and beyond. The Hanford Site represents one of the most complex environmental cleanup projects facing the country. Critical management challenges include defining clear endpoints for cleanup, establishing approaches acceptable to all involved regulatory bodies and stakeholders, and obtaining the new technologies and deployment means needed to safely and efficiently address the difficult cleanup actions.

The Laboratory is providing DOE-RL and the site's two management contractors with decision, systems, and risk analysis tools to support their planning of a cleanup program which eliminates urgent risks, reduces mortgages, and applies more site funding to cleanup actions. The Laboratory's involvement in integrated planning at Hanford will help ensure that our science and technology investments are focused on priority needs.

The Laboratory is providing technology evaluation, acquisition, adaptation, and demonstration services to the Project Hanford Management Contractor and the Environmental Restoration and Decontamination and Decommissioning contractor. Evaluation efforts are focused on challenging the technology baseline and suggesting new solutions for consideration by the cleanup projects. Solutions are sought from a variety of sources, and leveraging with others to reduce acquisition costs is emphasized. For example, solutions with a high potential for cost savings will be leveraged with the DOE-EM Technology Deployment Initiative over the next several years.

The Laboratory is providing new technologies, scientific investigations, and other technical services to Hanford's major programs, including Spent Nuclear Fuel, Hanford Tank Waste Remediation, and Environmental Restoration. Future emphasis will be on in situ and surface barriers, spent fuel and tank waste characterization, and tank safety. Staff also provide a number of direct support services to the site overall, including integrated groundwater monitoring, radiation 
protection, analytical services, analyses supporting privatization, and environmental assessments.

\section{Environmental Science and Technology}

One of the Laboratory's most visible critical outcomes is the development and demonstration of new technologies, and we have made significant progress against this outcome through our work for DOE's Office of Science and Technology. The Department has invested over $\$ 200$ million at the Laboratory over the last eight years in projects creating or adapting over 70 new technologies or analysis tools, projects providing technical management of programs which were responsible for bringing in new technologies, and technical studies leading to better problem understanding or improved operations. The major management function is the Tank Focus Area which is responsible for integrating a nationwide program for solving tank-waste problems at four DOE sites. The Laboratory is also a major contributor to the Environmental Management Science Program with 11 projects started in FY 1996 and 12 in FY 1997 focusing on research in areas such as understanding tank wastes and associated treatment processes, in situ treatment of groundwater, and health effects. The work directly supports critical Hanford science needs.

To promote rapid deployment and utilization, the Laboratory ensures that technology projects address all technical, policy, regulatory, and economic issues early in the development life cycle. Over the program's life at the Laboratory, we have supported deployment of over 25 new technologies. The Laboratory expects to continue to play a major role in this program in terms of translating science to solutions, rapidly developing new technologies, supporting broad deployments, and providing technical management support where needed. We are working to extend our model for carrying science concepts through to deployable solutions to the broader DOE system through the Tank Focus Area and collaborations with other laboratories.

\section{Technical Management and Deployment}

The Laboratory has historically provided substantial support to DOE-EM headquarters for technically based planning and management tools and support to complex-wide initiatives, such as the Baseline Environmental Management Report. Technical activities include integrated risk management support and assessments supporting the Programmatic Environmental Impact Statement.

The Laboratory supports the DOE-EM programs at other DOE sites by providing environmental, safety, and health services, such as dosimetry and exposure and safety assessments, information management systems, problem characterization, in situ barrier and treatment technologies, and waste processing systems and associated technical support. We intend to expand these programs, possibly focusing on the DOE sites in Idaho, Rocky Flats, Fernald, and West

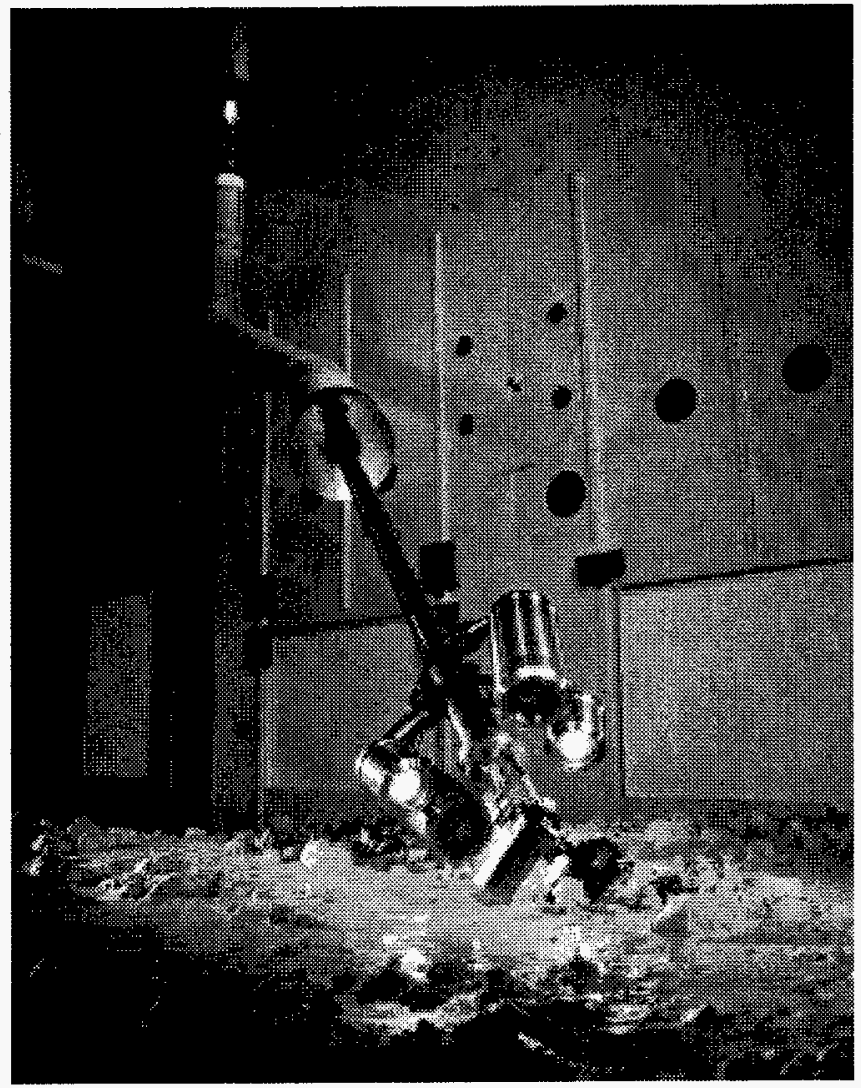

The Extended Reach End Effector when deployed on the Light-Duty Utility Arm increases the arm's reach from 13.5 to 20.25 feet. This end effector allows the arm to obtain 50-millimeter surface samples from the tank walls and floor. The device is pneumatically actuated and has a unique detachable sampler with a clamping force of 50 to 300 pounds. As with all Light-Duty Utility Arm end effectors, the extended reach device is designed to meet the requirements for safety in operation, radiation, corrosion, and flammable gas specified for deployments in Hanford tanks.

Valley. The Technology Deployment Initiative will provide an additional avenue to bring Laboratory technologies into wider use across the DOE complex.

\section{Commercial Operations Supporting DOE-EM}

The objective of this new area of emphasis for the Laboratory is to increase the deployment of technologies and knowhow, developed under our DOE programs, at other DOE sites and at sites owned by industry and other governmental agencies. Laboratory staff will be involved through agreements with private companies which are in the position of providing technical services directly to DOE-EM programs. These initiatives for commercializing DOE-sponsored intellectual property will also lead to the diversification of the Laboratory's business portfolio. This diversification has historically led to development of new capabilities and insights which have benefited DOE's programs. 


\section{Office of Environment, Safety, and Health}

The Pacific Northwest National Laboratory supports a number of programs across the Office of Environment, Safety, and Health. Policy and oversight efforts are supported and a variety of technical studies are also conducted. Work in the environment area includes environmental protection assistance; air, water, and regulatory support; recommendations for environmental and ecological risk standards; and environmental management systems. Worker Health and Safety work provides technologies to monitor exposures and predict health risk, technical assistance to DOE Operations Offices, studies on chemical and radiation risk to support safety guidance documents, and support on emergency response approaches. Health studies include technical support for epidemiology and health surveillance, for the Comprehensive Epidemiologic Data Resource, and for development of health protection standards for hazardous chemicals.

\section{Energy Resources}

We believe that DOE's Energy Resources mission will be of increasing importance to the nation for the foreseeable future. However, rapid changes in the structure of the U.S. and world energy industries, increasing recognition of critical environmental issues, and the rapid pace of technological advances lead us to conclude that changes in that mission are inevitable. Our energy programs support three key DOE goals: 1) enhancing energy productivity; 2) ensuring reliable, secure energy supplies; and 3) reducing the environmental impacts of energy production. All of these are important and enduring goals, however there are evident tensions among them produced by traditional energy technology. We believe that the best means of resolving the conflicts is the incorporation of state-of-the-art science and technology into the energy system. Surmounting the limitations of an energy technology system originating in the 19th century will require a science-based energy strategy.

The programs in PNNL's Energy Resources area integrate DOE's energy technology development and deployment activities with DOE's basic science programs. In addition, we plan to use industrial partnerships to bring the resultant advances in energy technology to market. We intend to take advantage of the full range of science and technology capabilities within industry, the national laboratory system, and the Department to advance DOE's agenda.

Pacific Northwest National Laboratory is committed to helping DOE in responding to its current challenges and charting its future through a focused energy strategy in two broad areas:

1. improving the utilization of the current national and international energy infrastructure through development of technologies that save energy and control costs (nearterm focus)
2. developing and applying the next generation of science and technology to increase our nation's energy security in an environmentally acceptable manner consistent with an increasingly competitive energy marketplace (longerterm focus).

The first of these focus areas, improving our current infrastructure, is rich with opportunities for DOE to moderate our nation's dependence on imported oil by improving the efficiency of energy use. The second of these focus areas represents our broader vision of the nation's energy future.

The Laboratory has been making LDRD investments in technology that it believes will enhance the public interest as the energy industry responds to the energy revolution currently under way. Capitalizing on our strengths in molecular science, we have been investing in the development of science and technology for energy applications at the frontiers of scale: using nanoscale molecular science to improve the efficiency of energy and chemical processes and employing microscale technology to link this science to application. Microtechnology-based devices might significantly improve many characteristics of our energy system. Components, such as micro-sized heat pumps could improve the efficiency of heating and cooling our homes in a cleaner, more reliable and efficient manner. Micro-scale fuel processors and fuel cells enhanced by improved catalysts and materials might lead to a revolution in economic and more environmentally desirable transportation - a major consumer of imported oil. With these investments in science and advanced technological capabilities, the Laboratory plans to be ready to serve DOE in dealing with the problems of the 21 st century.

In addition to developing new technologies and products, we are also leading several innovative efforts to improve the value of DOE's programs. Specific examples include:

- supporting DOE-EE's Office of Industrial Technologies' Chemical Industry of the Future, where we collaborated with OIT and industry to understand industry's vision for the 21 st century. We are helping to develop a publicsector research and development agenda that focuses on reducing energy consumption and the costs of meeting environmental regulations consistent with this vision.

- playing a leadership role in developing the Northwest Alliance for Transportation Technology, public private partnership to meet the weight reduction challenge of the Partnership for a New Generation Vehicle

- building an innovative public private partnership to develop an economically efficient science- and technology-based strategy to respond to the threat of global climate change.

PNNL's scientific and technical activities in each DOE program office contributes to DOE's Energy Resources mission. The descriptions below also explain the proposed expansion of the Laboratory's role within these organizations' initiatives. 


\section{Office of Energy Efficiency and Renewable Energy (EE)}

\section{Office of Utility Technologies (AK)}

DOE-EE's Office of Utility Technologies (OUT) faces significant challenges in the rapidly changing energy environment to define the federal role in the new age of deregulation. The Laboratory has a tradition and history of working with the Office of Utility Technologies and the utility industry, and expects to support OUT in addressing the technology needs for a reliable electricity supply in the 21 st century. In particular, we propose to work with the Office of Utility Technologies and the utility industry in the areas of superconducting magnetic energy storage, real-time controls, and advanced information technologies to ensure security and integrity in an unregulated utility industry.

\section{Electric Energy Systems (AK)}

The Laboratory will continue its basic research in electromagnetic field (EMF) interactions with biological systems and in the identification of potential health effects in support of DOE's Biological Mechanisms Research Program and the EMF Research Public Information Dissemination (RAPID) Program.

\section{Office of Building Technology, State and Community Programs (EC)}

Throughout most of the world, buildings are an ever-present artifact of human existence. The demand for safe, healthful, productivity-enhancing shelter is a fundamental human need. The Laboratory's Buildings Energy Program supports the Office of Building Technology, State and Community Program's objective to improve the energy efficiency of the nation's buildings and to increase their use of renewable resources. Our support includes research, development, and deployment activities designed to target areas with highefficiency improvement potential that are not addressed by other organizations. The Laboratory supports the initiation of the Buildings of the 21st Century program leading to the integration of modern technologies to produce a more economical, efficient, and environmentally friendly buildings.

\section{Office of Industrial Technologies (ED and EF)}

The Laboratory's role in supporting the Office of Industrial Technologies (OIT) covers a broad range of activities from program planning and technical evaluation to technology development and demonstration. Current technology development programs draw upon our process science and engineering competencies to recover energy from dilute industrial wastes and to develop renewable-based routes for chemical manufacture.

In support of OIT's focus on seven energy-intensive and waste generating industries (aluminum, chemicals, forest products, glass, metal casting, petroleum refining, and steel),

\section{FLC Award Winner}

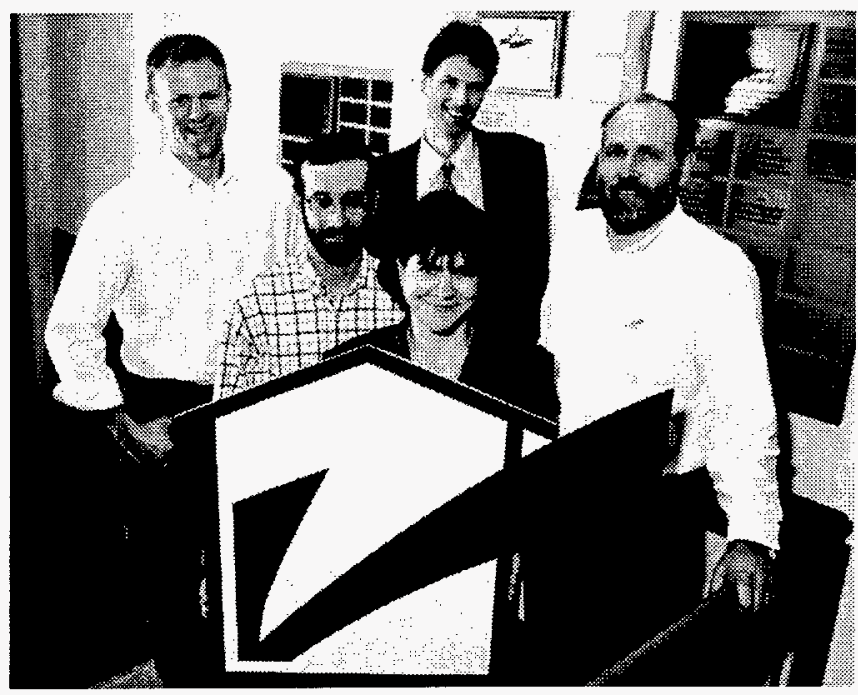

While most federal technology transfer success stories involve a complex process or high-tech product with immediate benefits for one or a few clients, this is a story of making a complex task simple with a product that has directly aided thousands. PNNL staff members undertook the job of making the Model Energy Code more understandable and accessible to federal, state, and local government agencies; building code officials; builders; and manufacturers of energy-efficient materials; and ultimately, helping to ensure energy efficiency in new homes for the American consumer. The staff members sought advice from the end users and turned the collection of complex technical requirements comprising the MEC into a simple, yet comprehensive set of tools called MECcheck ${ }^{\mathrm{TM}}$. The MECcheck team did more than generate a group of toolsit supported the code users and their organizations in application of those tools. More than 10,000 copies of the MEC check tool kit have been requested and distributed to users, and it is the material specified for compliance in 10 states.

the Laboratory has joined with 16 other DOE national laboratories and facilities to form the Industries of the Future Laboratory Coordinating Council. Under a Memorandum of Cooperation, this group facilitates access to capabilities that can be applied to solve technology challenges identified in each industry's vision of the future. Collaborative efforts in OIT's Industries of the Future initiative have led to broad national benefits of efficient energy and resource use, economic competitiveness, and enhanced environmental quality. The Laboratory's intent is to vigorously solicit industrial partners to apply our special science and technology capabilities to achieve these industry visions.

\section{Office of Transportation Technologies (EE)}

Pacific Northwest National Laboratory is a key contributor to the Office of Transportation Technologies' Transportation 


\section{R\&D 100 Award Winner}

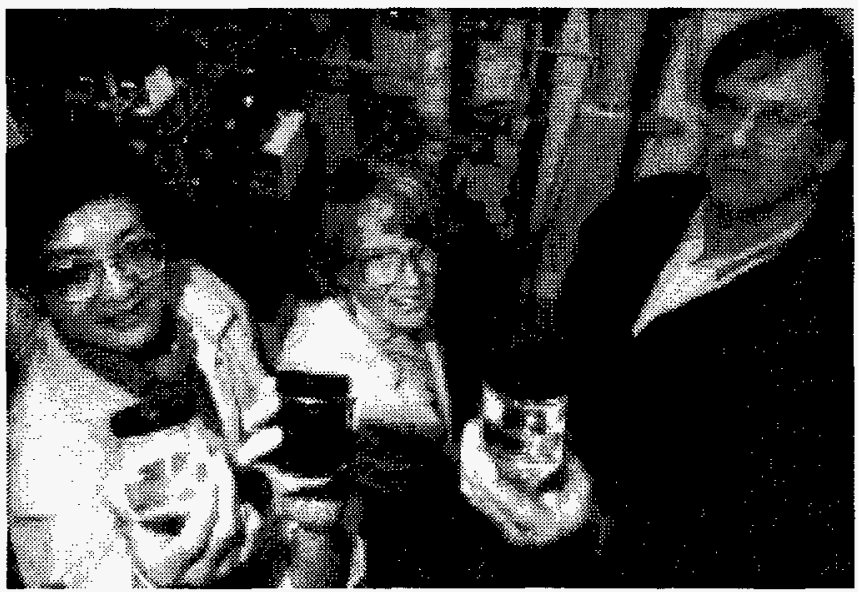

(Tri-City Herald photo)

The Production of Chemicals from Biologically Derived Succinic Acid (BDSA) process converts corn into a costefficient, environmentally friendly source of the chemicals used to make polymers, clothing fibers, paints, inks, food additives, automobile bumpers, and an array of other industrial and consumer products. The process produces succinic acid by fermenting glucose sugar from corn. After separation and purification, the succinic acid is used as a chemical intermediate that is converted into chemical feedstocks used to make a wide assortment of products. Currently, more than 90 percent of the basic feedstocks used to make these products originate from crude oil and natural gas, and the BDSA process will compete with these production routes by providing a lower-cost means of obtaining commodity chemicals from renewable resources.

Technology Program. The objective of the Transportation Technology Program is to develop and commercialize technologies that can radically reduce petroleum consumption in the transportation sector. The program is expected to reduce U.S. reliance on imported oil, reduce environmental impacts from transportation, improve the balance of trade, make resources available to invest in other sectors of the economy, and improve international competitiveness of U.S. firms.

The Laboratory is contributing to all of these major elements of the Transportation Technology Program, working in close partnership with the U.S. Council for Automotive Research (USCAR) and the other DOE laboratories. We are applying our core capability in materials sciences and materials processing technology to develop advanced forming technologies for lightweight metals suitable for rapid forming processes and composites. We are developing the Northwest Alliance for Transportation Technologies to unite the capabilities of industry, national laboratories, and universities in the development of materials and manufacturing processes necessary to achieve the weight reduction goals of the Partnership for a New Generation Vehicle.
Programs to reduce emissions for internal combustion engines are also being developed. These programs focus on both reducing hydrocarbon generation in the engine cylinders and on trapping and destroying hydrocarbons and $\mathrm{NO}_{x}$ coming from the engine.

\section{Federal Energy Management Program (EL)}

PNNL, along with the National Renewable Energy Laboratory, LBNL, and ORNL, is a key participant in the Federal Energy Management Program (FEMP). The Laboratory supports FEMP's goal to lower federal operating costs by facilitating implementation of energy and water conservation measures in federal facilities through policy action, coordination, assistance with technology and financing tools, and leveraging private investment.

\section{Bonneville Power Administration}

Bonneville Power Administration (BPA) faces significant challenges that will dramatically alter its focus and business approach over the next 2 to 5 years. These challenges stem, to a large extent, from dramatic deregulation of the energy utility industry in general, and the electric utilities in particular. In response to these dramatic changes, BPA has restructured, becoming three separate business units under a common corporate umbrella.

PNNL will support the "new" BPA with research and development support to lower operating costs and increase the value of services offered by each of the new BPA entities. First, we will continue to deploy our capabilities to serve the new Bonneville transmission group in real-time power system control and operation via the Wide Area Monitoring project, conducted in partnership with the Electric Power Research Institute and DOE. This includes joint commercialization of selected Wide Area Monitoring products developed by BPA and PNNL. Second, we will continue our current programmatic support in energy resource and environmental programs to serve the power and energy services entities. This includes the BPA Fish and Wildlife programs as well as BPA's market transformation initiatives. Finally, we will seek to deliver advanced operations and maintenance technologies to both the power and transmission entities to further BPA's goal to reduce the cost of power to the region. The benefits to the nation will be an improved power marketing function in the Northwest as well as new technologies that can be applied to the nation's public and private power transmission and hydroelectric generation infrastructure.

\section{Office of Fossil Energy}

PNNL's involvement in DOE's Fossil Energy programs is expected to grow as the Office of Fossil Energy continues to refocus its programs toward DOE's new challenges. The Laboratory's research will continue to be focused on natural 
gas and oil industry needs, environmental regulation, energy conversion, gas and coal chemistry, advanced materials development, and environmental effects of coal use. We will focus on the role of science and technology in helping the Office of Fossil Energy respond to concerns over global climate change.

\section{Policy Office}

PNNL provides assistance to the Policy Office in the area of economic and policy analysis, both on major long-range studies and on short-turnaround issues as they emerge. The main strength of the assistance the Laboratory provides to the Policy Office is the relevance of our economic analysis and technology focus.

The Laboratory's extensive modeling capability provides another valuable input to the policy decision process. Significant improvements in understanding policy approaches to controlling greenhouse gas concentrations are being realized as our efforts to develop the Second Generation Economic Model come to fruition. Working with collaborators in Western Europe, Korea, Japan, Canada, the former Soviet Union, Australia, Mexico, and India, the global version of the model is now supporting U.S. government preparations for the next meeting of parties to the Global Climate Change Convention.

\section{National Security}

Pacific Northwest National Laboratory has a growing, technologically rich, and well-recognized role in four national security focus areas: arms control and nonproliferation, intelligence, safeguards and security, and defense technologies. These national security activities are derived from and support DOE's national security core business area. Our current national security mission is based on the historical role of the Laboratory in defense materials production, the early tasking by the Atomic Energy Commission to develop sensitive radionuclide collection and analysis capabilities to monitor worldwide radioactive fallout and Hanford Site sources, and its continuing support to each of DOE's mission areas.

Our national security objective is to integrate the full spectrum of technical knowledge at PNNL to anticipate and rapidly respond with creative and innovative solutions that enhance national and international security. Our goal is to provide an objective and independent national technical resource to national and international agencies and industries to

- support policy development and implementation planning

- develop and apply technology to implement national security policy

- provide technologies to meet national security requirements generated by the disparate threats across the broad spectrum of mission requirements.
The Laboratory's national security work is principally conducted for DOE's Office of Nonproliferation and National Security, Office of Defense Programs, and other federal agencies through the Work for Others Program.

\section{Office of Defense Programs}

Pacific Northwest's work for the Assistant Secretary for Defense Programs includes safeguards and security activities in direct support of defense programs and technical support to the nuclear weapons complex. The Laboratory also assists Defense Programs in interpreting safeguards and security policies and identifying cost-effective implementation procedures for the Defense Programs complex.

We continue to provide technical support to the Defense Programs complex in specific materials support activities. Pacific Northwest is working closely with the Office of Military Application and Stockpile Support (DP-20) to define a light-water reactor tritium target qualification programa program designed to qualify the target system design first demonstrated in a previous Tritium Target Development Program initiated under DOE's New Production Reactor Office between FY 1989 and FY 1992. The qualification program would provide a tritium target system that could be used with confidence in DOE's contingency option for tritium production for nuclear weapons applications.

\section{Office of Nonproliferation and National Security}

The Laboratory is a participant in the Initiative for Proliferation Prevention with the Newly Independent States (NIS/IPP) of the former Soviet Union. The goals of this U.S. government program, executed jointly by the Departments of State and Energy, are to stabilize supporting technology, equipment, and facilities to enhance global nonproliferation; develop advanced technology commercial opportunities and markets; enhance U.S. science and engineering capabilities; and engage weapons scientists, engineers, and technicians in nonweapon activities.

The Laboratory has been requested to act as the coordinator for the chemical and biological cooperative program under IPP. The Laboratory also is in a leadership role for both the Former Soviet Union Materials Protection, Control and Accountability and the North Korean Agreed Framework programs. Under the latter, the U.S. is assisting the Democratic Peoples Republic of Korea (DPRK) in placing spent nuclear reactor fuel under international safeguards. The Laboratory is also heavily involved in supporting Russia and other states of the former Soviet Union in preventing the theft and diversion of its excess nuclear weapons material. The Laboratory participates in the Executive Council of the Office of Nonproliferation and National Security and provides direct technical support as requested. 


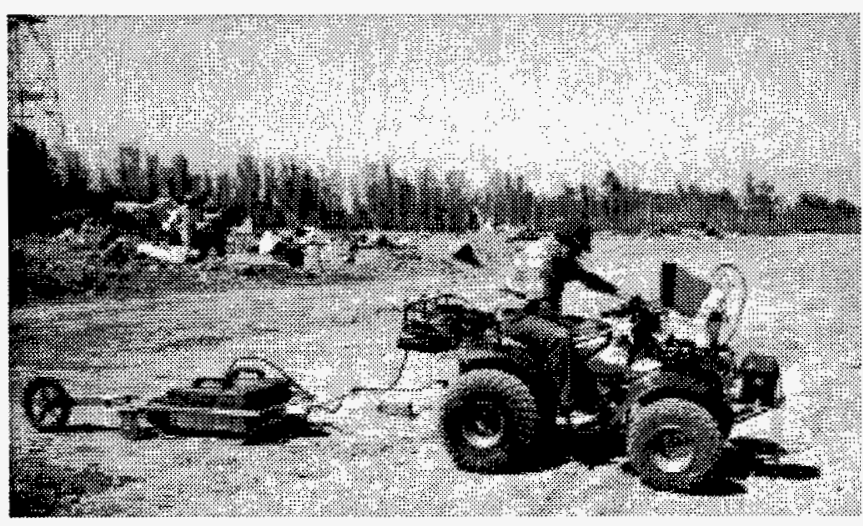

Pacific Northwest scientist conducting an underground survey using ground penetrating radar at the Tuwaitha nuclear site in Iraq as part of a DOE program supporting the United Nations Special Commission.

\section{Office of Research and Development}

A critical national concern is proliferation of nuclear, chemical, and biological weapons and their associated delivery vehicles. The DOE has an objective to detect and assess nuclear proliferation and to ensure that the U.S. government has the ability to enter into and evaluate compliance with existing and future bilateral and multilateral agreements controlling nuclear weapons and their proliferation. The Laboratory is focusing its national security technology capabilities to identify needs and develop technologies to monitor, detect, and analyze for indications of such proliferation.

Pacific Northwest was the lead laboratory for the Airborne Multisensor Pod System mission to Kazakstan in 1997. The objective of this mission was nuclear nonproliferation and confidence building with simultaneous support for international commercial enterprise in this former Soviet communist republic. The mission deployed advanced remote sensing equipment to demonstrate its utility for nonproliferation as well as mineral and hydrocarbon exploration, and geological data acquisition for other purposes.

The Laboratory, through the sponsorship of the Office of Research and Development, has developed remote monitoring instrumentation as candidates for use by the U.S. government and other governments worldwide for the monitoring of the Comprehensive Test Ban Treaty. One device, the Automated Particulate Sampler System, is based on longstanding particulate radionuclide sampling and analysis techniques for atmospheric and vented underground test monitoring. Another system, the Automated Radioxenon Analyzer is similarly configured, but is based on the novel detection and measurement of xenon-133 and other xenon gas-phase isotopes as unique indicators of recent (illegal) testing. The Automated Particulate Sampler System was chosen by the U.S. government as the system for worldwide deployment.

The Laboratory has also played a key leadership role in formulating an integrated diversion detection, "nuclear smuggling" program through the support of not only the Office of Research and Development, but other Nonproliferation and National Security components as well. Laboratory activity is primarily related to attribution assessment through advanced nuclear forensic analysis and is part of a multilaboratory capability that is being integrated to provide direct support to U.S. government agencies.

We also support DOE's treaty involvement through technology development, expert knowledge, and on-site support in Washington, D.C.; the Conference on Disarmament in Geneva, Switzerland; the United Nations Special Commission; and the International Atomic Energy Agency. A Laboratory staff member is also assigned as DOE's representative on the U.S. delegation negotiating modifications to the Anti-Ballistic Missile Treaty.

\section{Office of Energy Intelligence}

Pacific Northwest directly supports the DOE Office of Energy Intelligence in areas of nuclear nonproliferation, energy assessment, and intelligence support. We perform intelligence data processing and analyses that address national issues in weapons materials production, nonproliferation, energy resources, and other tasks as appropriate. The Laboratory further supports studies and application of technologies in special programs. Products and services provided to the DOE Office of Energy Intelligence contribute to the support of policymakers and the intelligence community. Additionally, in coordination with DOE's Office of Energy Intelligence, we apply our capabilities and technologies to perform intelligence-related work for other government organizations.

\section{Office of Arms Control and Nonproliferation}

Pacific Northwest directly supports the DOE Office of Arms Control and Nonproliferation in the specific functional areas of former Soviet Union materials protection, control, and accounting; negotiations and treaty implementation; export control; and international safeguards. Laboratory staff serve in several key leadership positions related to nuclear threat reduction.

The Laboratory participates as a member of the Materials Protection, Control and Accounting Steering Committee coordinating DOE efforts to improve safeguards on nuclear weapons materials in the former Soviet Union, particularly the Russian Federation. Laboratory staff are involved in many of the tasks associated with this highly visible and growing U.S. government activity.

The Laboratory' also supports Office of Arms Control and Nonproliferation activities focused on strengthening the Nuclear Nonproliferation Treaty Regime. Three Laboratory staff members are the major part of the DOE technical team overseeing U.S. government assistance to the DPRK in safely containing and disposing of DPRK reactor fuel under the Framework Agreement. The International Atomic Energy Agency has been investigating environmental monitoring 
techniques as a method of determining illicit nuclear activities. Monitoring the environment adjacent to suspected nuclear facilities has high probability of detecting effluents from nuclear processes. The Laboratory is supporting this initiative through DOE.

The Laboratory provides scientific, engineering, and operations expertise from the DOE weapons material production complex for the negotiation and implementation of arms control treaties and agreements. The Laboratory has facilitated the use of the Hanford Site, a past weapons material production site, to provide "real-world" familiarization and insight for the Conference on Disarmament's U.S. and foreign ambassadors and principals negotiating the Fissile Material Cutoff Treaty. Laboratory staff support DOE in the preparation, review, and analysis of U.S. government policy positions/ options for the cessation of Russian plutonium production. The Laboratory also provides technical support for verification under the U.S.-Russian highly enriched uranium purchase agreement that the materials delivered to the U.S. Uranium Enrichment Corporation have been derived from Russian weapons-grade uranium.

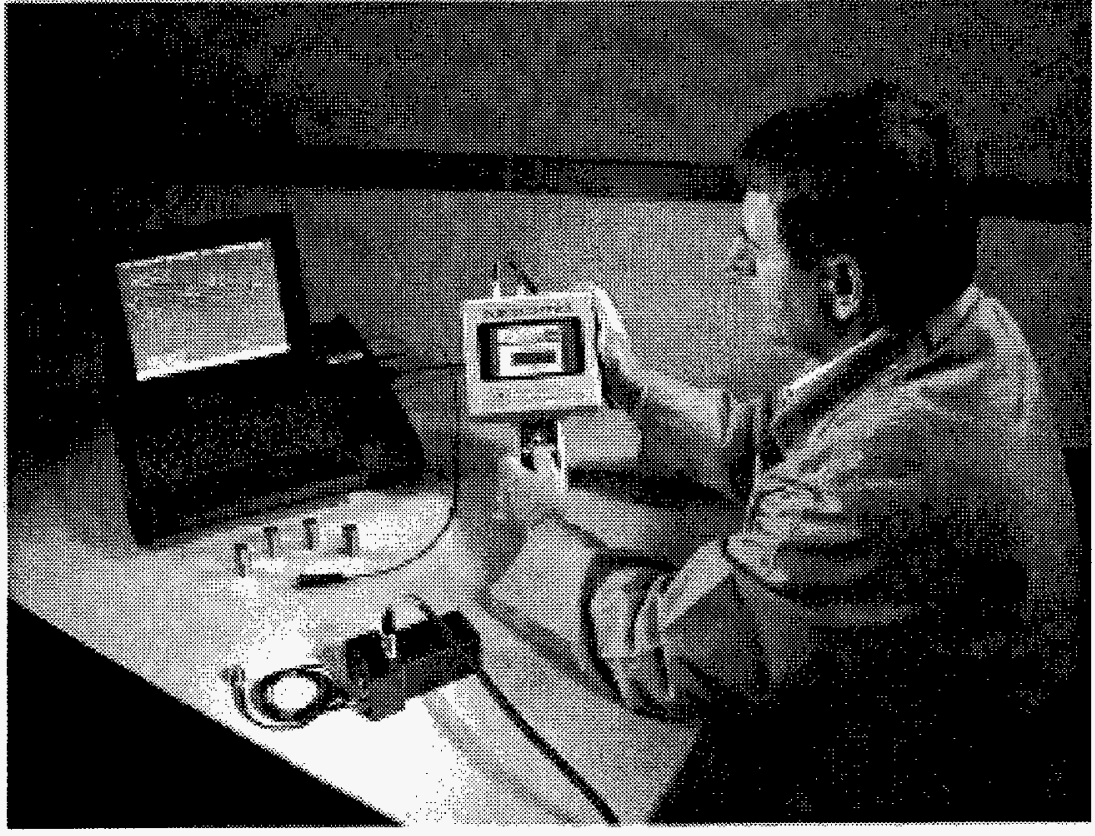

Pacific Northwest scientist demonstrates the use of the Material Identification System developed for U.S. Customs and the On Site Inspection Agency for international border security applications.
The Laboratory supports DOE efforts with the 31-country Nuclear Suppliers Group that develops and institutes multilateral export controls to non-Nuclear Suppliers Group countries. Laboratory staff provide assistance to DOE under the Nuclear Suppliers Group by providing the technical justification for changes and modifications to the former International Atomic Energy Agency list and the U.S. recommendations for nuclear dual-use export control. In addition, other classified services to DOE in the technology export arena are provided. PNNL staff act as technical reviewers for DOE on specific authorization requests by U.S. companies who wish to assist foreign atomic energy activities. Laboratory capabilities are applied in support of the DOE role in developing the nuclear-related technology sections of the Military Critical Technologies List. Laboratory staff are also members of a U.S. delegation headed by the U.S. Customs Service to assess and train Newly Independent States nonweapons states on export controls of strategic and dual-use materials.

\section{Office of Security Affairs}

Pacific Northwest activities for the Office of Security Affairs cover four major areas that provide strong linkages across the Nuclear Safeguards and Security Program. Each of the major activities addresses significant portions of the overall protection program and focuses on integrating these portions to enhance the effectiveness and efficiency of the operation.
The primary areas addressed by the Laboratory include 1) Information Security planning, policy, practices, and procedures; 2) Material Control and Accountability technology transfer, performance-based policy implementation, and technology and procedural alternatives; 3) management assessment techniques and resource review support; and 4) national level initiatives of Arms Control and Nonproliferation impacting domestic safeguards and security.

The identification, dissemination, development, and transfer of technology, practices, and procedures across the DOE complex will ensure that a state-of-the-art safeguards and security program is in place and capable of providing effective and efficient protection for DOE assets, including accountability and control of special nuclear material.

\section{Office of Emergency Management}

Pacific Northwest supports the Office of Emergency Management in the determination of technical requirements and the development and deployment of technical systems in support of mission needs. The Laboratory participates in the coordination with other government agencies led by this office. The Laboratory also supports the Office of Emergency Management through a direct high-speed communication link between DOE Headquarters and PNNL. Using the Emergency Operations system, Laboratory scientists can provide real-time analysis and support during emergency situations where expertise is needed to manage and solve real-world problems. 


\section{Nuclear Energy}

\section{Office of Nuclear Energy, Science and Technology}

Pacific Northwest has increased its participation in programs for the DOE Office of Nuclear Energy, Science and Technology (NE). Current and projected funding for the DOENE programs are shown in the Resource Projections.

\section{Nuclear Energy Research and Development (AF)}

The Laboratory continues to provide primary support to DOE-NE in its international nuclear safety and security missions. Over the planning period, the Laboratory plans to continue and expand its role in DOE-NE's research and development programs as follows:

- provide lead project management, technical, and administrative support for DOE's work to improve international nuclear safety. This work reduces the risks of Sovietdesigned reactors by working cooperatively with host countries to upgrade nuclear power plants to meet international standards and to build lasting safety cultures.

- take a lead role in implementing bilateral efforts to stabilize the deteriorating "shelter" surrounding the destroyed Chornobyl reactor in Ukraine and supporting the transition of this work to the European Bank for Reconstruction and Development, which will consolidate international funding and provide oversight

- provide increasing support to DOE-NE in developing and implementing its nuclear security program to stop the production of weapons-grade plutonium

- support DOE-NE's evaluation of the potential use of the Fast Flux Test Facility as an interim source for the nation's tritium production and a longer-term medical isotope production mission by managing the Facility's standby and analysis activities until DOE makes its decision in 1998.

\section{International Nuclear Safety and Chornobyl Initiative Program}

The mission of the International Nuclear Safety and Chornobyl Initiative Program is to reduce risks at Sovietdesigned nuclear power plants and to create institutional and infrastructure changes that put host countries on a sustainable path toward the achievement of internationally accepted safety levels.

This work supports the Laboratory's mission of meeting national security, energy, and human health needs by

- providing protection for Europe's public, economic, and environmental health and for U.S. personnel located in Europe
- reducing the risk of destabilizing nuclear accidents in the emerging free-market democracies of the New Independent States

- working with other countries toward the shutdown of the least safe Soviet-designed nuclear power plants, such as the Chornobyl plant

- supporting U.S. nuclear security goals by supporting countries in eliminating the production of weapons-grade plutonium.

DOE has assigned the Laboratory the responsibility for providing project management and lead technical and administrative support for the program, with assistance from other DOE national laboratories, U.S. commercial organizations, and governmental and scientific organizations in the host countries. The Laboratory contracts for safety-related services and equipment from U.S. firms and from the nuclear power plants and scientific institutions in the host countries. The Laboratory continues to staff adjunct offices in Moscow, Kyiv, and Slavutych (Ukraine) in support of this work.

Under the International Nuclear Safety and Chornobyl Initiative Program, the Laboratory supports DOE in four major efforts described below.

\section{Soviet-Designed-Reactor Safety Program}

The mission of the program is to reduce the risks at Sovietdesigned nuclear power plants and to create institutional and infrastructure changes that put host countries on a sustainable path toward the achievement of internationally accepted safety levels. The countries involved are Armenia, Bulgaria, Czech Republic, Hungary, Lithuania, Russia, Slovakia, and Ukraine. As of FY 1997, 20 nuclear power plants with 64 reactor units in these eight countries are participating in the program.

Laboratory experts and others work cooperatively with the host countries to

- improve the capabilities of nuclear power plant operators to establish sound operational procedures and to develop methods for responding to operational abnormalities

- upgrade the performance of plant safety systems to a level of safety consistent with their remaining lifetimes

- provide professionals involved in the design, operation, and regulation of nuclear power plants with the techniques and expertise required to conduct safety analyses that are consistent with internationally accepted practices

- provide technical support to identify and resolve safety issues related to interim storage of spent nuclear fuel in Ukraine and other New Independent States

- develop an international and national legal framework to promote nuclear safety legislation and improve independent regulatory oversight of nuclear power plants. 


\section{Chornobyl Center for Nuclear Safety, Radioactive Waste and Radioecology}

One way DOE maintains core competencies in nuclear safety is through supporting international nuclear safety centers, which undertake cooperative research and development programs, information exchanges, computer modeling, and other technical projects. DOE continues to work with Ukraine to develop one such center, called the Chornobyl Center for Nuclear Safety, Radioactive Waste and Radioecology. The Center's administrative offices are in Kyiv. The Center's collaborative research is conducted through the Slavutych Laboratory for International Research and Technology, in Slavutych, Ukraine, near the Chornobyl nuclear power plant. The Center's objectives are to

- develop sustainable operational safety programs that support Ukrainian nuclear power plants

- address decontamination and decommissioning, spent fuel, and radioactive waste management issues at Chornobyl and elsewhere in Ukraine

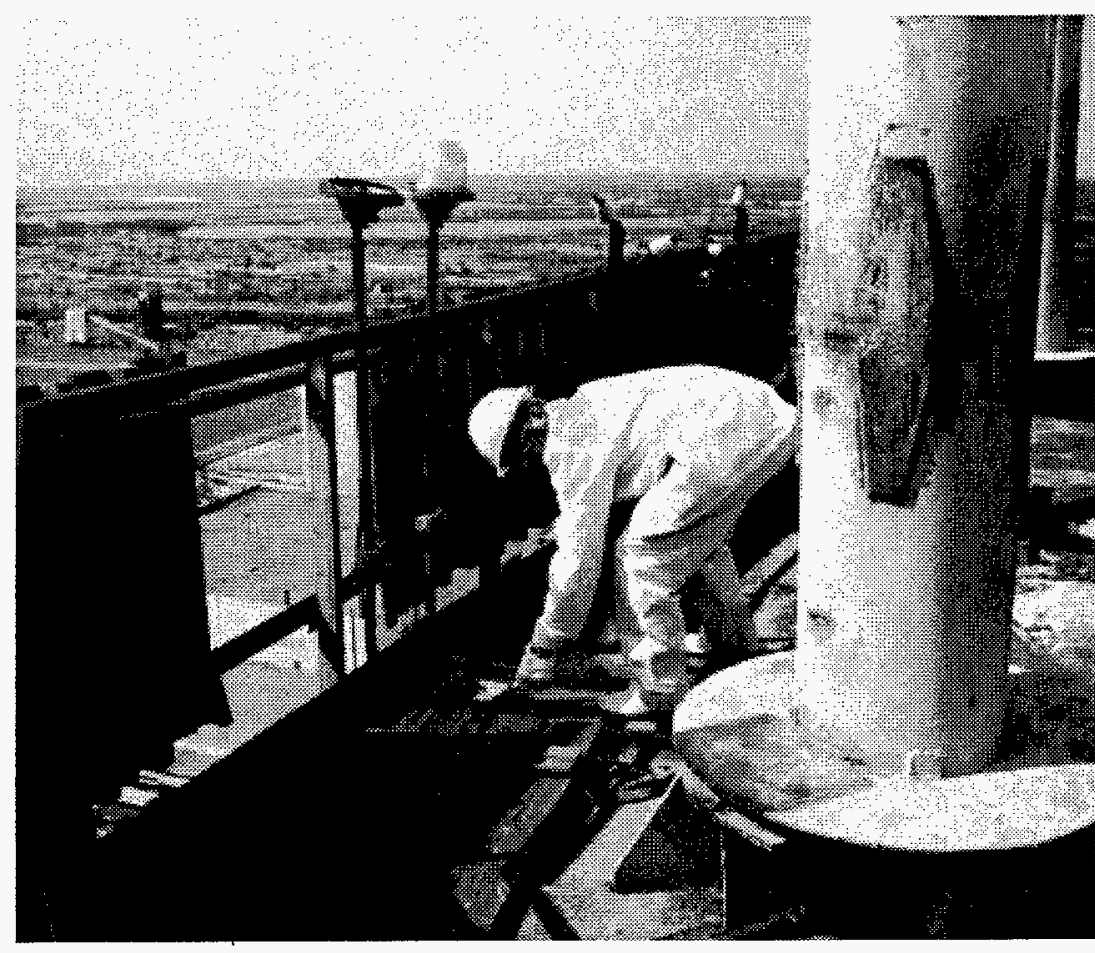

The Deputy Director of the Shelter at the base of the ventilation stack for units 3 and 4 assisting with pre-bracing repair decontamination activities, Chornobyl NPP.
- provide a means for international cooperation in addressing environmental, ecological, and health-related issues for the areas affected by the Chornobyl accident

- maintain necessary nuclear expertise and help diversify Chornobyl's economic base after the plant is shut down in 2000 .

DOE has given the Laboratory a key role in facilitating Center development and implementation. Over the planning period, the Laboratory will continue transferring and developing nuclear safety and environmental management technology and applying that technology to address the needs at Chornobyl and throughout Ukraine.

\section{Nuclear Security Program}

The mission of DOE's Nuclear Security Program is to reduce the threats posed by reprocessing of spent fuel in former Soviet countries and to minimize the risks of proliferation of weapons-usable nuclear materials. The Laboratory supports DOE-NE in two key goals of this program: 1) implementing the U.S.-Russian agreement to cease the production of weapons-grade plutonium in Russia, and 2) providing alternatives to the reprocessing of spent nuclear fuel by former Soviet countries.

DOE is supporting Russia in changing the type of fuel used in that country's three remaining operating plutonium production reactors to a type that will not produce weaponsgrade plutonium. The new type of fuel will burn highly enriched uranium from the Russian stockpile in the converted reactors and improve reactor safety, while enabling these reactors to provide heat and electricity necessary to the regions they service. The two-year design, analysis, testing, and regulatory approval phase of the project began in FY 1997. All three reactor cores are expected to be converted by 2000 .

DOE provides direction on technical issues, nuclear safety, and integration of the associated DOE risk-reduction efforts at the three Russian production reactors and coordinates regulatory issues pertaining to core conversion with the U.S. Nuclear Regulatory Commission. The Laboratory leads technical and management activities of the core conversion project with assistance from other U.S. contractors and Russian organizations. The majority of the work is performed by the Kurchatov Institute and its supporting Russian design and engineering organizations, and by the Russian regulatory organization, Gosatomnodzor, under subcontracts from the Laboratory. This cooperative project is funded jointly by the U.S. Department of Defense's Cooperative Threat Reduction program along with DOE's Nuclear Security program.

The Laboratory also is supporting DOE work to minimize reprocessing of spent nuclear fuel in former Soviet countries. This involves working with the countries to develop spent fuel management plans that include viable economic alternatives to reprocessing and supporting the transfer of U.S. nonproliferation and nuclear safety concepts and technologies. 


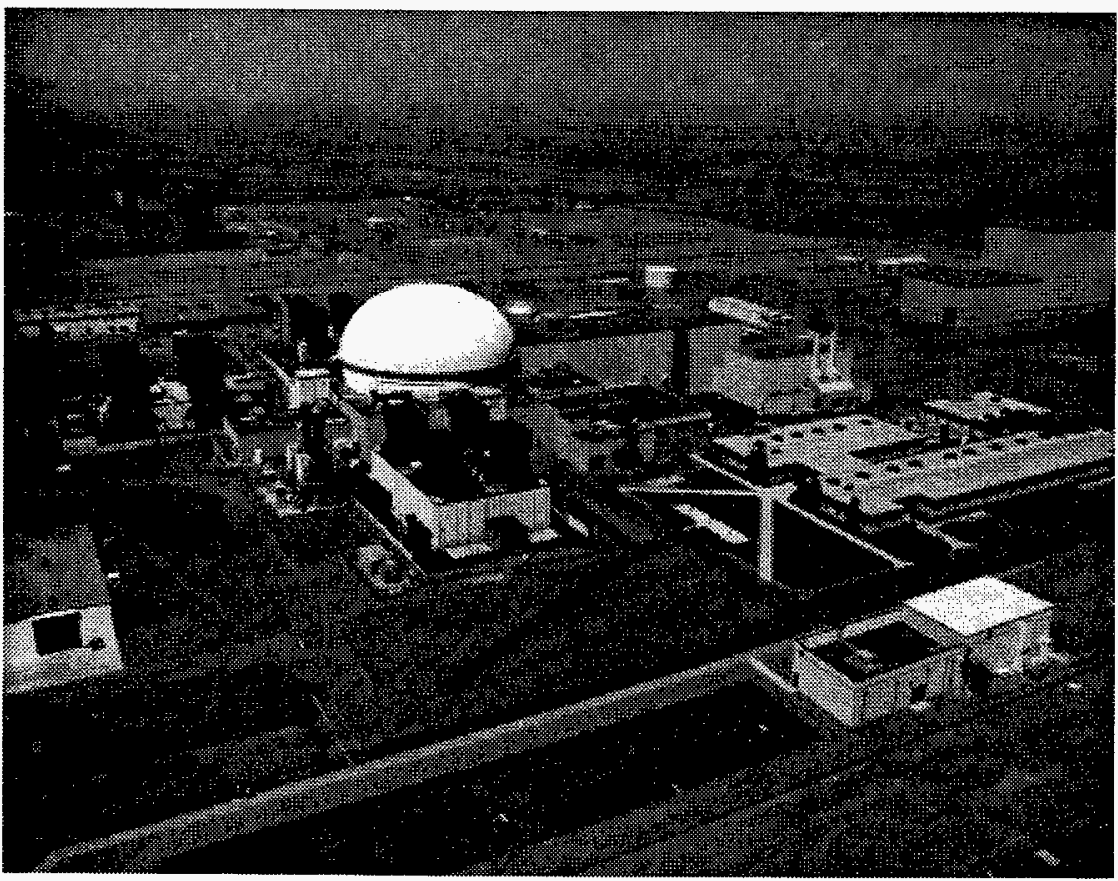

DOE is evaluating the potential use of the Hanford Site's Fast Flux Test Facility as a source for producing tritium and medical isotopes. The Laboratory is responsible for standby operations and for directing the analyses and reviews necessary to support DOE's decision.

nation's future tritium production strategy. The Secretary of Energy directed in 1997 that safety and environmental analyses associated with using FFTF for potential interim tritium production be conducted and that the feasibility of using FFTF for medical isotope production also be reviewed.

The Laboratory is playing a major role in supporting standby operations as well as directing the analyses and reviews. In a 1997 DOE-approved Memorandum of Agreement between Battelle Memorial Institute and Fluor Daniel Hanford, Inc., an FFTF Standby Project Office was established. The Laboratory is managing this Office, which is responsible for all aspects of FFTF operation as well as for generating the information supporting DOE's determination regarding the feasibility of FFTF's future role. FFTF operating staff will continue to be assigned to the appropriate Project Hanford Management Contractor (Fluor Daniel Hanford, Inc. or Babcock \& Wilcox Hanford Company) until DOE makes its decision about FFTF's future.

This work supports DOE's national security mission by helping to ensure a stable

\section{Chornobyl Closure Initiatives}

The DOE mission in this area is to implement the United States commitments under the 1995 G-7 Memorandum of Understanding with Ukraine on the closure of the Chornobyl nuclear power plant. The Laboratory continues to carry out its DOE-assigned role in providing project management and lead technical and administrative support to DOE with assistance from other DOE laboratories and industrial contractors. Chornobyl closure work involves

- improving worker safety and reducing hazards associated with the deteriorating "shelter" surrounding the destroyed reactor Unit 4 by providing radiological monitoring and industrial safety equipment and training

- participating in the development of the multinational plan to stabilize the existing shelter and construct a new one by 2005

- providing technical support for Ukraine to deactivate, decontaminate, and decommission Chornobyl reactor Units 1,2 , and 3, including evaluating options for providing adequate heat at the site.

\section{Fast Flux Test Facility}

The Fast Flux Test Facility (FFTF) is a 400-megawatt reactor at the Hanford Site that from 1982 until its shutdown in 1992 tested advanced nuclear fuels, materials, and components. DOE is maintaining the FFTF in "hot standby" while evaluating whether the reactor should play a role in the supply of tritium for the nation's defense needs. The Laboratory also is chartered, through the Hanford Strategic Plan, to apply existing Laboratory and Hanford Site assets to new science-based missions. The evaluation of FFTF as a potential interim tritium and long-term isotope production facility clearly falls within this role. Continued FFTF operation also would enable excess plutonium disposition and the continuation of research and development programs that require this reactor's unique capabilities.

\section{Radioisotope Production and Use}

Since 1996, the Laboratory has been responsible for the Hanford production and sales of medical radioisotopes such as yttrium-90. This work supports the DOE mission of supplying medical isotopes to enhance U.S. health care.

The Laboratory is developing new radiochemical separation technologies for retrieving various isotopes from nuclear waste materials for applications in medical diagnostic and therapeutic procedures. In reclaiming useful byproducts from nuclear waste for application to health care, the work supports the Laboratory's mission of delivering environmental science and technology in the service of the nation. A new area of emphasis in this program is the isolation and purification of several short-lived, alpha-emitting radionuclides for use in cancer therapy. These radionuclides are being tested in preclinical laboratory research for their ability to selectively destroy cancer cells when attached to targeting molecules such as monoclonal antibodies. 


\section{Work for Others}

\section{Department of Defense}

Pacific Northwest National Laboratory's work for the Department of Defense (DoD) primarily uses the Laboratory's capabilities in electronics and sensors, statistics and applied mathematics, computer and information sciences, materials science, chemical and instrumentation analyses, process technology, risk management, and social-technical systems analysis. The Laboratory is currently working in the following technical areas:

- treaty verification and technology assessment

- information sciences and architectures

- advanced materials and process development

- sensors, electronic and automated systems, and their applications

- systems analysis and technology evaluation

- environmental science and waste technology

- pollution prevention and technology development, demonstration, and deployment

- environmental toxicology

- analytical chemistry and radionuclide applications

- process technology.

The Laboratory has a significant role in the area of treaty verification and technology assessment. This work, carried out in close coordination with DOE, is performed for a number of DoD clients in support of national security needs.

The Laboratory supports Navy, Marine, Army, and Air Force research and development needs for systems integration and technology development using our capabilities in information sciences, networking architectures, and software development. Programs with the Air Force and Army use advanced graphic technologies, automated training systems, expert systems, and advanced workstation technology to simplify and automate operations. Network architectures and distributed computing techniques are developed to meet the unique needs of federal and state emergency organizations and the U.S. Army Chemical Biological Defense Command.

We also expect to continue providing support to the U.S. Army in advanced materials and design testing. The Kinetic Energy Projectile Project supports design, analysis, testing, and development of advanced munitions and manufacturing techniques for the Armament Research Development and Engineering Center. Studies of composite materials and other unique materials are performed for other DoD clients.

The Laboratory has developed unique capabilities in very thin film and high-quality optical coatings. This leadingedge capability has historically met needs for missile guidance filters for the Army and large-scale laser mirrors for strategic defense needs. The Laboratory is now applying this technology base to high-power density battery and unique identification and paint filters for both military antifratricide and industrial applications.

Sensors, electronics, and automated-systems development work is also expected to continue. We are developing sensors and integrated collection, detection, and evaluation technologies for chemical, environmental, and biological measurements for DoD. In addition, millimeter wave, radio frequency, electrooptical, and fiber-optic technologies have been developed for test range instrumentation systems for the Army and missile test systems for the Navy. Ultrasonic and electromagnetic imaging systems to evaluate airframe, munitions, and undersea components are being fielded. The Air Force and Army continue to support our radar crosssection holographic imaging technology. A variety of unique robotics for safety testing and specialized repair and operations tasks, such as reverse engineering systems and printed circuit board repair, have been developed for the Army and Navy. Large and small mobile robots equipped with various sensors have been developed for the DoD, Navy, and DOE communities. We developed a telerobotic system for disposal of explosive ordnance for the Navy. A serpentine robotic arm is currently under development for the Navy Explosive Ordnance Disposal Technical Center.

The Laboratory supports DoD environmental program needs for the Army, Navy, and Air Force using our capabilities in process technology, pollution prevention, water and land resources, risk management, environmental and regulatory compliance and marine science, and strategic environmental management. A wide range of integrated products and services are provided to our DoD customers, including system engineering; decision analysis; life-cycle analysis; strategic planning; technology management; site assessments/ characterization/remedial investigations; feasibility studies; National Environmental Policy Act (NEPA) support; environmental toxicology; remediation and pollution prevention; and technology development, adaptation, demonstration, and deployment. The emphasis is on demonstration and deployment of improved and innovative approaches and technologies to assess and clean up complex sites and reduce waste (pollution prevention) from existing and new systems.

PNNL provides expert assistance to the DoD in systems analysis, technology evaluation, and statistics. This work includes the technical support for modernization of major weapons production and logistics elements for the Army; evaluation of organization systems, procedures and methods, safety systems, and functioning of joint programs; and the assessments of human factors impacts and training requirements. Industrial base modernization programs evaluate and apply computer-integrated manufacturing in Army production plants, and provide efficient automation technology options to meet specialized maintenance technology requirements of the Army, Navy, and Air Force.

The Laboratory has a program with the Defense Advanced Research Projects Agency (DARPA) Army Medical Research 


\section{Discover Award Winner}

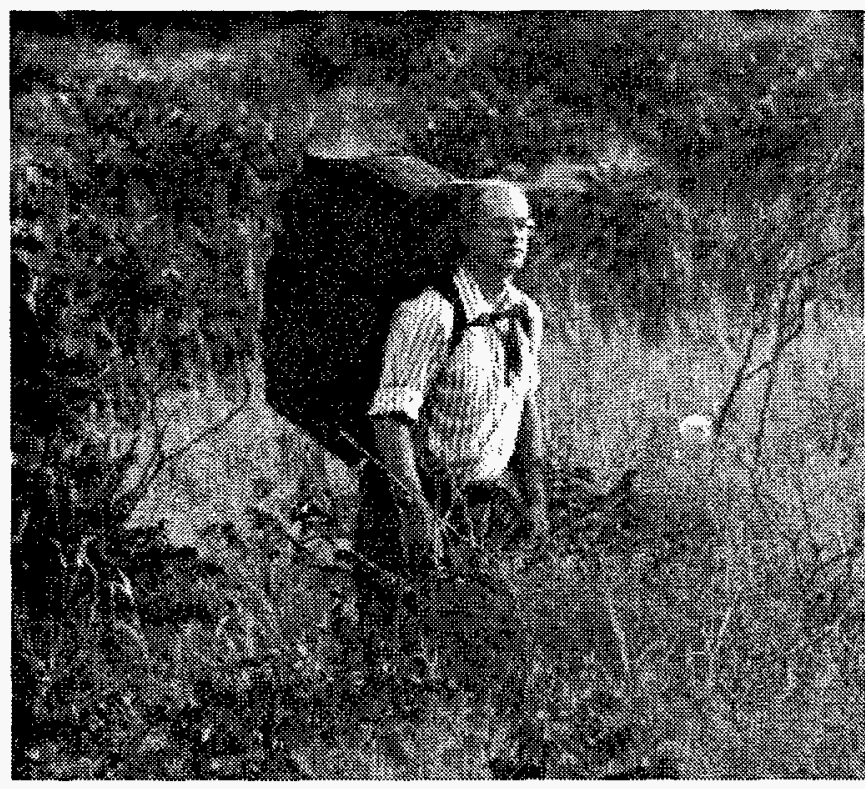

MUSTPAC-1, or Medical Ultrasound, Three-dimensional and Portable with Advanced Communications, won the Discover Awards Computer Hardware and Electronics category. Sponsored by Discover magazine, the Discover Awards for Technological Innovation honor individuals whose creative genius improves the quality of everyday life and alerts us to what is next from the frontiers of human achievement and ingenuity. MUSTPAC-1 allows a field medic or physician to perform three-dimensional scans of an ill or injured soldier. Those scans can then be interpreted by experts anywhere in the world. Developed for the military, the unit weighs about 85 pounds, fits in a backpack, and can be configured to run on batteries. The portable unit will bring the benefits of sophisticated ultrasound imaging used in major hospitals to the front lines.

and Development Command for developing medical imaging systems and technologies that improve health care and battlefield treatment of the injured. We are working with both DoD and DOE to expand this effort into a broad and integrated partnership that would include all the national laboratories and Army and Air Force medical centers.

The Laboratory is continuing development of significant microsystems technology capabilities in areas of microthermal and microchemical systems that are of particular interest to DoD clients. For DARPA, we are developing compact, microchannel chemical reactors. Our current efforts consist of the development of an integrated combustor/ evaporator, which is designed to serve as a low- $\mathrm{NO}_{x}$ heat source to drive man-portable soldier systems such as a compact personal cooling unit, and a liquid-hydrocarbon fuel processor that is designed to support man-portable power generation in a light-weight fuel cell. These projects are benefiting as leveraged investments, by DARPA, against companion efforts to develop compact, microsystem-based heat pumps and hydrocarbon conversion units for the U.S. Army Land Warrior Program and DOE.

The Laboratory continues to provide a variety of DoD clients with analytical chemistry support and radionuclide applications development. Very sensitive and high-precision analytical techniques are available at the Laboratory to meet measurement and testing requirements. Unique skills in analyzing radionuclides support specialized DoD needs.

Laboratory staff are assisting the U.S. Army and Navy in developing unique and innovative technologies to effect the disposal and remediation of highly toxic defense systems material. We are currently assisting the Army Program Manager for Non Stockpile Chemical Weapons (PMNSCW) examine and characterize the inhalation toxicity of aerosolized blister agents. Additionally, our technical staff have been supporting PMNSCW in the examination, testing, and qualification of the Laboratory's chemical weapons destruction technologies.

The Laboratory's program to support the U.S. Navy in the disposal of a unique weapons/fuel mixture continues. The first effort involves the removal of over a million pounds of obsolete and leaking containers of napalm (a mixture of gasoline, benzene, and polystyrene). This is a 5-year effort led by our technical staff who will design, validate, and implement the disposal strategy. This effort is in its third year.

Furthermore, our technical staff completed work this year for the U.S. Navy Surface Warfare Center-Indian Head to design and validate a torpedo fuel disposal facility for deployment at Keyport Undersea Warfare Center using our patented Catalyzed Electrochemical Oxidation technology. A follow-on program has been proposed to construct the full-scale treatment facility.

\section{Nuclear Regulatory Commission}

Pacific Northwest National Laboratory's research and technical work supports all of the U.S. Nuclear Regulatory Commission (NRC) program offices, regional offices, and several administrative offices. The work covers all aspects of nuclear safety regulation.

\section{Office of Nuclear Reactor Regulation}

The Laboratory continues to provide support during FY 1998 to the Office of Nuclear Reactor Regulation's (NRR's) Operator Licensing Branch in licensing commercial power plant nuclear reactor operators and senior reactor operators, and in evaluating facility operator requalification programs. However, the workload continues to decline due to regulatory changes being adopted for the administration of NRC initial and requalification examinations. 
The broad background of the operator licensing examiners and their specialized training provides a pool of staff able to support a wide variety of other activities for both the NRC and DOE. The experience of the examiners continues to be beneficial in performing maintenance evaluations, operations and training inspections, risk analysis, risk management, simulator evaluations, emergency preparedness assessments, and individual plant examinations.

PNNL will continue to support NRR's Division of Reactor Project Management by providing technical assistance in improving work processes, supporting staff reviews of decommissioning-related activities, and supporting development of regulatory guidance and standard review plans related to the decommissioning process. PNNL will also provide the Division of Reactor Project Management with technical support related to the review of emergency action levels and the development of emergency preparedness training for NRC inspectors.

The Laboratory will continue to support NRR's Division of System, Safety and Analysis in the area of commercial in-reactor fuel performance. This work includes performing technical reviews of vendor and utility submittals on fuel designs, fuel performance codes, and control rod assemblies. Laboratory staff will continue to prepare an annual summary of in-reactor fuel performance based on information from the vendors and open literature publications. This summary includes discussions of design trends, failure trends, and other topics of relevance to fuel performance. An increasing role will be to assist the Nuclear Regulatory Commission in on-site audits and inspection of fuel vendors and utilities.

Laboratory staff will provide assistance to the NRR in regulatory and licensing activities in the siting and environmental protection areas, including the Environmental Standard Review Plan update and development effort. We will provide multidisciplinary managerial and technical expertise to assist the NRC in its licensing reviews for early site permits and operating reactors, and in updating regulatory guidance.

\section{Office of Nuclear Regulatory Research}

Laboratory staff will continue to provide technical assistance to the Office of Nuclear Regulatory Research (RES) in support of decommissioning analysis and regulation. Technical analysis and cost estimates are provided for decommissioning licensed nuclear reactor power plants and for licensed fuel-cycle and nonfuel-cycle nuclear facilities. The support PNNL has provided to the NRC on short-turnaround analyses and addenda to previous decommissioning analysis reports should continue on a task basis. Current and future work for the NRC includes completing the reevaluation of the original pressurized-water reactor and boiling-water reactor power station decommissioning analyses (NUREG/CR-0130 and NUREG/CR-0672) and developing a computer program for estimating decommissioning costs, periodic updates of NUREG-1307 to reflect changes in the low-level waste burial site charge schedules, an analysis of the decommissioning of a large sealed-source user facility, and the reevaluation

\section{FLC Award Winner}

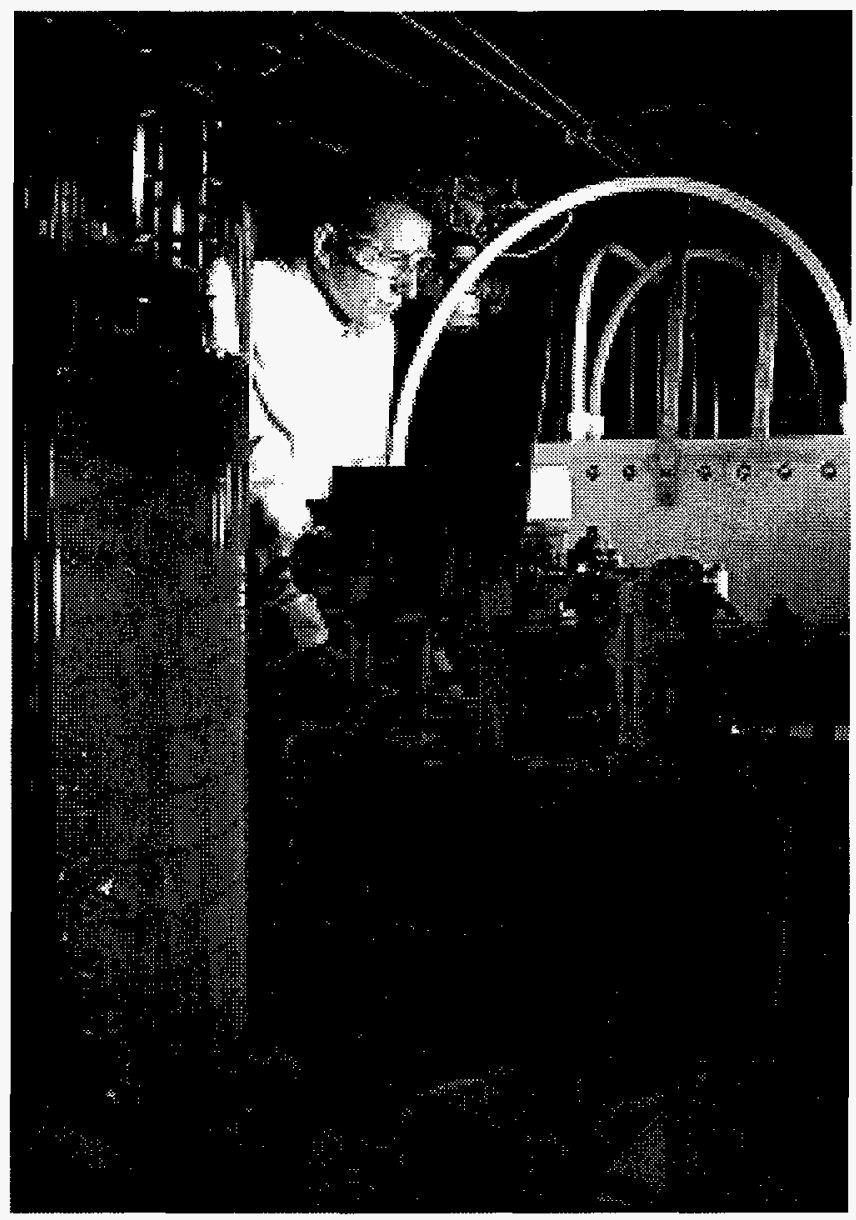

A team from PNNL had the vision to recognize the potential value of a new use for a defense-related nuclear waste treatment technology. They made the new concept work and marketed it to a company capable of putting it to broad use. The technology is Catalyzed Electrochemical Oxidation, an electrochemical process that provides a viable alternative to incineration for the destruction of hazardous solid and liquid wastes. The licensee is EOSystems, Inc., a small waste treatment company located in San Jose, California. The team members have helped both Pacific Northwest and EOSystems through the transfer of this world-class technology. The key to their success was their willingness to help a potential partner (EOSystems) by demonstrating the technology on EOSystems' customers' waste samples and their ability to redirect the defense technology to meet PNNL customers' needs.

of the earlier fuel-cycle and nonfuel-cycle facility reports to reflect current financial and regulatory conditions.

Nondestructive evaluation projects conducted at the Laboratory for RES have provided the engineering databases to support the NRC's position and policy on regulatory guides, 
position statements, codes, and regulations. The elements of these projects include 1) studying nondestructive evaluation reliability to determine the effectiveness of in-service inspections, 2) optimizing in-service inspection programs using nondestructive evaluation reliability data and parametric fracture mechanics analysis to control risks, 3) assessing new nondestructive evaluation techniques and transferring technology to the NRC regional offices and to the utility industry, and 4) developing a technical database for fabrication flaws in U.S. reactor pressure vessels for use in remaining life predictions. The nondestructive evaluation technologies under study at the Laboratory include ultrasonics (including the synthetic aperture focusing technique for ultrasonic testing [SAFT-UT]), eddy currents, and acoustic emission. It is anticipated that when the advanced lightwater reactor designs proceed, the Laboratory will be involved in similar work for the new designs.

The Laboratory will continue to provide technical assistance in support of low-level radioactive waste storage. Such support includes classification, characterization, and assessment of waste streams and activated metals; source terms for performance assessments; and characterization of chelating agents.

The Laboratory is one of the primary technical resources for RES on commercial nuclear fuel. Issues related to high burn-up fuel in nuclear power plants have high importance for the NRC. Continued development and revision of two fuel performance computer codes will be performed by the Laboratory. This work closely connects with the fuel-related work being done for NRR.

In FY 1997, PNNL staff completed the document Regulatory Analysis Technical Evaluation Handbook, which was issued by NRC as NUREG/BR-0184. This document will be used by NRC staff and contractors to evaluate the values and impacts of all proposed regulatory requirements to be imposed on licensees. During FY 1998, we will participate with RES staff in presenting training to NRC staff on use of the Handbook.

\section{Office of Nuclear Material Safety and Safeguards}

PNNL will continue to provide technical assistance to the Office of Nuclear Material Safety and Safeguards (NMSS) in the area of regulation of the gaseous diffusion uranium enrichment plants at Portsmouth, Ohio, and Paduccah, Tennessee (these plants are operated by U.S. Enrichment Corporation [USEC] through a lease arrangement by DOE). The Laboratory will assist NMSS in at least three areas:

1. security and safeguards

2. material control and accountability

3. criticality safety inspections.

USEC is also pursuing development of the advanced vapor laser isotope separation (AVLIS) technology to supplement/ replace the gaseous diffusion plants for commercial enrichment services. The NRC is expected to ask PNNL for assistance in reviewing such a license application in the future.

The Laboratory continues to provide support to NMSS in FY 1998 in the area of chemical safety, security, and safeguards; fuel-cycle regulatory guides; and international physical protection. As DOE turns over additional fuel cycle facilities to NRC regulation, opportunities exist to assist the NRC in reviewing and inspecting those facilities.

\section{Other Nuclear Regulatory Commission Offices}

The Laboratory continues to support the Office for Analysis and Evaluation of Operational Data by refining analytical tools used by the NRC's Emergency Response Organization. New and/or improved models that address cloud shine, modify wind fields, process meteorological forecasts, present results graphically, calculate dose rates, etc., will be added to the RATCHET and RASCAL codes. After the codes are revised, tested, and installed, PNNL staff will train NRC staff in the use of the models.

PNNL is also assisting the NRC's Office of Administration, Division of Facilities and Security by preparing a classified automated information systems security program, and by reviewing security inspection procedures for the gaseous diffusion uranium enrichment plants.

\section{Environmental Protection Agency}

Pacific Northwest National Laboratory conducts research to assist the Environmental Protection Agency (EPA) in its central role of environmental regulation in the United States. The Laboratory continues to conduct a variety of research and development activities to improve the state of knowledge about exposure, impacts, and risk from pollutants on human health and ecological systems. The primary areas of research that we will conduct for the Environmental Protection Agency include the following:

- modeling and assessment of the environmental impacts of increasing concentrations of trace contaminants in the atmosphere and potential resultant global climate change

- assessing the technologies and economic impacts of selected international strategies to reduce greenhouse gas emissions

- analysis and modeling of hazardous waste transport and fate in soil, water (both fresh and marine), air, and biota

- measurements and mass balance determinations to assess sources and sinks of polychlorinated biphenyls in Lake Michigan

- research, evaluation, testing, development, and demonstrations of alternative or innovative hazardous waste treatment and radon mitigation technologies 
- measurement and analysis of the effects of toxic and hazardous chemicals on terrestrial and aquatic ecological systems, including the marine environment

- modeling the formation, transport, and impacts of acid rain and evaluation of strategies to control it.

The Laboratory is also conducting research to investigate the causes and effects of global climate change, and we expect that the EPA will continue support for such research in the Global Climate Research Program. The Laboratory is also involved in measuring and assessing the impacts of pollutants on ecosystems including the Arctic, Great Lakes, the Everglades, and Northwest watersheds. Laboratory researchers provide technical support to the Environmental Monitoring and Assessment Program by assisting in the design of studies to estimate the current status, extent, changes, and trends in indicators of the condition of the nation's ecological resources on a regional basis. We also provide technical support to the EPA's Ocean Disposal Program by conducting bioassays related to disposal area siting projects. PNNL also is developing and demonstrating methodologies and technologies to understand and mitigate risks associated with hazardous materials. Recent concerns of the EPA are the effects of contaminants on the reproductive health of humans and other mammals.

\section{Other Federal Agencies and Nonfederal}

Several other federal agencies fund work at the Laboratory. They include the Bureau of Reclamation, National Institute of Standards and Technology, Federal Aviation Administration, Department of State, National Institute for Occupational Safety \& Health, Bureau of Land Management, and the United States Customs Service.

The Laboratory's work for nonfederal organizations (i.e., local governmental and commercial entities) under the 1830 operating contract was $\$ 1$ million is FY 1997 and is expected to be less than \$1 million in FY 1998. 


\section{Operations/Infrastructure Strategic Plan}

\section{Human Resources}

The Pacific Northwest National Laboratory Human Resources strategy is designed to support the Laboratory's goals to foster the creation of knowledge in our core competencies and to deliver related products to serve high value client needs. This support is composed of three primary strategies:

1. the creation of a supportive work environment through improvements in the quality of work life

2. alignment of PNNL human resource management systems with the customer service model and with related systems at Battelle Memorial Institute

3. the continued improvement of human resource management processes and operations to better and effectively serve the needs of the Laboratory, the Divisions and Directorates, and the staff.

The Human Resources Directorate supports these strategies by developing and implementing programs, policies, and processes to enable the Laboratory to hire, develop, and reward a highly qualified and diverse staff within the guidelines of federal and local laws and normal business practices. The delivery of these strategies and support is achieved through a decentralized, distributed Human Resource Manager network with assistance from several Human Resource core services. The Directorate also provides consultation and advice to management in leading and managing the Laboratory's human assets as well as acting as an advocate for all staff in representing their needs and interests in the quality of work life at the Laboratory.

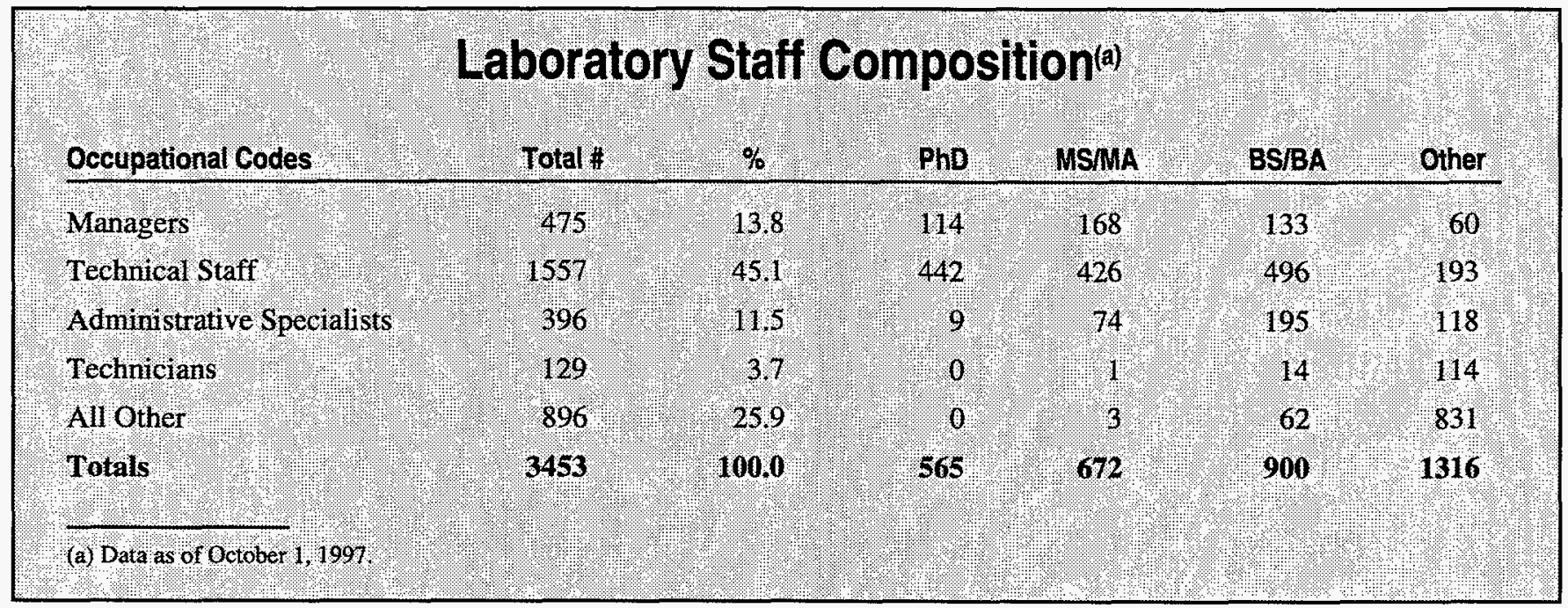

\section{Environment, Safety and Health Management}

The Environment, Safety and Health Program supports PNNL's aspiration to be the Department of Energy's premier environmental science and technology laboratory. In order to accomplish this, excellence in environment, safety and health (ES\&H) protection within our operations must be achieved. PNNL's ES\&H organization and our management systems provide the highest quality, most cost-effective products and services in support of PNNL's mission to fully satisfy our customers.

\section{Goals and Objectives}

PNNL established six critical outcomes, of which one is ES\&H/Operations. This Critical Outcome states: "Battelle will conduct all work and operate Laboratory facilities with distinction, fully supportive of and integrated with the Laboratory's science and technology mission and fully protective of workers, the public, and the environment."

This Critical Outcome is supported by four objectives and underlying performance indicators. These objectives and performance indicators were negotiated with and agreed to by DOE-RL (Richland Operations Office), prior to inclusion 
in the Appraisal Plan and the operating contract. They also provide the vehicle for PNNL to communicate its strategic ES\&H goals to all staff and incorporate appropriate performance indicators into work plans and individual staff goals.

\section{Philosophy and Approach}

ES\&H activities are an integral part of the work conducted by PNNL. A set of integrated management systems ensures that the work is accomplished in a safe and environmentally sound manner by a careful application of controls tailored to the work being performed. The philosophy behind the Integrated Environment, Safety and Health Management System (IES\&HMS) is to integrate ES\&H activities into the work rather than attempting to superimpose ES\&H requirements onto the work. Benefits include a more competitive cost structure, shorter research and development cycle times with fewer ES\&H surprises, and an exceptional ES\&H program that demonstrates the Laboratory's expertise.

All work conducted within PNNL has potential ES\&H hazards and risks. Managers responsible for the work are required to understand the hazards associated with the work being performed and ensure appropriate mitigation strategies are used to control the risks. A broad spectrum of technical support, such as field-deployed ES\&H technical experts and efficient management systems are available to assist managers in meeting their responsibilities.

The Laboratory has instituted a "core service" and "purchased service" model. Core services are those services funded out of Laboratory-level overheads to provide services to the entire Laboratory. Purchased services are those that are funded out of resources managed by the purchaser, such as project funds or organizational overhead. Much of the Environment, Safety and Health organization is operated as a purchased service provider. The ES\&H services are designed to provide managers with the specific resources needed by their business to carry out their activities, and to meet their ES\&H responsibilities in an efficient and effective manner. Our intent is to provide project managers and line organizations with the maximum possible control over their costs while at the same time ensuring operations are carried out in a safe, compliant, and environmentally sound manner.

\section{Pacific Northwest Improvement Initiatives}

PNNL's Laboratory Director initiated the Operations Improvement Program (OIP) in November 1994. The Operations Improvement Program specifically identified ES\&H, Conduct of Operations, and training and qualifications, as well as several related support systems as key initiatives for improvement. The objective of the OIP is to implement organizational structures with clear roles, responsibilities, accountabilities, and authorities that are supported by efficient management systems and excellent technical support service personnel, resulting in sustainable operational excellence. From its inception, OIP has been a joint effort between
PNNL and DOE to proactively and systematically implement the infrastructure tools to make the Laboratory safer and more efficient.

At the end of FY 1997, the improvement initiatives of the OIP were completed enabling a fully functional, effective, and efficient set of management systems. These management systems include self-assessment to identify opportunities for continuous improvement as a key element of our integrated approach to ES\&H. The FY 1997 initiatives included the following:

- resolution of significant legacy waste and operational waste management program/system weaknesses via a strategic, change-controlled special project in place under the ES\&H Directorate

- completion of implementation of a new Laboratory-wide Integrated Assessment Program in FY 1997. This includes the Laboratory-level and key division/directorate-level self-assessment programs and a fully functional Independent Oversight Program.

- demonstration of effective Conduct of Operations implementation.

\section{Current Status}

PNNL continued to make significant improvements. DOERL's performance appraisal of PNNL was an overall rating of "excellent." Our performance was measured using a set of mutually agreed upon Critical Outcomes. In the areas of ES\&H and Conduct of Operations, our performance with respect to worker health and safety, environmental protection, and operational discipline was strong, earning us an overall rating of excellent. The Laboratory will continue to move forward to achieve a highly efficient, "best-in-class" status among its national and international peers in the next three to four years.

\section{Issues}

- Surveillance and Maintenance of ER Facilities. PNNL is in the process of closing underutilized and uneconomic facilities for which ER is the landlord. Surveillance and minimum maintenance activities for these facilities must be performed to prevent deterioration of the facilities and to ensure control of safety hazards such as roof or floor failures, animal or insect infestation, and weather damage. This includes radiological surveillance of radiologically contaminated facilities as required by 10 CFR 835 , and appropriate controls for other hazardous materials such as asbestos, PCBs, etc.

- Configuration Management. One of PNNL's highest priorities is completion of its configuration management and labeling program. Identification and labeling of equipment and systems enhances our ability to prioritize investments and minimize risk to staff and the environment. Available indirect and direct funding does not ensure fully 
functional and safe building systems. Without additional capital investments, aging and use will drive the closure of strategic buildings to ensure the safety of staff.

- Price Anderson Amendments Act Program (PAAA). Because PNNL manages and conducts nuclear activities, it is subject to the requirements of the PAAA. We have responded to these requirements by appointing a Price Anderson Coordinator. Significant progress has been made in the last six months by providing funding for a PAAA Program and processes. The current process results in accurate identification of the majority and all significant PAAA related noncompliances. At present, however, there are insufficient resources for an exhaustive review of all available information that might trigger PAAA reporting requirements. Failure to completely implement these requirements could result in facility shutdown with resulting impacts on project schedules. Without this added capability, nuclear safety deficiencies identified cannot be fully reviewed for potential inadequacies of a systematic and programmatic nature.

- Targeted Occupational Medical Examinations. Hazardbased medical monitoring must be conducted for employees. A process to identify the appropriate type of medical exam based on hazards associated with each job and potential exposures of individuals is partially implemented. Currently, this process has been applied for those staff at highest risk of exposure (i.e., those working with carcinogens, OSHA regulated chemicals, and craft workers). The process should be extended to all staff members to ensure that only those medical exams necessary are being conducted and to provide information for return-to-work evaluations.

\section{Emerging Issues}

The most significant emerging issue that is currently unfunded is the development of the Environmental Radiological Protection Plan (ERPP) and procedures for 10 CFR 834. Once 10 CFR 834 is issued, the ERPP and procedures necessary to support implementation of 10 CFR 834 must be developed. Final verification of implementation is also necessary. The regulation is expected in the second half of FY 1997 with full implementation required 18 months later. PNNL has sought funding sources to support this effort, but no funding has been secured to date due to higher priorities and repeated delays in issuing the rule.

\section{Environmental Management Funded Activities}

A systematic approach is being used to manage and operate PNNL's environmental compliance and waste management systems. Numerous activities of vital importance to all phases of environmental compliance and waste management are currently being funded by DOE-Environmental Management. Activities include the following:

- minimum safe surveillance and maintenance of Hanford facilities for which DOE-EM is assigned landlord responsibilities
- waste management and operational services that support compliant management of waste generated from the work we currently perform

- effluent management program that ensures compliance with airborne and liquid release limits

- environmental technical support services that provide subject matter expertise to ensure we operate within the regulatory requirements imposed by federal, state, and local agencies.

In addition, the Public Safety and Resource Protection Program provides environmental monitoring in and around the Hanford Site to help assess health and safety impacts to workers and the public. Program activities are aimed at monitoring and tracking the movement of radioactive materials through environmental pathways leading to potential human exposures. The program monitors radioactive contamination in air, vegetation, wildlife, and the Columbia River. Environmental reports are issued annually that assess radiation exposures and estimate doses to people. PNNL's meteorological and climatological services provide localized weather forecasting and information that primarily supports Hanford emergency management activities and is also useful to numerous site organizations for conducting routine operations (e.g., tank farms, well drilling, construction) in a safe manner.

The ES\&H risks not addressed within the current projected EM budget include certain compliance and support activities including the following:

- Conducting certain pollution prevention activities including recycling/chemical exchange, affirmative procurement, employee involvement, return-on-investment implementation, alternative vehicles, Lab-wide systems support, performance indicators/goals development and tracking, and data collection improvements. Funding for these activities will be sought from alternative sources.

- Performing certain RCRA Hazardous Waste and other regulatory activities including regulatory analyses, subject matter expert support to environmental compliance representatives, site-wide issue coordination, and limited support to the 305-B and 325 high-level waste treatment units for meetings with regulators to discuss issues and conduct of compliance inspections.

The potential risk associated with noncompliance increases with this diminished technical support. PNNL remains committed to working with DOE-RL to establish a mechanism for direct recovery of waste management and associated costs and a stable level of funding to meet our needs.

\section{Conclusion}

The redesign of PNNL's ES\&H program has had a significant impact on the way we deliver ES\&H services and allowed the overall ES\&H budget to be reduced while improving protection of the environment and the safety and 
health of the workers and the public. Our ES\&H program is focused on integrating ES\&H into the planning and design of work resulting in improved performance as evidenced by fewer accidents and incidents, reductions of injuries and illnesses, better control of hazards, and improved compliance with environmental regulations. We have accomplished this by providing managers and staff with the technical resources in ES\&H that they need to meet their responsibilities. This approach has allowed PNNL to control and reduce risk even during difficult budget times. By incorporating performancebased incentives into our contract, management has shown the commitment to improve ES\&H performance. The ES\&H program is focused on delivering value-added services and eliminating activities that do not provide the benefit of protection of the environment and safety and health of workers and the public.

\section{Site and Facilities}

Pacific Northwest National Laboratory serves as one of five DOE multiprogram energy research laboratories and as the research and development center for the Hanford Site. Because of this dual role, the Hanford Site Landlord Program, under the Assistant Secretary for Environmental Management, is responsible for general purpose facilities and equipment primarily supporting Hanford Site mission activities. The Multiprogram Energy Laboratories-Facilities Support (MEL-FS) Program, under the purview of the Office of Energy Research, is responsible for multiprogram facilities and equipment.

The Laboratory consists of a collection of buildings containing 195,000 square meters ( 2.09 million square feet) with assigned responsibility as follows:

- DOE-owned facilities 97,000 square meters (1.04 million square feet)

- Battelle-owned facilities 45,000 square meters (0.49 million square feet)

- DOE-leased facilities 10,000 square meters ( 0.10 million square feet)

- Battelle-leased facilities 43,000 square meters ( 0.46 million square feet).

Through formal arrangement with DOE, these facilities make up the Consolidated Laboratory and are used by over 3,400 employees to perform work for DOE, other federal agencies, and private industry.

\section{DOE-Owned Buildings Managed by PNNL}

The graphics and remaining text focus on the $84 \mathrm{DOE}-$ owned buildings that are managed by PNNL.

The information contained in the table entitled, Laboratory Space Distribution, illustrates that the Laboratory's DOE facilities are located primarily in two areas. Most DOEowned facilities are located in the south end of the Hanford
Site's 300 Area. The 300 Area occupies approximately 4 square kilometers (1.5 square miles or 960 acres) in the southeastern portion of the Hanford Site, along the west bank of the Columbia River. DOE-leased facilities are located south of the 300 Area and adjacent to the Battelle private facilities in the Richland North Research Complex. The other DOE-owned facilities are located in different operating areas on the Hanford Site. PNNL, as well as other 300 Area occupants, interface with the Hanford Site Infrastructure Contractor to obtain utility and site infrastructure services.

The graph entitled Laboratory Area and Age Distribution illustrates that 35 of the Laboratory's 52 active DOE-owned facilities are over 20 years old, with 24 of those over 30 years old. The average age of the 52 active DOE-owned buildings is 30 years. Only 19,000 square meters $(0.2$ million square feet) of the total 85,000 square meters $(0.92$ million square feet) of active DOE-owned facilities are less than 10 years old. Currently, there are 32 vacant, surplus buildings, 12,000 square meters $(0.13$ million square feet), in "cheap to keep" status awaiting transfer to other contractors in accordance with the Hanford Excess Facility Management Plan.

As shown on the Condition of Laboratory Space by Functional Unit chart, the research and development space type, 70,000 square meters $(0.76$ million square feet), is by far the predominant space type within the PNNL operated, DOEowned space.

Included in this category are laboratories (nuclear and nonnuclear) for chemistry, materials, environmental and biological research, computation, electrical/electronics, applied physics, and general purpose research. The remaining functional types of space include administrative, service, storage, and other. The Laboratory's facilities inventory includes a collection of other structures such as meteorological towers. In general, the condition of these structures is considered adequate. The figure also illustrates that the general condition of all space is 36 percent adequate, 19 percent minor rehab required, and 45 percent requiring major rehab modifications.

The Facilities Replacement Value chart summarizes the replacement value of the Laboratory's buildings and the capital funded contents. The FY 1997 data comes from the Richland Property System, a site-wide computerized inventory of DOE's property holdings. The replacement value of $\$ 300$ million for building structures is due to the extensive array of research, engineering, and computational laboratories operated by the Laboratory.

\section{Facilities Plans and Options}

The facility strategy supports PNNL's intent to provide the nation with the greatest possible research product for each dollar invested and to achieve focused, strategic growth. PNNL's proposed facility investments demonstrate a high return on investment by extending the useful life of strategic laboratories, lowering facility management costs, providing uninterrupted safe operations, and optimizing the use of Laboratory space. 


\begin{tabular}{|lcc|}
\hline \multicolumn{3}{|c|}{ FY 1997 Laboratory Space Distribution } \\
Location & $\begin{array}{c}\text { Square Feet } \\
\text { (million) }\end{array}$ & $\begin{array}{c}\text { Area } \\
\text { Square Meters } \\
\text { (million) }\end{array}$ \\
\hline Main Site (300 Area) & 0.78 & 0.072 \\
Leased & 0.09 & 0.008 \\
All Other & 0.16 & 0.001 \\
Total & 1.03 & 0.081 \\
\hline
\end{tabular}

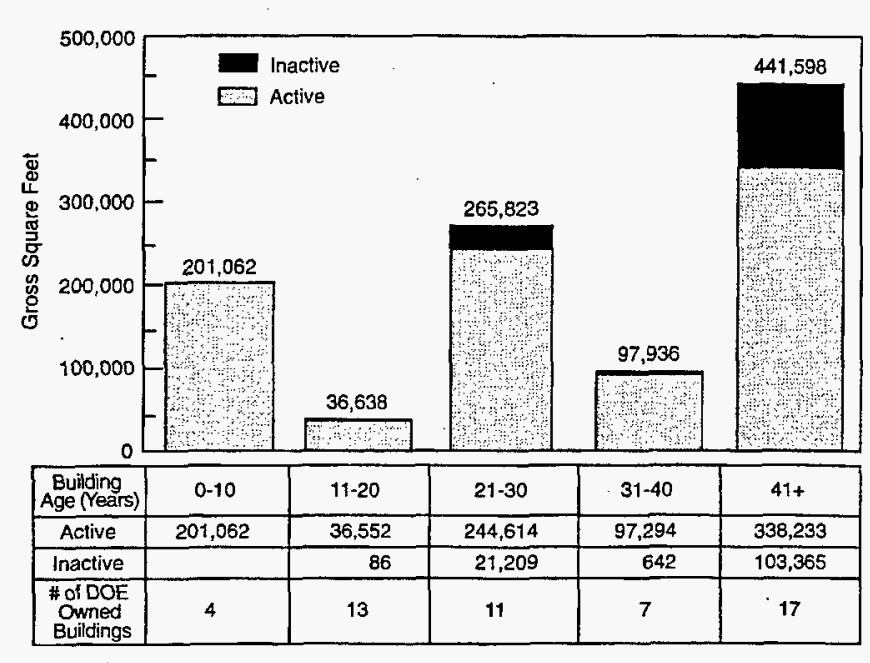

Laboratory area and age distribution.

This strategy assumes PNNL will be part of a successful Hanford Site transition to a post-cleanup era. In this era, wellmaintained Hanford facilities with unique capabilities will be interlinked with expanded private research facilities. The Tri-Cities Science and Technology Park remains the means to this end by integrating local basic science, applied research, and technology application capabilities. The park's newest assets are the Environmental Molecular Sciences Laboratory and the Consolidated Information Center.

\section{General Purpose Facilities Plans}

All PNNL facilities are considered general purpose-i.e., the facilities and equipment are used by two or more DOE programs. The facility consolidation effort started in 1995 is scheduled for completion in the year 2002. This will place over 42 surplus buildings into a "cheap to keep" mode. In conjunction with consolidation efforts, PNNL has partnered with DOE and other site contractors in the first Energy Savings Performance Contract. This contract sizes the 300 Area utility infrastructure for post-cleanup and updates building systems with energy-efficient components.

PNNL continues its aggressive building maintenance program with an emphasis on preventive maintenance. Postconsolidation line items and general purpose projects will effectively maintain the infrastructure and optimize the space within eight critical DOE facilities. Those facilities include buildings $320,325,326,329,331,337,338$, and 3760 . Designs for laboratory renewal will allow collaboration between research staff through shared equipment and laboratory space. The movement away from laboratory rooms assigned to a single researcher will allow for programmatic growth within existing facilities.

General Purpose Equipment investments will support nonprogrammatic equipment for functions such as safety, information systems, security, maintenance, and other support services. The addition of the EMSL facility will increase pressure on the limited general purpose equipment funding.

\section{Inactive Surplus Facilities Plan}

PNNL currently has 32 inactive surplus facilities. At the completion of the facility consolidation project, there will be a total of 42 inactive surplus facilities. All surplus facilities are general purpose.

Of the 42 inactive surplus facilities, 9 Energy Research and 3 Environmental Management facilities are contaminated, and 27 Energy Research and 3 Environmental Management facilities are not contaminated. Contamination in surplus facilities is the result of defense activities related to fuel processing and production prior to 1971 . The estimated annual surveillance and maintenance budget for the 42 surplus facilities is $\$ 90,000$. The cost of final disposition for the clean and slightly contaminated facilities is estimated at $\$ 5.05$ million, and the cost for the moderately to highly contaminated facilities is yet to be determined. Alternatives to demolition are being sought for surplus facilities in good condition. This includes leasing them to private entities.

The Hanford Excess Facility Management Plan assigns decommissioning and demolition responsibilities for all 300 Area buildings to one contractor. This allows a contractor experienced in decommissioning and demolition to package individual cleanup activities together in the most costeffective manner. Funding and resolution of the secretary program office responsibilities for decommissioning and decontamination of surplus facilities is required for the plan to be implemented.

\section{Facilities Resource Requirements}

The Laboratory's capital facility requirements, as currently authorized and projected, are summarized in the major construction project table. The program and funding profiles were developed to establish a balance between high-priority work and the realities of the current federal budget climate. A review of capital investments shows increases in inadequate facility square footage when the annual capital investment is $\$ 2$ million or less. Continuous years of $\$ 5$ million or more in capital investments will lead to a decrease in the inadequate space percentage. The Laboratory's project priority-setting process uses a DOE-developed prioritization methodology, the Capital Asset Management Process (CAMP). The deficiencies, purpose, and needs of each project are evaluated using guidance criteria given in one or more of four basic 


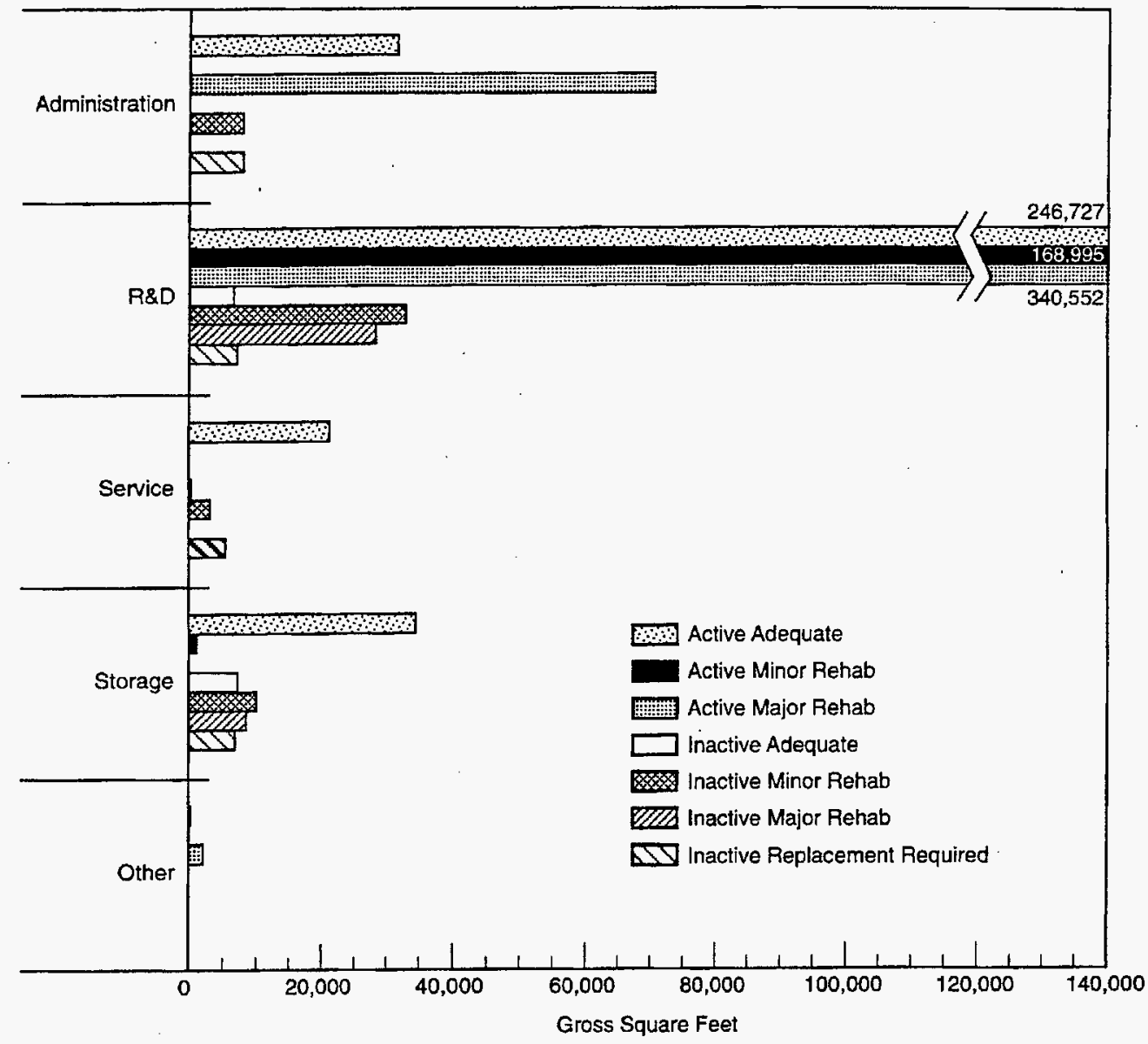

\begin{tabular}{|c|c|c|c|c|c|c|c|}
\hline & $\begin{array}{c}\text { Active } \\
\text { Adequate }\end{array}$ & $\begin{array}{l}\text { Active } \\
\text { Minor } \\
\text { Rehab }\end{array}$ & $\begin{array}{l}\text { Active } \\
\text { Major } \\
\text { Rehab }\end{array}$ & $\begin{array}{l}\text { Inactive } \\
\text { Adequate }\end{array}$ & $\begin{array}{l}\text { Inactive } \\
\text { Minor } \\
\text { Rehab }\end{array}$ & $\begin{array}{c}\text { Inactive } \\
\text { Major } \\
\text { Rehab }\end{array}$ & $\begin{array}{l}\text { Inactive } \\
\text { Replacement } \\
\text { Hequired }\end{array}$ \\
\hline $\begin{array}{l}\text { Administration } \\
\text { R\&D } \\
\text { Storage } \\
\text { Service } \\
\text { Other }\end{array}$ & $\begin{array}{r}31,617 \\
246,727 \\
34,641 \\
21,183 \\
400\end{array}$ & $\begin{array}{r}168,995 \\
1,013\end{array}$ & $\begin{array}{r}70,424 \\
340,552 \\
\\
2,203\end{array}$ & $\begin{array}{r}6,654 \\
7,337 \\
326\end{array}$ & $\begin{array}{r}8,030 \\
32,644 \\
10,194 \\
3,200\end{array}$ & $\begin{array}{r}28,192 \\
8,703\end{array}$ & $\begin{array}{l}8,030 \\
6,744 \\
5,248\end{array}$ \\
\hline Total & 334,568 & 170,008 & 413,179 & 14,317 & 54,068 & 36,895 & 20,022 \\
\hline
\end{tabular}

Condition of laboratory space by functional unit.

categories: Health and Safety, Environment and Waste Management, Safeguards and Security, and Mission and Investment. This prioritization methodology is the basic tool used to objectively aid the decision-making processes in weighing the relative importance of our facility improvement projects. Following are the funded, budgeted, and proposed projects.

\section{Electrical Safety Rehabilitation (95-E-303)}

This ES\&H-driven FY 1995 line item has a total estimated construction cost of $\$ 3.2$ million for replacing deteriorated wiring and outmoded equipment and eliminating unsafe

\begin{tabular}{|c|c|}
\hline \multicolumn{2}{|c|}{$\begin{array}{c}\text { Facilities Replacement } \\
\text { Value }\end{array}$} \\
\hline Facilities Type & $\begin{array}{l}\text { Replacement } \\
\text { in FY } 1996 \\
\$ \text { (millions) }\end{array}$ \\
\hline Buildings & 300 \\
\hline Building Contents & 49 \\
\hline Total & 349 \\
\hline
\end{tabular}




\title{
Major Construction Projects
}

(Budget Authorization \$ in Millions)

Total Est.

Const. Costs

1996

Fiscal Year

\section{FUNDED CONSTRUCTION \\ General Plant Projects}

General Plant Projects (Kr) ${ }^{(a)}$

General Plant Projects EM 60 (EW)

General Plant Projects EM 30

-

Multiprogram Energy Laboratories.

Facilities Support Program Projects (KG)

Multiprogram Laboratory Rehabilitation

Electrical Safety Rehabilitation

Program Related Projects

Environmental Molecular Sciences

Laboratory ER (KP)

Total Funded Construction

BUDGETED CONSTRUCHION

Multiprogram Energy l aboratories

Infrastructure Piping Replacement

General Plant Projects

General Plant Projects (KP)

Total Budgeted Construction

\section{PROPOSED CONSTRUCTION}

General Plant Projects

General Plant Projects (KP)

General Plant Projects EM 60 (EW)

Multiprogram Energy Laboratories:

Facilities Support Program Project (KC)

320 Building Rehabilitation ard Reconfiguration

Total Proposed Construction

Total Construction

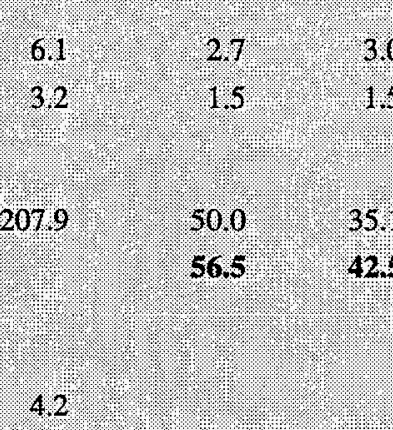

$2.1 \%$

12

1998

1999

2000

\author{
.
}

(a) Budget codes are identified in parentheses:

operating conditions in several key multiprogram laboratories. Actions include rehabilitation of emergency power building distribution systems, motor control centers, correcting wire/ raceway sizes, protecting equipment by installing additional circuit breakers, and grounding and bonding of electrical systems for safety purposes.

Affected buildings range from 20 to 40 years old and have electrical systems that are worn out and present a safety hazard. These improvements are required to provide building electrical systems that are safe, efficient, reliable, and maintainable. The existing electrical systems do not meet the
National Electrical Code for safe working clearances, separation of cables, and shock prevention.

\section{Multiprogram Laboratory Rehabilitation (95-E-310)}

This building rehabilitation and upgrade FY 1995 line item has a total estimated construction cost of $\$ 6.1$ million. The 331 Building, Life Sciences Laboratory, was designed to accommodate the care and use of large and small animals. Originally, the facility was dedicated to life span animal research. Experiments included exposure to chemical 
carcinogens and radiation. Current and planned laboratory needs call for cell biology, tissue, and general chemistry type laboratories to support new programs related to areas of molecular biology. This project will consolidate animal facilities on the first floor and replace the third floor small animal area with the necessary laboratories. The 331A Building, adjacent to the main 331 Building, is currently vacant and in relatively poor condition. The building cannot be effectively remodeled to suit any current or future research need and therefore will be demolished.

\section{Multiprogram Energy Laboratories Infrastructure Piping Replacement (99-E-XXX)}

This FY 1999 line item has a total estimated construction cost of $\$ 4.2$ million. This project will replace the water piping for three facilities $(326,331,337)$. The facilities are strategic assets of the Laboratory and require continued stewardship to maintain their value. Failed components and pipe sections are common occurrences which have disrupted operations and resulted in property loss. Inspections and analysis have confirmed deficient piping infrastructure.

\section{Building Rehabilitation and Reconfiguration (O0-E-XXX)}

This FY 2000 line item has a total estimated construction cost of $\$ 8.7$ million. The 320 Building is one of the core facilities of PNNL. The Laboratory's business strategy is to consolidate mass spectrometric capabilities into the 320 Building. The mission of the building remains basic research. The focus is on analytical research of low-level, ultra-trace radionuclear and chemical materials using optical and mass spectrometric equipment and procedures. The building's current condition cannot meet mission requirements because of aged systems. The condition has been confirmed by inspections and overviews of life-cycle analysis based on the nominal life expectancy of the building components. This project will replace building piping systems and major HVAC components. Interior modifications will address noncompliant life safety code issues, inefficient HVAC capacities and controls, and make the building compliant with $\mathrm{ADA}$ access and use codes. Technology updates will include the replacement of an inefficient and dated clean room capability and installation of components that will make the building system more energy efficient.

\section{Assets Management}

PNNL partners with DOE-RL to implement the principle of life-cycle asset management as outlined in DOE Order 430.1. A gap analysis identified the need for a more integrated set of documented asset management PNNL standards and guidelines, a masterful application of industry-based life cost analysis methodology, and a fully implemented set of metrics to drive continuous improvement. Through the standards based management system, self assessment program, and performance agreements with DOE-RL, PNNL is working toward filling these gaps.

In parallel, PNNL's integrated business planning process has formalized the planning links between programs and facilities. This includes representation on the Technical Council, a laboratory-level advisory body which evaluates the technical merit of proposed investments.

In 1995, the need to make large divestitures of facilities, equipment, and materials prompted the creation of the twoyear Facility Transition Project. This project acts upon strategic facility planning recommendations and carries out the vacating and closure of surplus facilities. The project team works with DOE-RL and other Hanford Site contractors to excess materials and equipment. Innovative methods are practiced to the benefit of DOE. Excess furniture is sold in place to landlords of terminated DOE leases eliminating relocation costs. DOE trailers are excessed and sold in place with the new owner assuming all removal costs. DOE-RL markets excess facilities to private industry as leased space. Finally, DOE-RL and the Hanford contractors have signed a 300 Area Excess Facility Management Plan. The plan puts the "best of class" contractor in charge of decommissioning and demolition activities for all 300 Area surplus facilities.

\section{Information Resources Management}

The Laboratory's Information Resources Management program exists for the sole purpose of supporting PNNL's missions in environment, science and technology, energy, and national security. The successful execution of these missions is significantly enabled by convenient, reliable, and effective access to scientific and administrative information, electronic communication resources, computational facilities, and user-oriented information services.

Pacific Northwest National Laboratory's overall information technology strategy is to maintain, enhance, and operate a world-class information technology infrastructure that directly and significantly contributes to the achievement of PNNL's mission-directed strategic goals. The success of this strategy will be marked by four major conditions that serve as the drivers for developing the Laboratory's information technology strategy.

- High Personal Productivity. All staff will enjoy a constantly increasing level of personal productivity by being proficient in the use of and having access to the information resources they need to perform their assigned scientific and/or business tasks.

- Effective Collaboration. Information technology is used to facilitate communications and project activity between staff, collaborators, customers, and suppliers.

- Access. Access to information, systems, and services will be available where and when the staff need them without regard to whether they are in their offices, laboratories, or somewhere else in the world. 
Information Management Resource Requirements

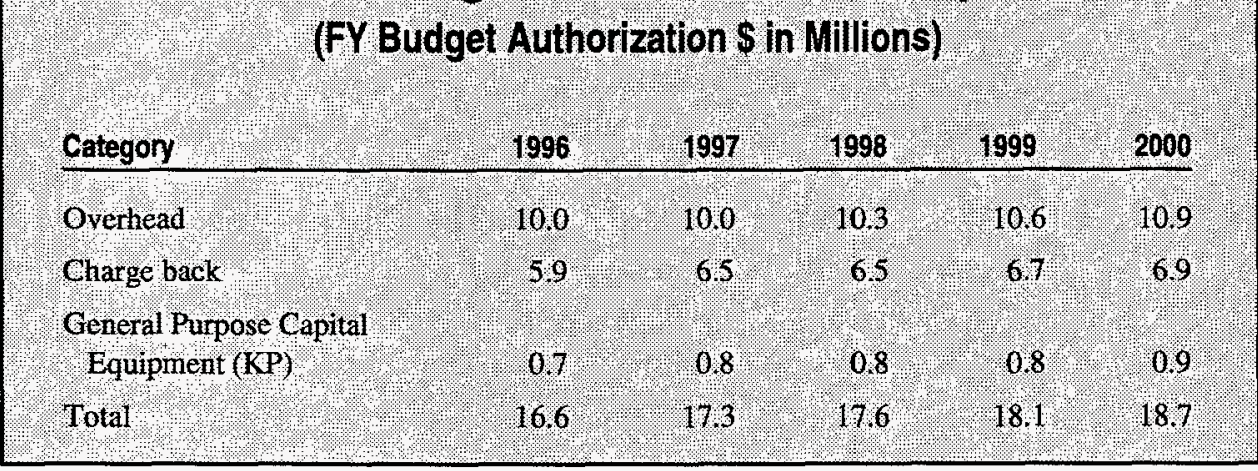

introduced in FY 1997 to provide less widely used software packages as an alternative to individual purchases.

Supercomputing is available on the high-performance IBM $\mathrm{RS} / 6000$ SPJ installed in the EMSL. The system, installed in FY 1996, was upgraded in FY 1997 to its full configuration of 472 processors, 62 Gbytes of memory and 2600 Gbytes of disk storage. The SP is augmented by a high-volume 20-terabyte EMASS archival storage system with multiple

SGI Challenge servers and a high-performance graphics and visualization laboratory. These hardware systems are complemented by a new generation of molecular modeling software for electronic structure and molecular dynamics calculations (NWChem) as well as the Extensible Computational Chemistry Environment (ECCE) for data management and visualization. A second IBM RS/6000 SP ${ }^{\circledR}$ with 128 processors, 22.5 Gbytes of memory, and 366 Gbytes of disk storage was installed at the end of FY 1997 to support the Northwest Alliance for Transportation Technology and will be used for advanced manufacturing and materials modeling and simulation. In addition, PNNL staff utilize over 400 highperformance UNIX-based workstations for a wide variety of modeling, simulation, and visualization applications.

\section{Strategies}

The Laboratory strategy for computing is described in the PNNL Information Technology Strategic Plan, September 1996, which is updated annually. The plan is structured in four parts:

1. The Fundamentals. Documents the overall information technology strategy for the Laboratory and a set of mission-oriented strategic goals. It also summarizes the drivers, planning assumptions, and major architectural principles.

2. Application and Data Architecture. Documents more specifically the objectives, technical approach, and road maps for deploying information systems to enhance the support of projects and the management of the Laboratory's business and assets.

3. Infrastructure Architecture. Contains the objectives, approach, and road maps for the PNNL computing and communications infrastructure, including information technology capabilities for enhancing personal and work group productivity.

4. Research Computing. This section is being developed and will document principles and plans concerning information technology in the conduct of Laboratory research and development activities. 
The network will evolve to higher speed with a transition to 100BaseT switched Ethernet and an ATM or Gigabit Ethernet backbone along with emphasis on increased reliability in recognition of the importance of the network to laboratory operations. The EMSL will continue to play a key role in advancing network technology which can then be migrated to the rest of the Laboratory.

In business computing, the Laboratory is addressing the year 2000 issue through a combination of replacing legacy systems and converting databases to year 2000 compliance. The transition from client-server to a more web-centric, browser based, environment which was initiated in FY 1996 will continue to be implemented.

With the selection of standards for operating systems, an office suite, and the development of a groupware architecture in FY 1996/97, the focus in desktop computing will be on increased functionality in joint authoring, work flow management, and electronic forms.

\section{Resources and Initiatives}

Resource requirements for direct programmatic research programs are included in program-specific sections of this document. Business information systems and most infrastructure investments are funded from general purpose and overhead accounts. In order to more effectively manage the Laboratory investment in computing, enterprise applications (e.g., payroll, human resources, etc.) and baseline infrastructure capabilities (i.e., those designed to be available to all staff) are funded as core services across the Laboratory. Organizational and/or functionally specific applications and services (i.e., not enterprise-wide) are separately funded (i.e., charged back) by the benefiting organization as valueadded components. Budgets for both classes of service are reviewed and approved by senior management as part of the annual budget planning and allocation process.

\section{Management Practices and Standards}

The Laboratory's management practices have been undergoing significant change since FY 1995 as a part of three major initiatives.

- Achieving the Competitive Edge (ACE). This initiative executed in FY 1995 to FY 1996 focused on productivity improvement by understanding the value of the work we do for our customers and subsequently addressing the cost of doing research and the quality of work life. Sustainable cost reductions of approximately $\$ 40$ million were captured as a result of fundamentally changing several management practices and systems.

- Operations Improvement Program (OIP). This initiative began in FY 1995 and continues through FY 1997. The operations improvement program focuses on improving ES\&H and operational performance by addressing a broad scope of issues including organizational constructs, operating standards, training and qualification, and key ES\&H-related systems and processes (for additional detail on this program, see the Environmental, Safety and Health Management section).

- Management Systems Redesign. This initiative began in FY 1996 and is scheduled to continue through FY 1997. Management systems redesign focuses on institutionalizing the total set of improvements initiated under ACE and OIP programs by creating a management systems infrastructure that provides for the ongoing configuration control and improvement in the Laboratory's management systems. This is accomplished by defining each of the Laboratory's management systems in a common processoriented format, checking for alignment with user's needs and DOE requirements, and integrating them to optimize effectiveness. A final step in this initiative will be to transition to an electronic documentation system.

The infrastructure and processes for controlling the Laboratory's management practices and standards are defined by the Standards-Based Management System. This system describes how the Laboratory identifies requirements and translates them into user-oriented information that describes management expectations and controls essential for the conduct of safe and quality work. Significant effort has been expended to ensure that the Laboratory's policies, standards, and procedures are internally consistent, streamlined to the degree possible, and supportive of research and development activities.

Our management systems must be continuously improved in order to meet the changing needs of the Laboratory and to continuously improve performance. Improvements to management systems are planned, monitored, evaluated, and implemented as described by the Integrated Assessment

\section{Management systems address the following key areas:}

Acquisition Management

Environnent, Safety, and Mealth

Human Resources

Intellectual Property

Quality Management
Business Development

Factities and Operations

Information Resources

Integrated Assessment

Standards Based Managenent
Communications

Financial Management

Integrated Planning

Project Management

Training and Qualification 


\section{FLC Award Winner}
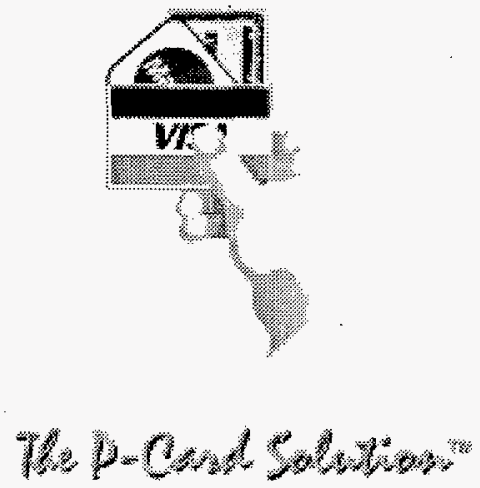

The remarkable new software-The P-Card Solution ${ }^{\mathrm{TM}}$ is saving time and money by automating and expediting the entire purchasing card process. This unique client/ server-based software package is being marketed through a new company, Credit Card Solutions, Inc. The firm was created after Pacific Northwest saved \$2 million in the first year of its purchasing card program. The team members recognized the potential the software they created holds for any organization utilizing purchasing cards. They convinced Pacific Northwest that they were "licensee" material, seized an opportunity to create a spin-off company, and competed successfully for a license to the software.

Management System. This system also defines the expectations and use of self-assessment, independent oversight, and peer review. These assessment methods are used in an integrated way to identify strengths and weaknesses across all dimensions of performance which lead to the implementation of improvement initiatives.

Key improvements have been made; systems described and baselined; and processes for ongoing control, monitoring, and improvement established. Future efforts will be focused on enhanced integration and performance improvement through the use of performance measurement and benchmarking.

\section{PNNL Efforts Toward Improved Cost Effectiveness and Continuous Improvement}

Beginning in late 1994 with a comprehensive, two-year initiative, Achieving the Competitive Edge, PNNL has been reducing overhead costs as well as increasing the value of each overhead dollar spent. These recent efforts have led to sustainable overhead cost reductions of approximately $\$ 40$ million (almost 20 percent) which has enabled the Laboratory to reduce costs passed onto customers as well as redirect overhead resources toward enhancing technical capabilities.

The current strategy is to build on this success by pursuing the following strategy over the next few years. First, the Laboratory is allocating resources at the management system level instead of the previous practice of allocating resources by organizational unit. In this way, we can hold management system owners accountable for performance for an entire process regardless of what organizational boundaries that process may cross. In addition, these management system owners are responsible for continuous improvement both within their management system and for the services provided by the system to the technical staff.

Second, utilizing information that comes from the Laboratory's Integrated Assessment Program, the senior leadership team focuses investment resources on a small number of critical, top-down initiatives that will significantly impact the Laboratory's high-level strategic objectives and associated performance measures. This small set of key initiatives is referred to as the Laboratory's "improvement agenda." Elements of the improvement agenda deal directly with cost effectiveness, as well as with improving safety performance, and quality of work life for staff.

\section{Communications and Trust}

Pacific Northwest National Laboratory is supporting DOE in its major priority of building trust through openness, timely communications, community involvement, and public awareness.

Effective external and internal communications help provide local, regional, and national support for DOE missions and increase the awareness of the Laboratory as a world-class science and technology organization.

The Laboratory's communications and trust initiative has six key features:

- Community Relations - The Laboratory is committed to involving and benefiting its local communities to ensure that DOE and the Laboratory advance the quality of life and remain valued assets to the Tri-Cities and Northwest region. This will be accomplished through continuous programs in community involvement, economic development, and education.

- Media Liaison - Open and timely communications with local, regional, and national media are crucial to building awareness of PNNL as a leading-edge organization and a premier environmental laboratory.

- Promotional Communications - Targeted Laboratory messages-on subjects such as the Laboratory's status as a premier environmental laboratory-to specific global and national audiences will develop increased awareness of PNNL and stimulate future projects and business as the Laboratory continues to grow and diversify.

- Speakers' Bureau - Local, regional, national, and international speaking appearances by science and technology leaders will reinforce the significance of DOE and Pacific Northwest National Laboratory programs.

- Technical and Electronic Communications - Sharing the results of major scientific and technological projects will help advance the quality of life and communicate the impact of national laboratory system breakthroughs. 
- Organizational Communications - Laboratory staff are the organization's best ambassadors - and well-informed staff are the best liaisons with the general public. The Laboratory will further broaden its array of internal communications mechanisms to guarantee that staff are well informed of new developments and future directions.

Today, a leading-edge laboratory cannot survive on scientific accomplishments alone. Its mission and accomplishments must be well understood and supported by a variety of publics-including local citizens, civic leaders, media, business and government leaders, and many others. Further, it must be valued as a technological and economic engine for local and regional growth and national achievement.

The continuing focus of the Pacific Northwest National Laboratory's communications and trust program is to continue to meet the needs of multiple publics and assure them of the Laboratory's presence in opening doors to a brighter future. 


\section{Resource Projections}

The resource requirements of research and development for Hanford Site support are included in the resource projections of the various funding programs. Research and development for other DOE sites at other DOE facilities; however, is shown as a separate program. The resource projections for FY 1997 are actual values.

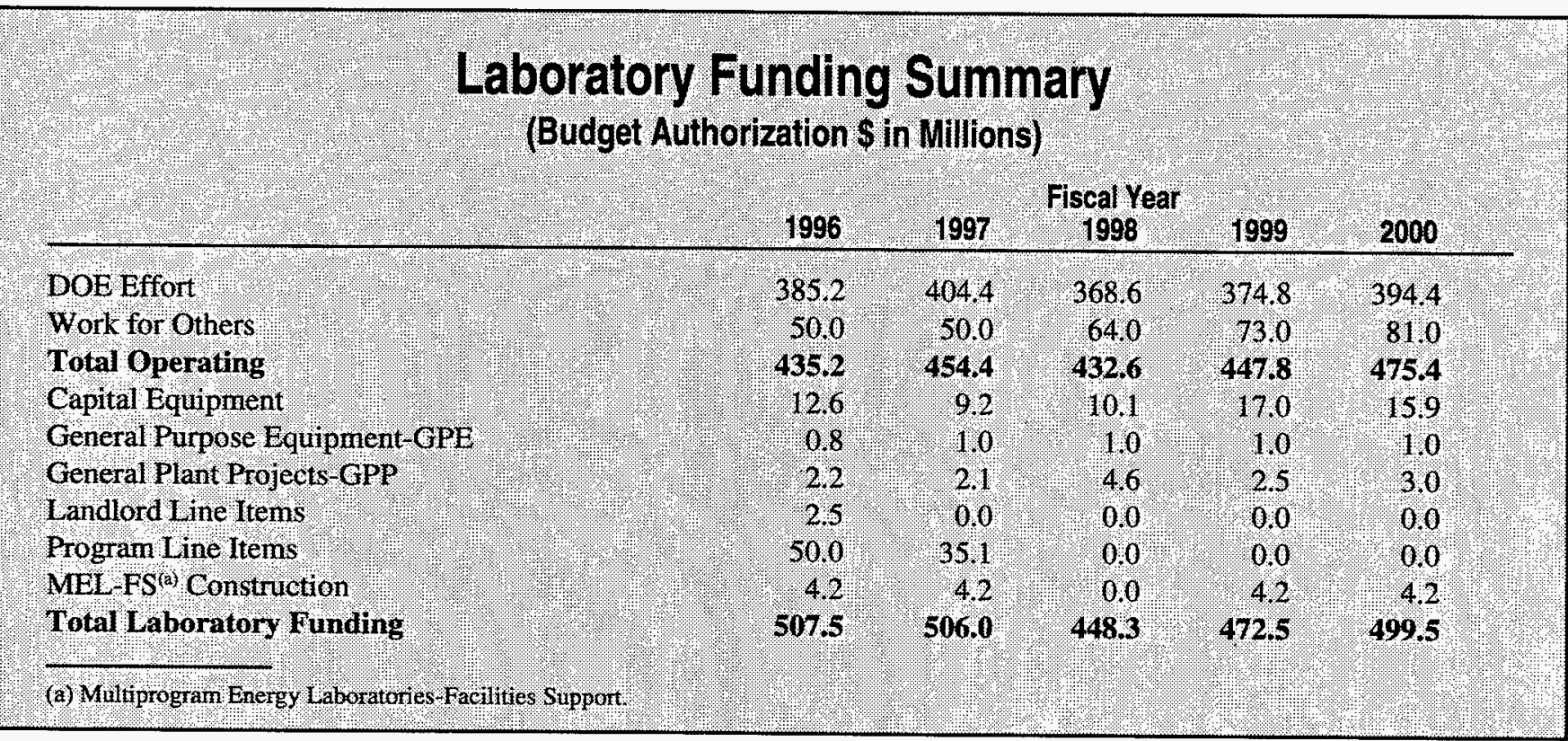

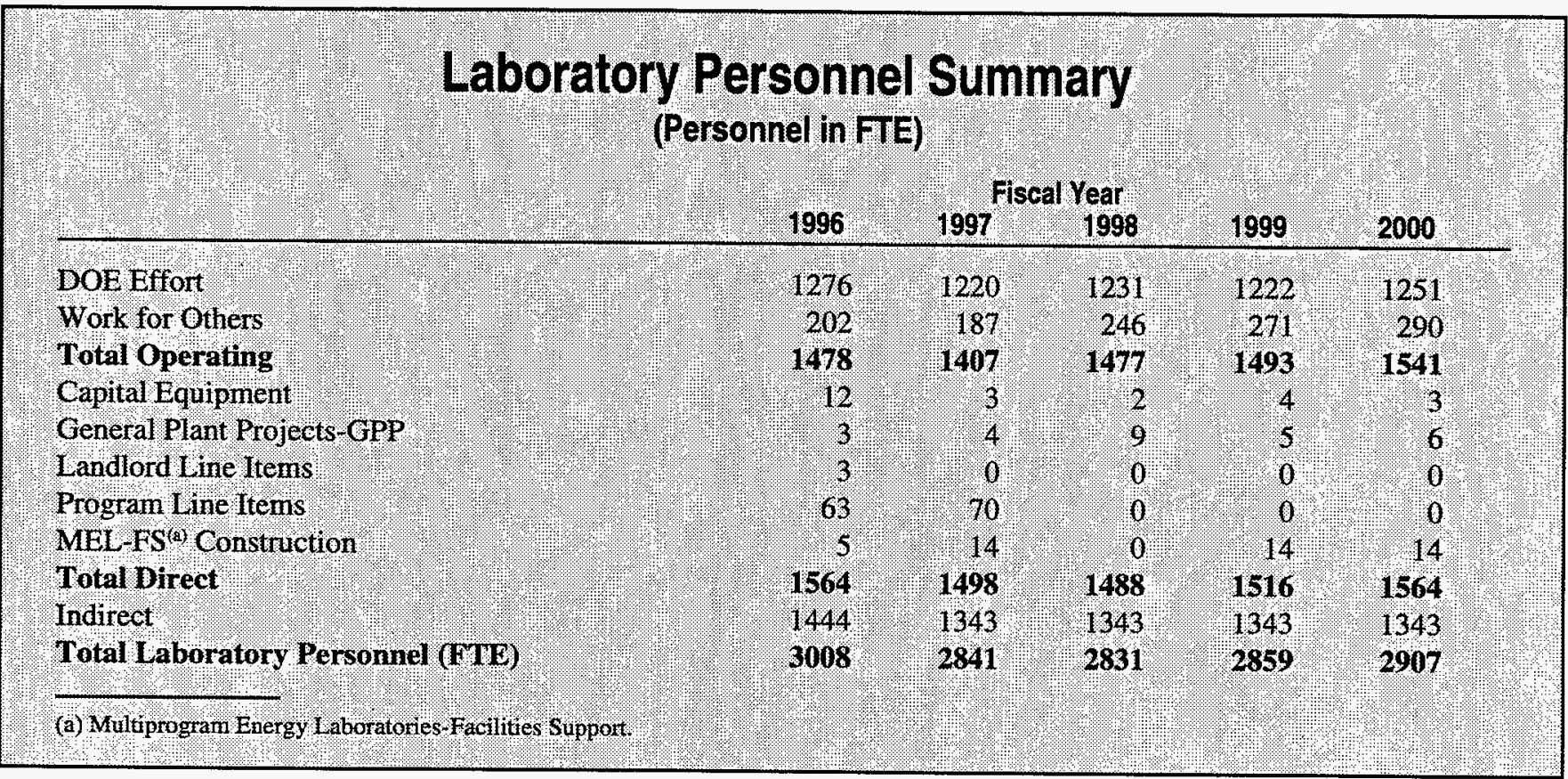




\section{Funding by Secretarial Officer}

(Budget Authorization \$ in Millions)

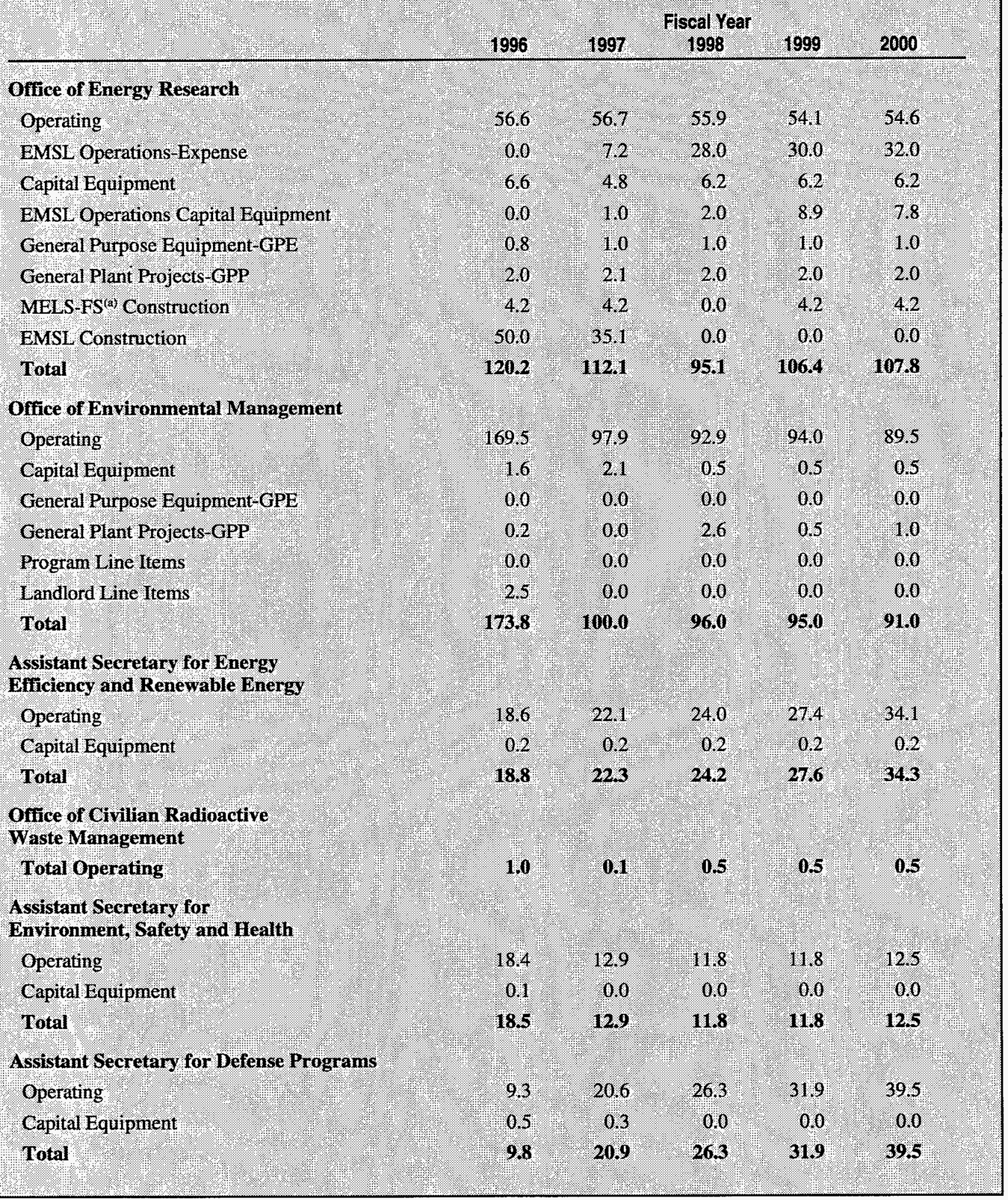




\section{Funding by Secretarial Officer (contd)}

\section{(Budget Authorization S in Millions)}

\begin{abstract}
Office of Science Education and Technical Information
\end{abstract}

Total Operating

Office of Nonproliferation and

National Security

Operating

Capital Equipment

Total

Assistant Secretary for

Nuclear Energy

Total Operating

Assistant Secretary for

Fossil Energy

Total Operating

Office of Policy

Total Operating

Other DOE Organizations

BPA

Total Operating

Other DOE Sites

Total Operating

Total DOE Programs

Operating

Capital Equipment

General Purpose Equipment-GPE

General Plant Projects-GPP

Landlord Line Items

Program Line Items

MEL-FS ${ }^{(a)}$ Construction

Total
1996

0.4

0.0

370

49.0

48.2

56.6

58.5

3.6

0.8

1.2

1.2

1.2

40.6

49.8

49.4

57.8

59.7

57.5

120.4

64.0

51.0

55.0

1.7

1.6

1.8

2.3

2.8

0.8

0.4

0.6

0.6

0.6

1.0

1.0

1.4

1.4

1.6

10

1.0

1.4

1.4

1.6

13.4

14.5

12.0

12.0

12.0

\begin{tabular}{|c|c|c|c|c|}
\hline 385.2 & 404.4 & 368.6 & 374.8 & 394.4 \\
\hline 12.6 & 9.2 & 10.1 & 17.0 & 15.9 \\
\hline 0.8 & 1.0 & 1.0 & 1.0 & 1.0 \\
\hline 2.2 & 2.1 & 4.6 & 2.5 & 30 \\
\hline 2.5 & 0.0 & 0.0 & 0.0 & 0.0 \\
\hline 50.0 & 35.1 & 0.0 & 0.0 & 0.0 \\
\hline 4.2 & 4.2 & 0.0 & 4.2 & 4.2 \\
\hline 457.5 & 456.0 & 384.3 & 399.5 & 418.5 \\
\hline
\end{tabular}




\section{Funding by Secretarial Officer (contd)}

\section{(Budget Authorization S in Millions)}

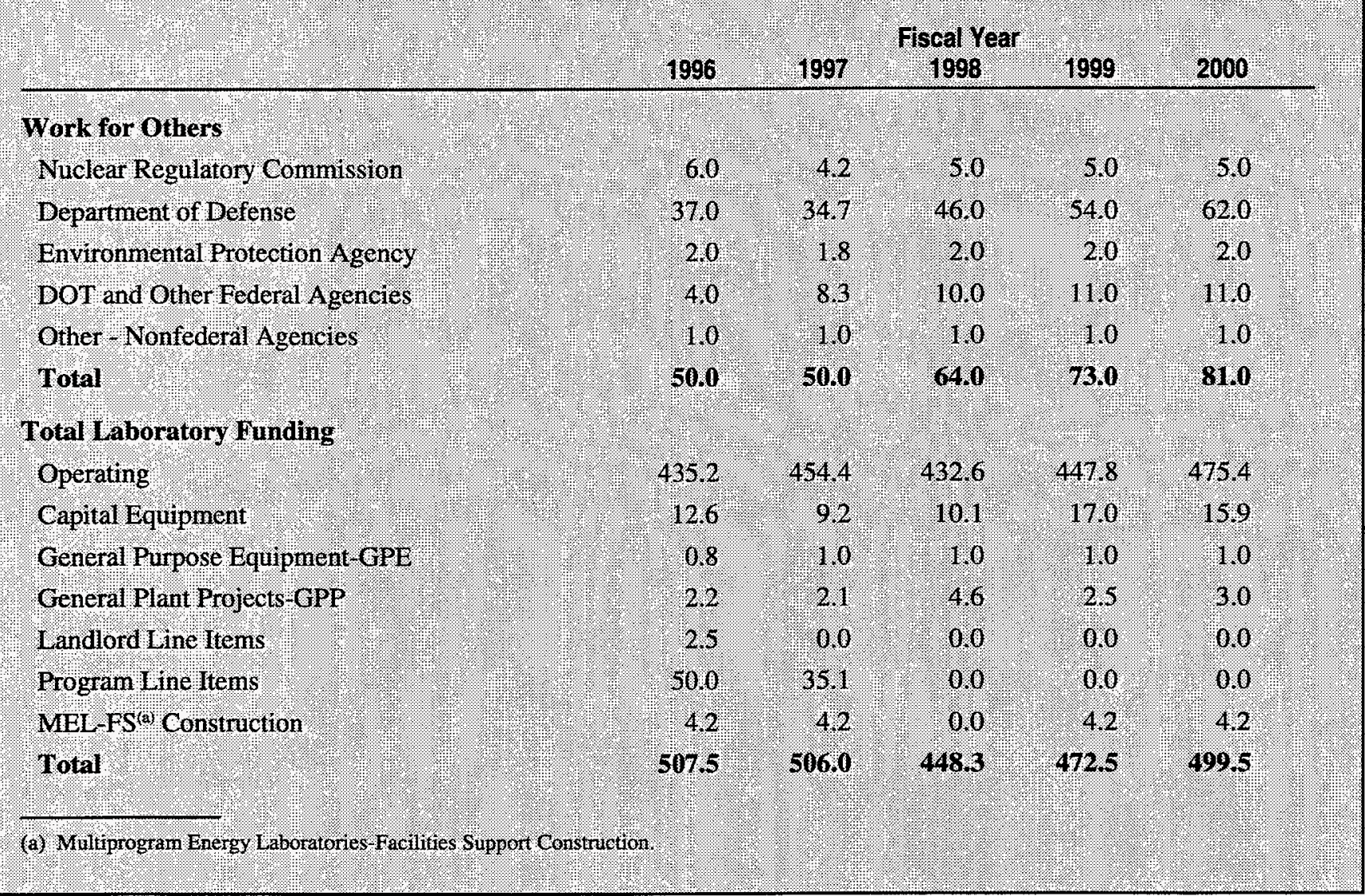




\section{Direct Personnel by Secretarial Officer}

(Personnel in FTE)

Office of Energy Research
Operating
Office of Environmental Management

Operating

620

Assistant Secretary for Energy

Efficiency and Renewable Energy

Operating

69

Office of Civilian Radioactive

Waste Management

Operating

Assistant Secretary for

Environment, Safety and Health

Operating

Assistant Secretary for

Defense Programs

Operating

34

4

68

48

82

92

102

122

Office of Science Education and Technical Information

Operating

Office of Nonproliferation and National Security

Operating

Assistant Secretary for

Nuclear Energy

Operating

195

182

185

210

210

Assistant Secretary for

Fossil Energy

Operating

Office of Policy

Operating
75

6

136

3
Fiscal Year

1998

1999

2000

310

78

2.

5

4

4

2

:




\section{Direct Personnel by Secretarial Officer (contd) \\ (Personnel in FTE)}

\section{Other DOE Organizations \\ Operating}

Other DOE Sites

Operating.

Total DOE Program

Work for Others

Nuclear Regulatory Commission

Department of Defense

Environmental Protection Agency

DOT and Other Federal Agencies

Other - Nonfederal Agencies

Total

\section{Laboratory Direct}

Operating

Capital Equipment

General Plant Projects-GPP

Landlord Line Items

Program Line Iterns

MEL-FS ${ }^{(n)}$ Construction

Total Laboratory Direct

Total Laboratory Indirect

Total Laboratory Personnel (FTE)

\section{6} 1997

Fiscal Year
4 .

49 .

1276

48

1220

1231

\section{0}

$$
24
$$

150

8

16.

4

202

1478

12
-3

. 3

63

5

1564

1444

3008

$$
16
$$

$$
129
$$

7

31

4

187

1407

. 3

?. 4

0

0
70

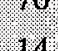

14

1498

1343

2841
37.

. 36

34

5

31

19

177

8

38 .

4

246

1477

2.

. 9.

. 0

. 0
. 0

4

1488

1343

2831
1493

1541

1222

1251

$19: 18$

$200: 222$

$17: 7$

41.39

$\begin{array}{l:l}4 & 4\end{array}$

271 : 290

$4: 3$

5 $: 0$

0. 0

0.0

14.14

$1516: 1564$

1343 . 1343

$2859: 2907$

(a) Multiprogram Energy Laboratories Faciltites Support 


\section{Resources by Major DOE Areas}

\section{(Budget Authorization \$ in Millions)}

\begin{tabular}{|c|c|c|c|c|c|}
\hline 2.0 .2 & 1996 & 1997 & $\begin{array}{c}\text { Fiscal Year } \\
1998\end{array}$ & 1999 & 2000 \\
\hline \multicolumn{6}{|l|}{ Office of Energy Research } \\
\hline Magnetic Fusion (AT) & 1.5 & 1.2 & 1.5 & 1.5 & \\
\hline High Energy Physics (KA) & 0.1 & 0.1 & 0.1 & 0.1 & \\
\hline Nuclear Physics (KB) & 0.1 & 0.0 & 00 & 0,0 & \\
\hline Basic Energy Sciences ( $\mathrm{KC}$ ) & 11.5 & 11.3 & 11.6 & 11.7 & 11 \\
\hline Biological/Environ Research Prog Dir (KR) & 0.0 & 0.0 & 0.0 & 0.0 & 0.0 \\
\hline Advisory and Oversight Program Dir (KF) & 0.1 & 0.0 & 0.0 & 0.0 & 0.0 \\
\hline ER Laboratory Technology Transfer (KU) & 3.4 & 4.8 & 4.5 & 5.8 & 5.8 \\
\hline Multiprogram Energy Laboratories (KG) & 0.5 & 0.0 & 0.2 & 0.2 & 0.2 \\
\hline Energy Research Analysis (KD) & 0.6 & 0.2 & 0.6 & 0.6 & 0.6 \\
\hline Biological and Environmental Research (KP & 38.8 & 39.1 & 37.4 & $34: 2$ & 34.6 \\
\hline EMSL Operations-Expense (KP - BER) & 0.0 & 72 & 28.0 & 30.0 & 32.0 \\
\hline Operating & 56.6 & 63.9 & 83.9 & 84.1 & 86.6 \\
\hline Capital Equipment (AT) & 0.0 & 00 & 0.1 & 0.1 & 0.1 \\
\hline Capital Equipment (KC) & 1.2 & 1.3 & 1.1. & 1.1 & 1.1 \\
\hline Capital Equipment (KP) & 5.4 & 3.5 & 5.0 & 5.0 & 5.0 \\
\hline EMSL Operations Capital (KP - BER) & 00 & 10 & 2.0 & 8.9 & 7.8 \\
\hline Capital Equipment & 6.6 & 5.8 & 8.2 & 15.1 & 14.0 \\
\hline General Putpose Equipment-GPE (KP) & 0.8 & 1.0 & 1.0 & 10 & 10 \\
\hline General Plant Projects-GPP (KP) & 2.0 & 21 & 2.0 & 2.0 & 2.0 \\
\hline Multiprogram Energy Laboratories (KG) & 4.2 & 4,2 & 0.0 & 4.2 & 4. \\
\hline Program Line ltem (EMSL) & 5040 & 35.1 & 0.0 & 0.0 & 0.0 \\
\hline Total Funding & 120.2 & 112.1 & 95.1 & 106.4 & 107.8 \\
\hline \multicolumn{6}{|l|}{ Direct Personnel } \\
\hline Operating & 206 & 237 & 322 & 311 & 310 \\
\hline Capital & 8 & 2 & 2 & 4.4 & 43 \\
\hline General Plant Projects-GPP & 3 & 4 & 4 & 4 & 4 \\
\hline Multiprogram Energy Laboratories (KG) & 5 & 14 & 0 & 14 & 14 \\
\hline Program Line Items & 63 & 70 & 0. & 0 & 0 \\
\hline Total Direct Personnel & 285 & 327 & 328 & 333 & 331 \\
\hline
\end{tabular}




\section{Resources by Major DOE Areas (contd)}

(Budget Authorization \$ in Millions)

\begin{tabular}{|c|c|c|c|c|c|}
\hline$x^{2}$ & 1996 & 1997 & $\begin{array}{c}\text { Fiscal Year } \\
1998\end{array}$ & 1999 & 2000 \\
\hline \multicolumn{6}{|c|}{ Office of Environmental Management } \\
\hline Technical Development (EW) & 23.5 & 28.2 & 20.0 & 21.0 & 18.0 \\
\hline Waste Management (EW) & 125.0 & 63.4 & 55.2 & 55.1 & 54.3 \\
\hline Waste Management (EX) & 120 & 2.5 & 1.1 & 1.0 & 0.0 \\
\hline Environmental Restoration (EW) & 9.0 & 3.8 & 16.6 & 16.9 & 172 \\
\hline Environmental Restoration (EX) & 0.0 & 0.0 & 0.0 & 0.0 & 0.0 \\
\hline Total Operating & 169.5 & 97.9 & 92.9 & 94.0 & 89.5 \\
\hline Capital Equipment (EW/EX) & 1.6 & 2.1 & 0.5 & 0.5 & 0.5 \\
\hline General Purpose Equipment-GPE & 0.0 & 0.0 & 0.0 & 0.0 & 0.0 \\
\hline General Plant Projects-GPP & 0.2 & 0.0 & 2.6 & 0.5 & 1.0 \\
\hline Program Line Items & 0.0 & 0.0 & 0.0 & 0.0 & 0.0 \\
\hline Landlord Line Items & 2.5 & 0.0 & 0.0 & 0.0 & 0.0 \\
\hline Total Funding & 173.8 & 100.0 & 96.0 & 95.0 & 91.0 \\
\hline \multicolumn{6}{|l|}{ Direct Personnel } \\
\hline Operating & 620 & 341 & 330 & 304 & 278 \\
\hline Capital Equipment & 2 & 1 & 0 & 0 & 0 \\
\hline General Plant Projects-GPP & 0 & 0 & 5 & 1 & 2 \\
\hline Program I ine Items & 0 & 0 & 0 & 0 & 0 \\
\hline Landlord Line Items & 3 & 0 & 0 & 0 & 0 \\
\hline Total Direct Personnel & 625 & 342 & 335 & 305 & 280 \\
\hline
\end{tabular}




\section{Resources by Major DOE Areas (contd)}

\section{(Budget Authorization \$ in Millions)}

1996

1997

Fiscal Year

1998

1999

2000

Assistant Secretary for Energy

Efficiency and Renewable Energy

Electric Energy Systems (AK)

\begin{tabular}{c|c|ccc}
0.9 & 0.0 & 0.0 & 0.0 & 0.0 \\
0.0 & 0.0 & 0.0 & 0.0 & 0.0 \\
0.0 & 0.0 & 0.0 & 0.0 & 0.0 \\
0.6 & 0.9 & 1.2 & 1.2 & 1.2 \\
11.0 & 8.2 & 7.1 & 7.4 & 7.7 \\
2.6 & 1.6 & 2.7 & 2.8 & 2.9 \\
2.0 & 4.9 & 9.1 & 11.9 & 18.0 \\
1.2 & 0.0 & 1.0 & 1.1 & 1.2 \\
0.1 & 0.0 & 0.1 & 0.2 & 0.3 \\
0.1 & 4.1 & 0.4 & 0.4 & 0.4 \\
0.0 & 2.4 & 2.4 & 2.4 & 2.4 \\
0.1 & 0.0 & 0.0 & 0.0 & 0.0 \\
18.6 & $\mathbf{2 2 . 1}$ & $\mathbf{2 4 . 0}$ & $\mathbf{2 7 . 4}$ & $\mathbf{3 4 . 1}$ \\
0.2 & 0.2 & 0.2 & 0.2 & 0.2 \\
$\mathbf{1 8 . 8}$ & $\mathbf{2 2 . 3}$ & $\mathbf{2 4 . 2}$ & $\mathbf{2 7 . 6}$ & $\mathbf{3 4 . 3}$ \\
69 & $\mathbf{8 2}$ & $\mathbf{9 2}$ & 102 & 122 \\
\hline
\end{tabular}

Energy Storage Systems (AL)

Geothermal Systems (AM)

Solar Energy (EB)

Buildings Sector (EC)

Industrial Energy Conservation (ED)

Transportation Sector (EE)

Tech and Financial Assistance (EF)

Utility Sector (EK)

Policy and Management (EH)

Federal Emergency Management (EU)

Policy and Management (KK04)

Operating

Capital Equipment

Total Funding

Direct Operating Personnel

69

0.5

0.1

0.3

0.3

0.3

Givilian Radioactive Waste R\&D (DC)

0.5

0.0

0.2

0.2

0.2

Total Funding

1.0

0.1

0.5

0.5

0.5

Direct Operating Personnel

2

2

2

Assistant Secretary for Environment,

\section{Safety and Health}

Environmental, Safety and Health (HA-01)

14.1

0.0

0.0

0.0

0.0

Program Direction (HA-04)

0.6

0.0

0.0

0.0

0.0

Envir, Safety and Health-Non Def (HC)

0.0

6.2

5.8

6.5

Envir, Safety and Health-Defense (HD)

0.0

6.7

6.0

5.8

6.0

Office of Security Evaluation (HS)

2.3

0.0

0.0

6.0

0.0

Nuclear Safety Oversight (NS)

1.2

0.0

0.0

0.0

0.0

Radiological Oversight (NR)

0.2

0.0

0.0

0.0

0.0

Operating

18.4

12.9

11.8

0.0

12.5

Capital Equipment (HA-01)

0.1

0.0

0.0

11.8

0.0

Capital Equipment (HS)

0.0

0.0

0.0

0.0

0.0

Total Funding

18.5

12.9

11.8

0.0

12.5

Direct Operating Personnel

68

48

45

11.8 


\section{Resources by Major DOE Areas (contd)}

(Budget Authorization \$ in Millions)

\begin{tabular}{|c|c|c|c|c|c|}
\hline 440 & 1996 & & $\begin{array}{l}\text { Fiscal Year } \\
1998\end{array}$ & 1999 & 2000 \\
\hline \multicolumn{6}{|l|}{ Assistant Secretary for Defense Programs } \\
\hline Materials Production (GE/DP) & 9.3 & 20.6 & 26.3 & 31.9 & 39.5 \\
\hline Operating & 9.3 & 20.6 & 26.3 & 31.9 & 39.5 \\
\hline Capital Equipment & 0.5 & 0.3 & 0.0 & 0.0 & 0.0 \\
\hline Total Funding & 98 & 20.9 & 26.3 & 31.9 & 39.5 \\
\hline Direct Operating Personnel & 34 & 76 & 101 & 118 & 142 \\
\hline \multicolumn{6}{|l|}{$\begin{array}{l}\text { Office of Science Education } \\
\text { and Technical Information }\end{array}$} \\
\hline University and Science Education (KT) & 0.4 & 0.0 & 1.2 & 12 & 1.2 \\
\hline Univ, and Science Education-Defense (KV) & 0.0 & 0.0 & 0.0 & 0.0 & 0.0 \\
\hline Total Funding & 0.4 & 0.0 & 1.2 & 1.2 & 1.2 \\
\hline Direct Operating Personnel & 2 & 0 & 5. & 4 & 4 \\
\hline \multicolumn{6}{|l|}{$\begin{array}{l}\text { Office of Nonproliferation and } \\
\text { National Security }\end{array}$} \\
\hline Emergency Management Division (GB0506) & 0.1 & 0.0 & 0.0 & 0.0 & 0.0 \\
\hline Verification and Control Technology (GC) & 15.3 & 13.7 & 15.1 & 17.8 & 18.5 \\
\hline Nuclear Safeguards and Security (GD) & 3.0 & 2.8 & 2.7 & 2.8 & 2.9 \\
\hline Expt Control, Nonprolif and Safeguards (GJ) & 14.1 & 26.3 & 242 & 28.7 & 29.6 \\
\hline Emergency Management (ND) & 0.0 & 0.4 & 0.4 & 0.4 & 0.4 \\
\hline Nonprolif and Nat'l Sec. Program (NN) & 0.0 & 0.6 & 0.0 & 0.0 & 0.0 \\
\hline Intelligence $(\mathrm{NT})$ & 4.5 & 5.2 & 58 & 6.9 & 7.1 \\
\hline Operating & 37.0 & 49.0 & 48.2 & 56.6 & 58.5 \\
\hline Capital Equipment (GC) & 1.2 & 0.8 & 1.2 & 1.2 & 1.2 \\
\hline Capital Equipment (GD) & 0.3 & 0.0 & 0.0 & 0.0 & 0.0 \\
\hline Capital Equipment (GJ) & 2.1 & 0.0 & 0.0 & 0.0 & 0.0 \\
\hline Total Funding & 40.6 & 49.8 & 49.4 & 57.8 & 59.7 \\
\hline \multicolumn{6}{|l|}{ Direct Personnel } \\
\hline Operating & 136 & 182 & 185 & 210 & 210 \\
\hline Capital Equipment & 2 & 0 & 0 & 0 & 0 \\
\hline Total Direct Personnel & 138 & 182 & 185 & 210 & 210 \\
\hline
\end{tabular}




\section{Resources by Major DOE Areas (contd)}

(Budget Authorization s in Millions)

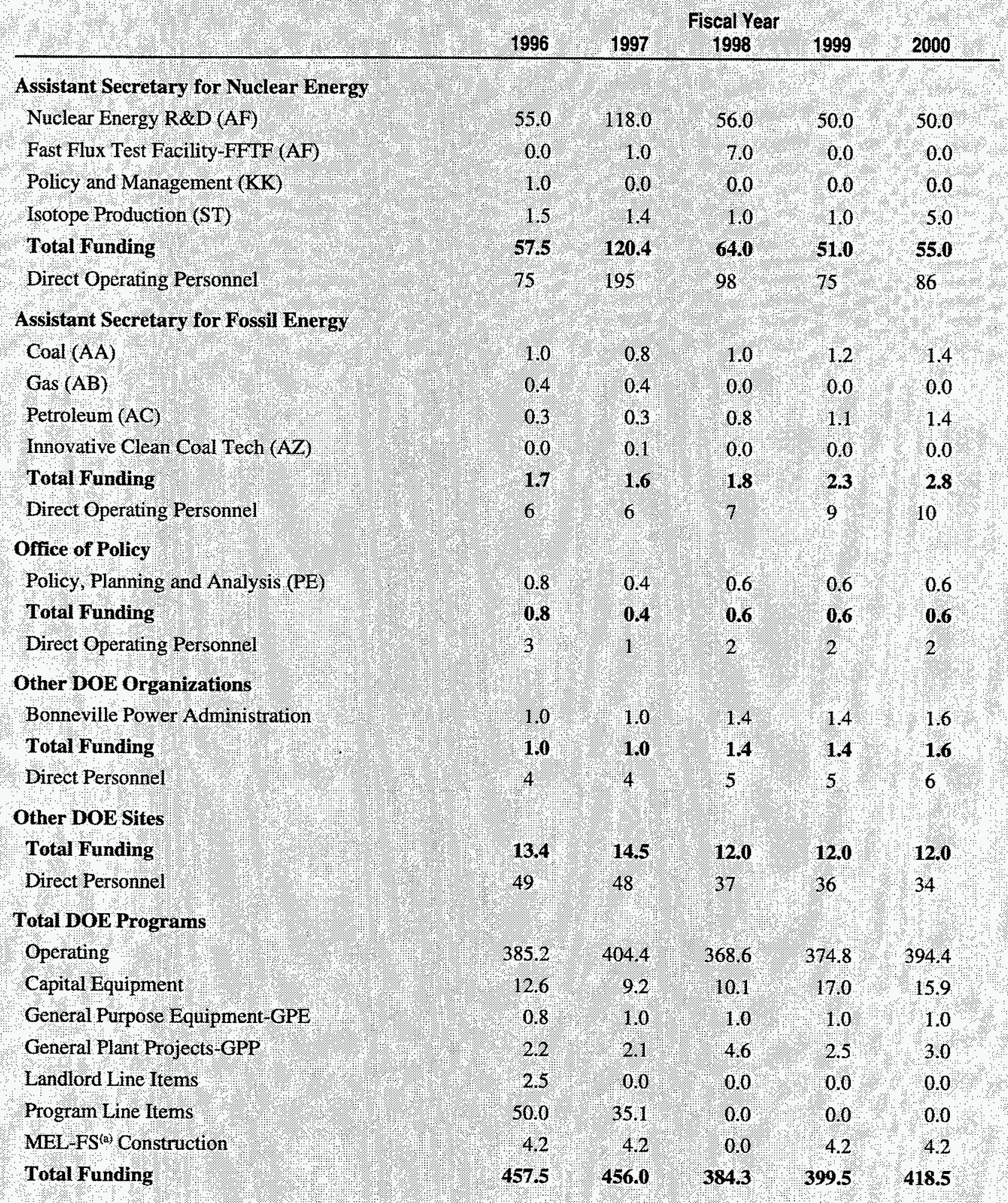




\section{Resources by Major DOE Areas (contd)}

(Budget Authorization \$ in Millions)

1996

1997

1998

1999

2000

Total DOE Programs (contd)

Direct Personnel

Operating

1276

1220

1231

1222

1251

Capital

General Plant Projects (GPP)

12

3

Landlord Line Iterns

- 3

Program Line Items

63

MEL-FS ${ }^{(a)}$ Construction

Total Direct Personnel

. 1.

1362

: 3

2

9

4

5

0

4. 0

14: 14

\section{Work for Others}

Nuclear Regulatory Commission

Operating

6.0

4.2

5.0

5.0

5.0

Direct Personnel

24.0

16.0

19.0

19.0

18.0

Department of Defense

Operating

37.0

34.7

46.0

54.0

62.0

Direct Personnel

150.

129.0

177

200.0

222.0

Environmental Protection Agency

Operating

Direct Personnel

20

1.8

2.0

2.0

: $:$ :

8.0

70

8.0

7.0

2.0

DOT and Other Federal Agencies

Operating

4.

Direct Personnel

160

- 8.3

10.0

11.0

11.0

Other Nonfederal Agencies

Operating

Direct Personnel

\begin{tabular}{l|l|l|l|l}
1.0 & 1.0 & 1.0 & 1.0 & 1.0 \\
4.0 & 4.0 & 4.0 & 4.0 & 4.0
\end{tabular}

Total Work for Others

Operating

50.

50.0

64.0

73.0

81.0

Direct Personnel

202

187

246

271 


\section{Resources by Major DOE Areas (contd)}

(Budget Authorization $\$$ in Millions)

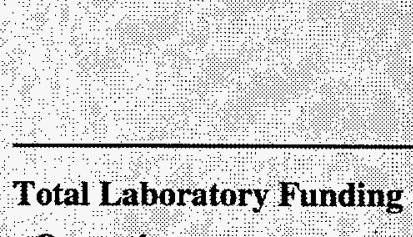

Operating

Direct Personnel

Capital

Direct Personnel

General Purpose Equipment-GPE

General Plant Projects-GPP

Direct Personnel

Landlord Line Items

Direct Personnel

Program Line Items

Direct Personnel

MEL-FS ${ }^{(a)}$ Construction

Direct Personnel

Indirect Personnel

Total Funding

Total Personnel
1.9. 40.4040 Fiscal Year

1996

1997

1998

1999

2000

435.2 454.4 U32.6 $447.8 ? \mathbf{4 7 5 . 4}$

1478 ( 1407 ? 1477 ? 1493 ? 154

12.6

9.2

10.1

170

15.9

12

3

2

0.8

1.0

2.2

2.1

3.

1.0

44

3

2.5 .40 .0

4.6

1.0

1.0

25

3.0

. 9 . ४ै४ 5 ४ै 6

3

3

50.0

0

0.0

0.0

0.0

0

0.0

0

0.0

0

4.2

14

1343

1442

507.5

3008

1343

448.3

472.5

2831 2859
2841

(a) Multiprogram Enefgy Laboratories-Facllites Stppont. 


\section{Subcontracting and Procurement}

The Laboratory is dependent upon external resources (universities and industry) for support in achieving timely and successful completion of assigned programs and projects. This is accomplished by staff in the Contracts organization who use the procurement acquisition process in acquiring needed equipment, materials, supplies, and services. The table below reflects actual subcontracted amounts for FY 1997 and projections for FY 1998 through FY 2000.

\section{Small and Disadvantaged Business Procurement}

The Laboratory is committed to support the socioeconomic objectives of DOE and has established procedures and programs that support meeting those objectives.

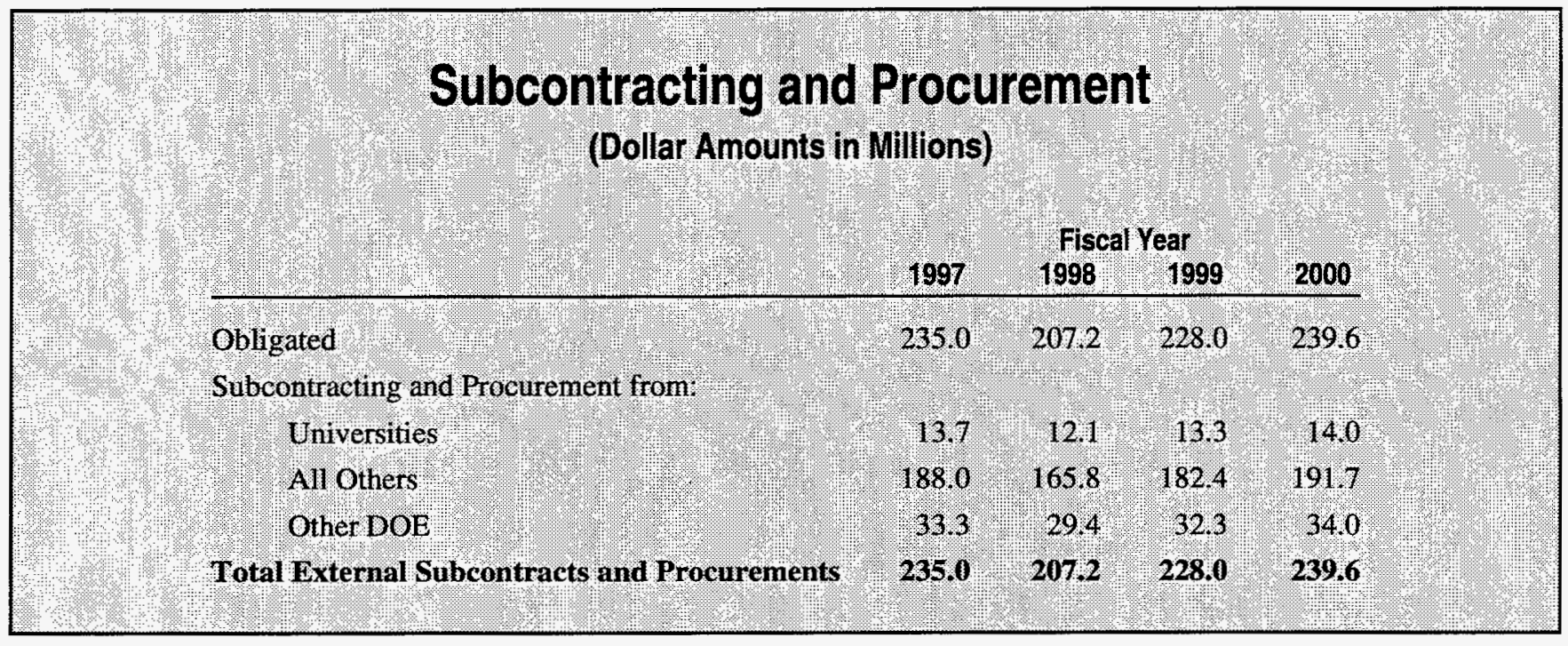

\section{Small and Disadvantaged Business Procurement} (Dollar Amounts in Millions)

Procurement from Small Business

Procurement from Disadvantaged Businesses
1997

66.0

13.5
Fiscal Year 1998

58.2

11.9
1999

64.0

13.1 


\section{Pacific Northwest National Laboratory}

Managed and Operated by Battelle for the U.S. Department of Energy

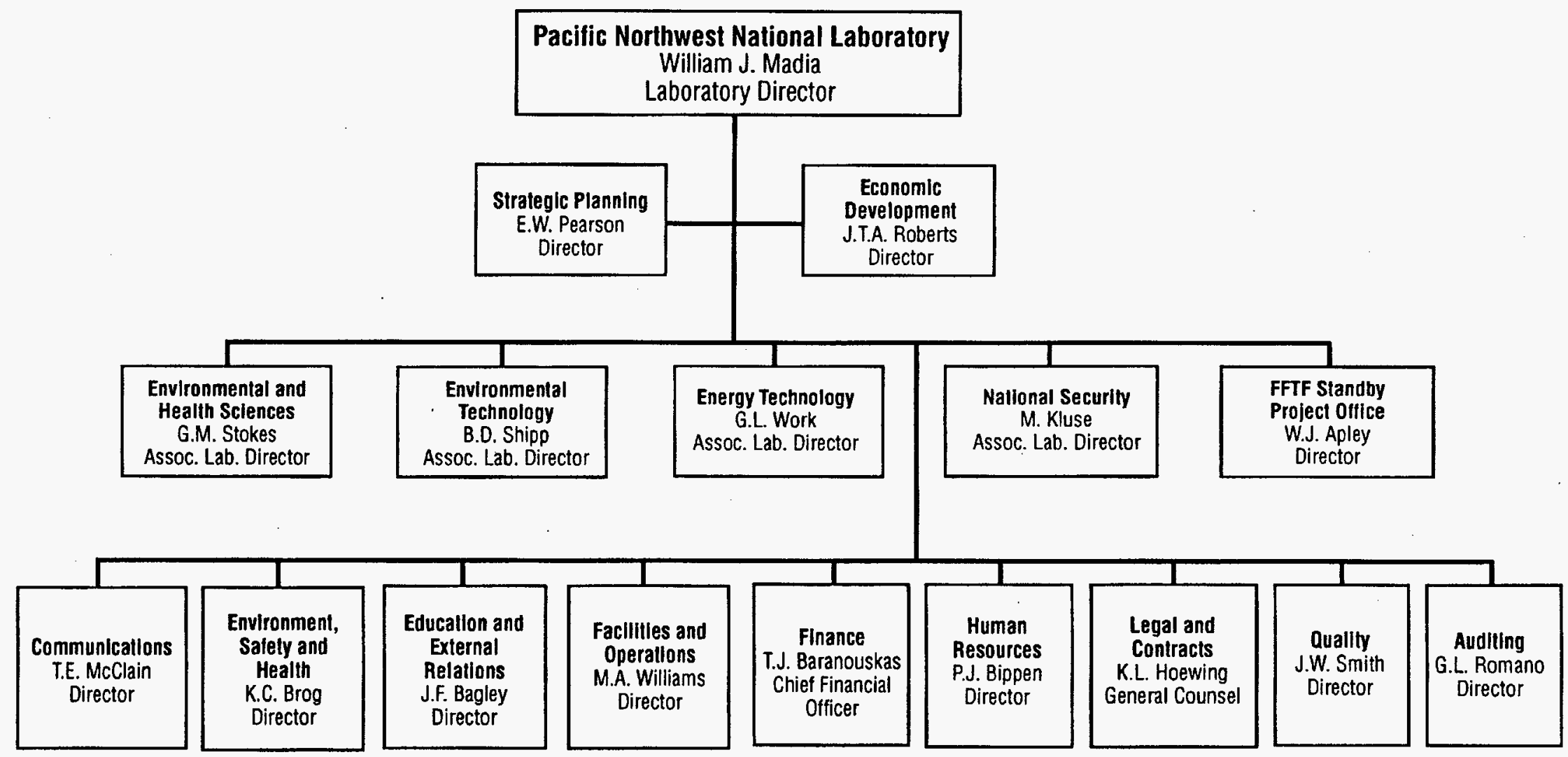




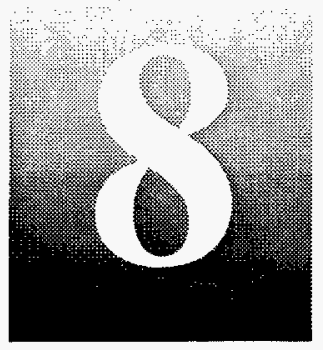

Acronyms and Abbreviations

ACE

AEP

ALARA

ANL

APEL

ARM

AVLIS

BES

BPA

CERCLA

CHAMMP

CHCs

CRADA

DARPA

DNA

DNP

DoD

DOE

DPRK

ecce'

EM

EMF

EMSC

EMSL

EMSP

EPA

EPRI

ERPP

ES\&H

FDDI

FE

FEMP

FFTF

FLC

FTICR

FUAs

GPE

GPF

GPP
Achieving the Competitive Edge

Advanced Energy Projects

as low as reasonably achievable

Argonne National Laboratory

Applied Process Engineering Laboratory

Atmospheric Radiation Measurement

Advanced Vapor Laser Isotope Separation

Office of Basic Energy Sciences

Bonneville Power Administration

Comprehensive Environmental Response, Compensation, and Liability Act

Computer Hardware, Advanced Mathematics and Model Physics

chlorinated hydrocarbons

Cooperative Research and Development Agreement

Defense Advanced Research Projects Agency

deoxyribonucleic acid

dynamic nuclear polarization

U.S. Department of Defense

U.S. Department of Energy

Democratic Peoples Republic of Korea

Extensible Computational Chemistry Environment

Office of Environmental Management

electromagnetic field

Environmental Molecular Sciences Collaboratory

Environmental Molecular Sciences Laboratory

Environmental Management Sciences Program

Environmental Protection Agency

Electric Power Research Institute

Environmental Radiological Protection Plan

Environment, Safety, and Health

fiber digital data interface

Office of Fossil Energy

Federal Energy Management Program

Fast Flux Test Facility

Federal Laboratory Consortium

Fourier transform ion cyclotron resonance

facility use agreements

General Purpose Equipment

General Purpose Facilities

General Plant Projects 
HEPA

HVAC

IAEA

IES\&HMS

LBNL

LDRD

MCSCF

MEL-FS

MRI

MRS

MSCF

NABIR

NATT

NE

NEPA

NIEHS

NIH

NIS/IPP

NMR

NMSS

NNSF

NPAR

NRC

NRR

OBER

OER

OIP

OIT

ORNL

OSHA

OUT

PAAA

PC

PHMC

PMNSCW

PNC-CAT

PNNL

RAAS

RCRA

RES

RLWS

RW

SBMS

SOFCs

STEP high-efficiency particulate air

heating, ventilation, and air-conditioning

International Atomic Energy Agency

Integrated Environment, Safety and Health Management System

Lawrence Berkeley National Laboratory

Laboratory Directed Research and Development

multiconfiguration self-consistent field

Multiprogram Energy Laboratories-Facilities Support

magnetic resonance imaging

magnetic resonance spectroscopy

Molecular Science Computing Facility

Natural and Accelerated Bioremediation Research

Northwest Alliance for Transportation Technologies

Office of Nuclear Energy, Science and Technology

National Environmental Policy Act

National Institute of Environmental Health Sciences

National Institutes of Health

Newly Independent States Initiative for Proliferation Prevention

nuclear magnetic resonance

Office of Nuclear Material Safety and Safeguards

near net shape forming

Nuclear Plant Aging Research

Nuclear Regulatory Commission

Nuclear Reactor Regulation

Office of Biological and Environmental Research

Office of Energy Research

Operations Improvement Program

Office of Industrial Technologies

Oak Ridge National Laboratory

Occupational Safety and Health Administration

Office of Utility Technologies

Price Anderson Amendments Act

personal computer

Project Hanford Management Contractor

Program Manager for Non Stockpile Chemical Weapons

Pacific Northwest Consortium - Collaborative Access Team

Pacific Northwest National Laboratory

Remedial Action Assessment System

Resource Conservation and Recovery Act

Office of Nuclear Regulatory Research

Radioactive Liquid Waste System

Office of Civilian Radioactive Waste Management

Standards-Based Management System

solid-oxide fuel cells

Science and Technology for Environmental Processes 
TWINS

TWRS

USCAR

USEC

WAM
Tank Waste Information Network System

Tank Waste Remediation System

U.S. Council for Automotive Research

U.S. Enrichment Corporation

Wide Area Monitoring 


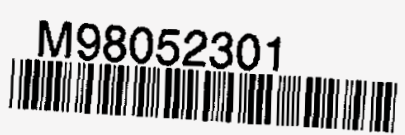

Report Number (14) PNNL-11752

Publ. Date (11)

Sponsor Code (18)

199712

UC Category (19)

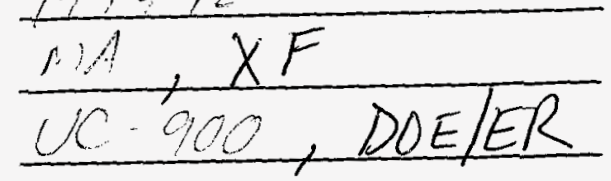

